\title{
WestVirginiaUniversity
}

THE RESEARCH REPOSITORY @ WVU

Graduate Theses, Dissertations, and Problem Reports

2010

\section{You Are and You Ain't: Redneck Literature and the Imposition of Identity}

Matthew Joseph Ferrence

West Virginia University

Follow this and additional works at: https://researchrepository.wvu.edu/etd

\section{Recommended Citation}

Ferrence, Matthew Joseph, "You Are and You Ain't: Redneck Literature and the Imposition of Identity" (2010). Graduate Theses, Dissertations, and Problem Reports. 4589.

https://researchrepository.wvu.edu/etd/4589

This Dissertation is protected by copyright and/or related rights. It has been brought to you by the The Research Repository @ WVU with permission from the rights-holder(s). You are free to use this Dissertation in any way that is permitted by the copyright and related rights legislation that applies to your use. For other uses you must obtain permission from the rights-holder(s) directly, unless additional rights are indicated by a Creative Commons license in the record and/ or on the work itself. This Dissertation has been accepted for inclusion in WVU Graduate Theses, Dissertations, and Problem Reports collection by an authorized administrator of The Research Repository @ WVU.

For more information, please contact researchrepository@mail.wvu.edu. 


\title{
You Are and You Ain't: \\ Redneck Literature and the Imposition of Identity
}

\author{
Matthew Joseph Ferrence \\ Dissertation submitted to the \\ Eberly College of Arts and Sciences \\ at West Virginia University \\ in partial fulfillment of the requirements \\ for the degree of
}

Doctor of Philosophy

in

English

John Ernest, Ph.D., Chair

Gwen Bergner, Ph.D.

Timothy Sweet, Ph.D.

John Grammer, Ph.D.

Dennis Allen, Ph.D.

Department of English

Morgantown, West Virginia

2010

Keywords: American literature; American Studies; Appalachian literature; Southern literature

Copyright 2010 Matthew Joseph Ferrence 


\begin{abstract}
You Are and You Ain't:

Redneck Literature and the Imposition of Identity
\end{abstract}

Matthew Joseph Ferrence

Redneck images pervade contemporary American culture and provide a pattern for national behavior. As globalization and multiculturalism change the demographics of the nation, covert Redneck codes enforce previous hegemonies of race, class, and gender. Imbued with incontestable American character, the Redneck becomes an ideological force capable of defending the nation from destabilizing cultural incursions. The maintenance of these Redneck codes relies on the continued reassertion of Southern and Appalachian stereotypes, since these regions must be maintained as authentic homelands for the identity character.

In this project, I locate a literary genealogy for the American Redneck and examine the roots and function of that identity through the complementary lenses of American Studies and Cultural Studies. My methodology draws on the seminal work of Henry Nash Smith and Richard Slotkin and their attention to the function of myth and symbol in American culture, with theoretical overlay from Louis Althusser, Jean Baudrillard, and Guy Debord. In considering the issues of representation present in these latter cultural theorists, I seek to reinvigorate Slotkin's notion of the narrative, instead of the discursive, expression of ideology. By examining primary texts ranging from Fenimore Cooper's Leatherstocking Tales to Erskine Caldwell's Tobacco Road, and pop-cultural texts like Smokey and the Bandit, and the Blue Collar Comedy Tour, I demonstrate how the mythological presence of the redneck narrative works to create a representational ideological category of hegemonic identity. The simulated and constructed realities of textual reception map onto the lives of the American working poor to emphasize a realistic if fully phantom and constantly shifting sense of common American identity. The notion of an authentic Redneck becomes normalized through the repetition of stock Southern and Appalachian myths, which in turn makes possible the hegemonic activation of these narratives. The force of representation seeks to make possible only dominant perspectives, defending hegemonic power from potential disruption. 


\section{Acknowledgements}

Tremendous volumes of intellectual gratitude extend to my unflappable mentor, John Ernest, as well as to my patient reader Gwen Bergner. Their comments and support guided me through the difficult process that bears the name "dissertation."

I am grateful, as well, for the work of committee members Tim Sweet, John Grammer, and Dennis Allen.

Andrew Urban accidentally helped me settle on this topic, which saved me years of drudgery on a less-interesting topic. Bronson Shonk repeatedly listened to ideas and demonstrated the viability of a life invested in stories.

The academics of my family helped model the life. The non-academics helped balance my life. All helped remind me of the joy of a life centered on people and not ideas. My parents - Gary and Carol Ferrence - serve as proof and inspiration for this life welllived.

And to Jen and Zef, thanks for trying to leave me to the quiet of the study. It's not your fault you're too cute to resist: thanks for the late afternoon trips to "las vegas." 


\section{Table of Contents}

$\begin{array}{ll}\text { Introduction } & \mathbf{1}\end{array}$

Chapter One

$\begin{array}{ll}\text { Rednecks Among Us } & 20\end{array}$

Chapter Two

Redneck Masculinity, Burt Reynolds, and The Man 63

Chapter Three

Redneck Electability $\quad 107$

Chapter Four

$\begin{array}{ll}\text { Normal Rednecks, Normal Americans } & 142\end{array}$

Chapter Five

$\begin{array}{ll}\text { Normal, Side Two } & 169\end{array}$

Chapter Six

Redneck Resistance $\quad 199$

$\begin{array}{lr}\text { Conclusion } & 238\end{array}$

$\begin{array}{ll}\text { Bibliography } & 250\end{array}$

$\begin{array}{lr}\text { Curriculum Vitae } & 272\end{array}$ 


\section{Introduction}

Rednecks are everywhere these days. Certainly, the term "redneck" itself carries pejorative weight, employed as it typically is to undercut working class, rural Americans. Yet it also carries great celebratory power. Some adopt the title as a mark of pride and others assume it to assert a theoretical position. The word is thus readily available for the critical humor of popular television shows, film, and comedy, just at it is also simultaneously available as a description of contemptible lower classes and as a badge of honor tapping into an historical and noble resistance to homogenizing mainstream mores. As such, "redneck" exists as a term that is difficult to pin down, in definition, origin, or idea. Consider the variable etymology of the word:

1) From the Oxford English Dictionary: "A member of the white rural labouring class of the southern States; one whose attitudes are considered characteristic of this class; freq., a reactionary. Originally, and still often, derogatory, but now also used with more sympathy for the aspirations of the rural American." The OED offers 1830 as the first such instance of this usage, as "a name bestowed upon the Presbyterians in Fayetteville."

2) Also from the OED, first used in 1900: "to be applied to Roman Catholics in Lancashire as a term of opprobrium."

3) Also from the OED, also first appearing in 1900 but as the South African "rooinek:" "in reference originally to some merinos introduced by an English farmer 
into the Free State, and marked with a red brand on the neck. These were spoken of as red-necks, an expression afterwards extended to the English themselves, and then as a term of contempt to the British troops in red uniform."

4) From David Hackett Fischer's Albion's Seed: as a term to denigrate seventeenth century Scotsmen who rejected the Church of England and sought a government aligned with the Presbyterian Church. Supposedly, members of the National Covenant and The Solemn League and Covenant signed documents to that effect in blood and began wearing red cloth at the neck as a sign of solidarity. The term carried to the Americas, into Appalachia and the South where Scottish immigrants supposedly settled. ${ }^{1}$

5) From the Encyclopedia of Southern Cultures:

a negative expression describing a benighted white southerner... any white southerner in the lower or working class.... He is undereducated; he talks funny in a bewildering variety of southern accents, which feature double negatives, jumbled verb tenses, slurred and obsolete words, and all manner of crimes against standard, television English. He is too physical in his approach to life; he sets too high a premium on athletic prowess, and he gets

\footnotetext{
1 Debates about the accuracy of this settlement and ancestral core of Appalachia lie at the center of contemporary studies of the region, with most scholars questioning and discarding this part of the popular "lore" of the region. For background on Appalachian stereotype and history see Biggers The United States of Appalachia; Billings Back Talk from Appalachia; Harkins Hillbilly; Miller American Vein; Williamson Hillbillyland; Shapiro Appalachia on Our Mind.
} 
into too many fights. He comes on too strong with women, and he may even scratch when it itches, wherever he or it might be.... He does not ski and has never seen a psychiatrist. He sometimes smells bad, especially after an eight-hour shift or a hunting trip. He occasionally still repairs his car in the front yard, and he might even leave the engine hanging from a branch of a chinaberry tree for awhile. His presence may well depress the local real estate market. He is reactionary but sometimes radical and thus politically unreliable.... And his children act as if they are just as good as anybody else. (1140)

6) Also from the Encyclopedia of Southern Cultures:

Today not many southern whites actually farm, and the term "redneck," when not used as a crude put-down, vaguely refers to lower- and working-class southern whites. Even so, it designates an important element of contemporary America's population, the most British group by blood and at the same time the group that has lived most closely with American blacks, another sturdy folk whose roots run deep in the soil of the South. (1140-41)

7) From scholar Patrick Huber: striking miners in the 1921 West Virginia Coal Miners March and the subsequent Battle of Blair Mountain wore red bandannas to 
signify their unified desire for organization, though using the term in conjunction with miners may have occurred as early as the beginning of the century ("Rednecks and Red Bandanas").

Thus, "rednecks" are definitionally rural working class whites of the American South, Roman Catholics, Presbyterians, coal miners, and sheep, all of whom don't ski. Quite obviously, it is a word of little precision and less uniformity. Notably, the bulk of the definitions are negative. "Redneck" is an epithet applied to separate a certain class away from the mainstream. But it is equally notable that contemporary use of the term is often quite positive. Think, here, of Gretchen Wilson's celebration song, "Redneck Woman," or the wildly popular Blue Collar Comedy Tour. In these instances, individuals proudly proclaim their own redneck position as a means to self-identify as different from a mainstream viewed as corrupt, or too urbane, or simply undesirable. In this sense, a new definition of the redneck as hero emerges, complicated by the selfavowal with which it is applied. This modern iteration of redneck exists within the fluid space encompassed by the totality of definitions that stick to the word. As such, "redneck" complicates the very act of definition. On one hand, the word maintains the residue of historical epithet, while on the other it adopts a form of purity and authenticity that earns power as a mobilizing contemporary socio-political philosophy. It is this newer version of redneck that I examine in this project. The identity spreads throughout American literature and culture, with the roots of a Redneck ideal 
in early American frontier literature, then continues though modern and contemporary Southern literature and, now, a broader popular culture. In the current state of America's Redneck identity, I contend that individuals choose and claim membership as a means to establish incontrovertible American citizenship. As well, individuals may earn a place within the nation by tacitly agreeing to follow Redneck codes of conduct. In essence, the Redneck subscribes to quintessentially American ideals of self-reliance and anti-elitism (despite political spin otherwise), and generally follows the ethos of the modern Redneck identification. That ethos can be defined by what it is not: not highfalutin', or overly intellectual, or overly-socialized or, perhaps most crucially, not notAmerican.

Put another way, you might be a redneck if you don't exist, at least not in an absolute sense. Even though the idea of the redneck may be traced historically as a social-political term assigned to a Southern laborer burned by the sun or to a striking coal miner wearing a bandana, a single representational function of the word cannot be ideologically pinpointed. In fact, the roots of the moniker are varied and difficult to determine definitively, just as the people and classes of people that fall under the title constantly shift. The parameters of participation in or assignation to the group are equally as slippery and mobile. In the same breath, "redneck" can negatively identify a person as Southern, racist, poor, and degenerate, and positively define a person as selfreliant and patriotic, as Richard Peterson points out. I argue that in contemporary 
America the terms of the redneck are ostensibly fixed in much the way that the Appalachian and Southern Regions are. Ideology relies on the myth of an unchanged class of person. The bumps of rural identity are ironed over to create an artificial category that allows adopters of the moniker to maintain power over both the images of the redneck and the real people who live in conditions of rural poverty. That power depends, as well, on the representative silence of individuals who live in regions considered "redneck." Ideology and icon are shaped from the outside, leaving Appalachians and Southerners stuck within age-old stereotypes.

My examination of the Redneck identity rests on a foundation of scholarship that has sought to expose how the residents of Appalachia and the South are bound by restrictive representations of the hillbilly and redneck figures. Similarly, Appalachia and the South function as representations instead of actualities. These regions-as-constructs must be considered in tandem with their actual histories. Typically, such full views of the region have been incompatible with the decidedly ahistorical renditions of history that have colored Appalachia and the South. To understand the effects of these regional constructs, one must consider both the fullness of Southern and Appalachian history and the persistent rewriting of histories that seeks to undermine such attempts. At stake here are many of the notions and caricatures of Southern and Appalachian culture that fit, neatly or otherwise, under the heading of "redneck." 
It is in Appalachia and the South that the redneck might be considered "native." As regional homeland of the redneck, the regions suffer a broad classification as substandard. The regions are considered hotbeds of the "white trash" that Matthew Wray identifies as a "disturbing liminality," as "a monstrous, transgressive identity of mutually violating boundary terms, a dangerous threshold state of being neither one nor the other.... White Trash names a people whose very existence seems to threaten the symbolic and social order" (2). Thus, the hillbillies of Appalachia have at times been portrayed as subhuman obstacles to economic development. They have been constructed as savages in need of salvation from themselves, even if salvation happens to lead to wealth for the industrialists doing the saving. Similarly, the rednecks of the South have been popularly presented as obstacles to national unity and racial harmony. Since the Redneck must define itself first as "down home" in order to offer a foundation for American identity, it must also employ particular "down home" images. Thus, the current renditions of Redneck I explore rely on the hillbilly images that have been constructed and molded in America. Simplified notions of the white rural class have long been part of American popular culture, and these root images continue to function overtly and implicitly in the U.S. Texts such as Anthony Harkins's Hillbilly, Jerry Wayne Williamson's Hillbillyland, and Mark D. Howell's From Moonshine to Madison Avenue reveal how these images have been employed. More importantly, they show how frozen images of, for example, the bootlegging stock car racer continue to 
hold sway in a culture where racing is a billion dollar industry far removed from its roots.

My project builds on scholarship that seeks to bust notions of absolute hillbilly types. Scholars offer important resistance to such homogenized imagery and explain how the region and its residents fit into American history. Jeff Biggers's The United States of Appalachia seeks to explode the notion of a backwards Appalachia by tracing the roots of national progress in the region, while Dwight B. Billings's Back Talk From Appalachia directly confronts the fixed and distorted images of the region that persist in contemporary America. Similarly, Ken Fones-Wolf and Ronald L. Lewis have gathered in Transnational West Virginia essays that reveal how Appalachia has "been entangled in a web of economic forces and relationships that transcended its political boundaries" (x). Appalachia is more than it seems, even if cultural constructions never give it credit for such influence. The people are more than their caricature, even if few outside the region allow for multiplicity of Appalachian identity.

As Katherine Ledford and Harry Shapiro reveal, the roots of Appalachian stereotypes that I see as closely related to the redneck lie within late nineteenth and early twentieth century local color travel writing. During this period, writers like John Lederer, Thomas Ashe, Mary Noailles Murfree, Will Wallace Harney, William Goodell Frost, and John Fox, Jr. penned stories about the "strange" people they found there. Ledford tracks how descriptions of the region and the people shifted from initial stories 
of danger to later treatises on the potential economic splendor in the mountains (50). She argues that such shifts followed the needs and anxieties of the nation, which at first found the "remote" citizens of Appalachia dangerously removed but later saw the same people as obstacles to financial gain. Shapiro argues that the early writing fixed baseline notions of the region and its denizens and thus served as models for future reactions (18).

Similarly, Shapiro tracks how these definitions served the specific needs of certain enterprises. Southern churches, for example, ignored the residents of Appalachia until it became apparent that Northern missionaries were moving in and staking their claims on the area (32). For North and South, the image of degraded, fallen Christians in the mountains served a religious economic purpose. Even though a long tradition of non-denominational Christian churches existed in Appalachia, mainstream denominations used the idea of heathen mountain folk as a way to expand their own parishes. Likewise, as president of Kentucky's Berea College at the turn of that century, William Goodell Frost enacted a certain Appalachian image (and even coined the term Appalachia America) in part as a means to solicit northern funding for his school. He portrayed the citizens of the region as worth saving, as potential allies against waves of immigration that "threatened" the nation. Frost suggested that Appalachians could be brought into the national fold if only the resources were available. A reformed Appalachia would help defend the nation against coming hordes (120). Such was the 
shifting nature of Appalachia, a region that seemed first to threaten the homogeneity of the American nation but, later, was redefined as a site of American root folklore and as deviant not from America itself, but only from modernity.

Similar constructions have harnessed perceptions of the South to narrowly antiquated and romantic narrative. A growing body of scholarship on the South seeks to continually disrupt such constructions, which have in fact often been reiterated within an older version of Southern literary study. Lewis Simpson's The Fable of the Southern Writer and Louis Rubin's The Mockingbird in the Gum Tree offer a baseline for what might be considered classical study of Southern literature, as both of these authors take up the question of what makes a writer particularly Southern. In so doing, Rubin and Simpson help delineate the sort of agrarian (and Agrarian) South that current Southern studies have sought to reconsider or even discard. Fitzhugh Brundage's The Southern Past and Michael O'Brien's Placing the South examine the way Southern cultural studies must deal with both the pervasiveness of history within Southern culture and the imposition of constant historical implications on Southern culture. Leigh Ann Duck's The Nation's Region, Tara McPherson's Reconstructing Dixie, and Suzanne Jones and Sharon Monteith's South to a New Place argue how the South can be considered in a contemporary fashion, as well as how the South affects the greater American culture. These texts also address how the material enterprises of globalization affect and are affected by the South. In my own argument, I see the current development of a Redneck 
identity as a response to the growth of globalization and, particularly, in the way previously unchallenged regions of white patriarchy are forced to recognize the growing impact of multiculturalism and multinationalism.

As a more direct response to older visions of Southern scholarship, James C. Cobb considers in Redefining Southern Culture how concepts of a New South are tied up in myth-making, relying on the ideals of the Old South that were supposedly discarded. Moreover, in Away Down South Cobb outlines how the images of a South outside of America began to develop, and how the South itself has become as much a representational icon as an actuality. Similarly, Martyn Bone argues in The Postsouthern Sense of Place in Contemporary Fiction that recent writers of the South have sought to discard the foundations of Agrarian myth, a necessity if a true reconceptualization is to occur. Such discarding has been made more difficult by the international reassertion of old Southern ideas, as Helen Taylor identifies in Circling Dixie. In retelling the old myths of the South, Europeans reify the very same worn out images of the region that prohibit fuller, modernized versions to emerge. ${ }^{2}$ As such, the South becomes an idea, a hyperreal construction. In The Real South: Southern Narrative in the Age of Cultural Reproduction, Scott Romine claims that he exacts "a study of the fake South, which I argue becomes the real South through the intervention of narrative. That the South is increasingly sustained as a virtual, commodified, built, themed, invented, or otherwise artificial

\footnotetext{
2 Emerging scholarship in Southern Studies continues to complicate older totalizing models. See Bartley's The New South, Bullock and Rozell's The New Politics of the Old South, Lowe's Bridging Southern Cultures, and Smith and Furuseth's Latinos in the New South,.
} 
territoriality — that is, as it becomes less imaginable as a 'natural' or 'organic' culture, if that antinomic construction ever existed — has hardly removed it from the domain of everyday use" (9).

The images of pop-cultural hillbillies have shifted in ways similar to the images of Appalachia and the South. Again, fabricated images have displayed tremendous representational change to fit the desires of broader America. As Anthony Harkins argues, the long-standing images of poor mountain people have responded directly to socio-political-economic conditions (3-4). He tracks how the earliest hillbilly roots lie in the rural rube tradition of Britain and New England, thus aligning the hillbilly with a broader canon of quintessentially American folk culture. The hillbilly image later shifted to violent portrayals, then back to the happier buffoons of Snuffy Smith, Lil' Abner and The Beverly Hillbillies. Likewise, Jerry Williamson tracks the hillbilly's shift from violent outsider to comic outsider to a mixture of each in American film. He suggests that the dual nature of the rural stereotype reveals the complexity of its mirroring: “[L]ike most mirrors [the hillbilly] can flatter, frighten, and humiliate” (2). There's something glorious about the non-institutionalized freedom of the rural outsider, but something at risk if the individual falls too far outside the institutions. For example, Williamson suggests that in the 1930s the poverty-stricken hillbilly evoked a warning of what could happen if the nation's finances collapsed. Simultaneously, the popularity of hillbilly images shows a cultural attraction to the idea of the outsider who 
cares little for the monetary chase of contemporary life. The hillbilly became a noble hero for the downtrodden, demonstrating how an individual can be happily hedonistic, barefoot, grungy, and fecund (41).

These representational shifts show the way hillbilly images are put in use. The capacity for shift further shows how the redneck or hillbilly does not represent an actual portrayal of actual people. Instead, the images function as constructs that serve broad national ideologies and change as those representative needs change. Mark Howell focuses on more recent images when he examines the bootlegging "roots" of NASCAR. Outlaw nature operates in the sport as a functional mythology that appeals to fans (5). Howell shows how NASCAR itself began as a means to regulate bootleggers' random races. The sport relies on the outlaw myth but developed as a means to prevent the outlaw nature of bootleggers from creating an unfair, chaotic racing field. In fact, the organizers of the sport have since the beginning operated as a totalitarian force, carefully regulating car design, harshly disciplining drivers who violate rules, even squashing nascent driver unions that sought greater voice in the sport (Howell). Here, the image of the bootlegger hasn't so much shifted as sought a foothold against the changing realities of stock car racing. Though contrapuntal to the shifts in hillbilly image over the years, this rigidity nonetheless shows the way that the externallydefined images of the rural working class are activated to support a broad, nonworking-class scope of America. 
In preparing to interrogate the Redneck nation, I enter into the midst of contemporary reconsiderations of Southern and Appalachian culture and literature while also drawing on a broader body of cultural criticism. In many ways, my project is aligned with the original focus of cultural studies at the Birmingham Centre. Just as Richard Hoggart sought to examine how mass culture devalued authentic working class culture, I seek to examine how cultural elites adopt an inauthentic version of working class culture to solidify ideological dominance. Perhaps most pertinently, I invoke Jean Baudrillard's sense of cultural simulation. At its deepest core, the ideological Redneck I examine in the coming pages relies on an artificial notion of Southernness and rural whiteness that creates a phantasmagoric Redneck icon. Within this constructed image, the real identity conditions of people of the South and Appalachia are consumed by an exaggerated popular culture vision of the redneck. Yet, while I see the Redneck responding to both global and domestic forces, the demonstrable actions of identity function on an explicitly local level.

All the South's a stage, or a construction, or a simulation, which brings me to the brink of my own sense of Redneck identity construction. The icon of the Redneck fits into the representational history of Appalachia and the South because it is an immediate and widely circulated stock image of those regions. At the same time, the Redneck operates as a fully constructed identity in contemporary discourse, drawing into itself 
the same sorts of stereotypical caricatures that have long bogged down the regions from which it comes.

Neither the regions nor the Redneck have been able to break free from their constructed pasts, and that rigidity has allowed the Redneck to serve the needs of ideology. Since the features of the ideological Redneck are both close at hand and imbued with certain iconic American characteristics, it becomes an easy mask to don. In so doing, those who align themselves with the Redneck do not align themselves with the reality of the South or Appalachia but, instead, with the ideas these regions represent. Simultaneously, individuals residing in those very regions are left to contend with the negative stereotypes of the Redneck identity that must remain intact in order to allow the icon to do its hegemonic work. As a result, the recirculation of the Redneck depends on the reiteration of tired visions of racist, anti-progressive, strange and separate regional trope. In the end, the Redneck icon is available for use only as a way to lend feigned-minority credibility to individuals and enterprises intent on maintaining an America that resists the actual inclusion of minorities, whether they be ethnic, gendered, or economic. After all, what self-respecting Redneck would allow America to fall to such furriners?

In my first chapter, I establish literary and cultural baselines for the Redneck, aligning this new conceptual citizenship with notions of American identity drawn from 
a broad swath of literature. While the scope of my examination of literary genealogy is necessarily limited, I sketch a trajectory from Fenimore Cooper's frontier, to Erskine Caldwell's poor white trash, to the violent hillbillies of James Dickey's Deliverance. I argue that cultural pressures and reactions exert a distorting force, allowing the selfreliant, regional and / or backwoods outsider, quintessential American literary hero to transmogrify into Larry the Cable Guy. Core concepts of lurid behavior align with images of the American frontier to make a champion of the crass and anti-progressive contemporary Redneck.

In Chapter Two, I engage issues of masculinity that function in tandem with Redneck identity to solidify traditional, heterosexual manhood. Drawing on readings of Deliverance in print and on film, and on interpretations of Burt Reynolds's redneck persona in the serious Deliverance and the campy Smokey and the Bandit, Gator, and White Lightning, I argue that the 1970s offered a potential for redneck escape from mainstream American codes. However, the difficult friction of socio-economic burden made for uncomfortable radicalism in the redneck icon, activating previously existent foundational hillbilly images. These pressures stalled any potential progressivism in the white, rural image.

Politically, the Redneck identity I propose and examine factors heavily in concepts of American citizenship and presidency, a situation I examine in Chapter Three. By tracing the effort to establish redneck authenticity in the political identities of 
Jimmy Carter, Bill Clinton, and George W. Bush, I argue that a narrative version of American rurality has become a requirement for citizenship. By applying the theories of Theodor Adorno and Guy Debord, I argue that America requires a tight performance of Redneck spectacle to sort individuals as proper and improper citizens. Barack Obama, in turn, faced a difficult task in his bid for presidential election. Assuming the identity of Redneck required an untenable discarding of race, but he nonetheless had to contend with the icon's power in America's definitional process. As such, the voice and autonomy of the actual rural poor becomes an inconsequential presence, rendering the use of Redneck into the arena of pure political rhetoric.

Chapter Four turns to the contemporary exertion of popular redneck images. In particular, I examine the way the rigidity of Redneck identity has brought the classification back under the power of traditional hegemonic America. Through an examination of World Wrestling Entertainment's Korean-redneck Jimmy Wang Yang, and the Blue Collar Comedy Tour, I argue that the persistent simulacra of Redneck maintains the analogy between rural status and America. I turn here, as well, to most directly engage the racial effect of the Redneck ideology. I argue that the image helps maintain a persistent and often invisible preference for whiteness in national citizenship. Throughout these manifestations of the contemporary Redneck, the rural image functions as a way to normalize outsiders and reassert the normality of America as a white masculine land. The process of normalization also uses the Redneck as a 
means to exert economic influence and forestall working class progress. Just as Jimmy Wang Yang must subsume his minority identity to participate in Redneck America, Larry the Cable Guy uses his redneck imagery to reassert the prominence of white individuals, and each presses the Redneck into service as an economic engine.

In Chapter Five, I examine the way the hegemonic reiteration of the Redneck works to forestall potential revolution. I argue that when the Dixie Chicks criticized George W. Bush, the main point of contention was the sudden revelation of Redneck construction. Ideology thus sought to force the music group back into line. Similarly, I argue that a new line of NASCAR romance novels seeks to provide reassurance of the safety of hegemonic positions. In each of these cases, coded Redneck standards work to render resistance futile. The identity functions to both prevent disruptive points of view and to preset in American culture the means to defend the status quo.

Finally, I seek in Chapter Six to offer the voices of the heretofore voiceless. I examine the writing of Fred Chappell, Trudier Harris, Silas House, and Janisse Ray to argue that, contrary to the popular use of Redneck imagery, individuals within rural Southern and Appalachian America seek control of their own identities. Notably, these claims for personal voice argue for progressive social and environmental considerations that would not normally be considered compatible with things called Redneck. The challenge for "real" rednecks lies in breaking free of the expected parameters of the identity. With the long circulation of functional stereotype pasted onto the identity, 
writers from Appalachia and the South who do not exhibit the expected identity characteristics face narrative obscurity. I argue that by giving credence to the individuals who write back against redneck stereotypes, the identity can be wrested free from its current ideological functions.

Resistance serves as an important aspect of this project, as I am wary of suggesting or implying the absence of Southern, Appalachian or even "redneck" agency in contemporary culture. Certainly, in many ways the nature of the South and the nature of working class Southern and Appalachian identity continues to be molded by the active cultural endeavors of real residents. By revealing the ways that redneck identity has been consumed by popular culture and, just as importantly, by filling in the details of the complicated redneck conversation that are left unsaid by the totalizing limitations of the identity, I seek to open space for more realistic and necessarily more complicated versions of redneckism. Just as the South is not as its representational history might suggest, and just as the hillbilly has never been quite the reprobate he's been drawn to be, those Americans who fall somewhere into the category of redneck are never as easy to pigeon hole as popular culture and politics imply. 


\section{Chapter One: Rednecks Among Us}

Wide-eyed Peter Griffin — "patriarch" of the FOX cartoon series Family Guy — sits in a crowded theater and receives his life's calling. In front of him, four men sit on the stage as part of the Redneck Comedy Tour, each offering quick and dirty introductions. Stink Fleaman: "You know you're a redneck if you come from a rural area and behave as such." Mike Drunkbeater: "Oooo, that dog of mine." Walt "Coffee \& Pie" Abernathy: "Woo hoo hoo hoo hoo hooo." And Larry, The Guy Who Works for the Department of Water and Power: "You tell me how that got in there. Whoooooooo." It is the last of these proclamations that pleases Peter the most. It is for him a defining moment: "These men and their redneck lifestyle really speak to me." The next morning, Peter pulls a pickup truck into the family driveway, a rig bestowed with requisite roll bar, fog lamp stack, and grill cover. The family is not impressed, wife Lois declaring that he "can't suddenly decide to be a redneck just because of some show." To this, Peter offers great indignation: "Some show? Lois, these men showed me a way to an identity I've been searching for my whole life. I am gonna do everything a redneck is supposed to do." And so he does, pulling the couch onto the front lawn, terrifying his teenage daughter with sexual proposition, stealing jet fuel to fill the tank of his pickup and causing a subsequent crash landing and the termination of his pilot neighbor's job. The stakes are high with redneck identity. 
This particular episode of Family Guy appeared in 2007, well into the run of the popular Blue Collar Comedy Tour skewered on the cartoon, and in response to nothing particular beyond a curious popularity of the American redneck image. In so doing, Family Guy offers both familiar stereotype - the pickup, incest, chewing tobacco — and quick critique of suburbanites. The show no doubt also seeks to skewer the then-sitting president who himself adopted the belt-buckle and blue jeans identity. Peter's desire to become a redneck offers entrance into a deeper ideological definition of the identity category, however, a place where the term "redneck" designates an ideologically powerful segment of the population that defines itself and the broader national identity as rural, country, working class, simple, true, and patriotic. Thus, in 2009, an episode of NBC's 30 Rock shows head writer Liz Lemon and head honcho Jack Donaghy traveling to Stone Mountain, Georgia in search of a new cast member for their sketch comedy program. It is here, in a self-consciously stereotyped rural South, that Jack hopes to find the kind of pure American who can appeal to a broader segment of television viewers. ${ }^{3}$ The redneck is presented by Jack as the quintessential American, a concept that can serve as both an object of critique and source of humor on 30 Rock. Outside of fiction, it is an identity through which many in the United States find a definition of America itself as a response to globalizing forces that threaten previously unchallenged

\footnotetext{
${ }^{3}$ Notably, Stone Mountain appeared in the show as a small, rural Southern town, when in fact it is a suburb of Atlanta, symbol of the Confederacy, and reputed meeting place for the Ku Klux Klan. This is fitting, and likely not coincidental, since Atlanta's "Southern" nature must in many ways be viewed as a mere figment of the imagination: it is more a regional metropolis than Southern capital. But, like the Stone Mountain of the television show, image often rises above reality.
} 
hegemonies predicated on "traditional" values of home, hearth, heterosexuality, whiteness, and patriarchy.

Keeping at hand the complex "definition" of the redneck I offered in the introduction, I wish also to place the concept of contemporary Redneck ideology into the scope of American literature. Sketched quickly, the redneck pedigree might begin with the low-down Southerners disdained by Southern aristocracy within William Gilmore Simms, move to George Washington Harris's proto-hillbilly Sut Lovingood, to Augustus Baldwin Longstreet's Georgia Scenes, in general to the Southwestern humorists, to more or less all of Faulkner, on through Hee Haw, the Grand Ole Opry, and NASCAR.

However, as a starting point I instead see a connection to the quintessential outsider status of James Fenimore Cooper's Leatherstocking Tales. These texts offer an early American link to the anti-establishment, glory-to-the-unrefined ethos that lies at the core of my notion of contemporary Redneck self-identification. Moreover, the images present within literature make possible the pop-cultural representations that permeate American culture. Additionally, the ideological use of contemporary Redneck identity claims underclass status, since it is so easily fit into the pejorative and oppressed model of the "actual" redneck or hillbilly. It adopts the weakness of the exploited poor working class and draws on the core degradation of Southern and Appalachian types. The power of the contemporary identity further draws on the 
inherent outsider presence infused with Redneck identity through its relationship to American narrative trope.

In identifying Cooper as a source for a proto-Redneck impulse in American literature, I am seeking to engage Richard Slotkin's notion that “[m]yth expresses ideology in a narrative, rather than discursive or argumentative, structure. Its language is metaphorical and suggestive rather than logical and analytical" (Gunfighter Nation 6). Indeed, the contemporary Redneck becomes the core face of America because he (and it is very much he) activates certain qualities of the quintessential American literary figure. The Redneck appears as the apex of anti-establishment evolution — which in the case of the current Redneck ideology would perhaps need to be phrased as the apex of antiestablishment intelligent design. The Redneck identity flows out of the noble outsider who resists the forces of restrictive government and restrictive civilization, who operates independently and purely. Moreover, the identity gains traction in more contemporary venues because the narrative ideas of Cooper resonate through our literary history. As Slotkin argues, Bumppo is "an enduring literary character, a central symbol that has continued to exercise an influence on American literary mythology" (Fatal Environment 81). Cooper writes from the inspiration of American myth but also helps create it. I am suggesting that Slotkin's recognition of the frontier as "our oldest and most characteristic myth" (Gunfighter Nation 9) maintains power in contemporary redneck figures who exist in a kind of permanent state of frontier. While I 
will explain and expound this particular frontier concept later in this chapter, I first wish to make clear just how Cooper writes an origin story for the pop-cultural moments I cited in Family Guy and 30 Rock.

Early on in The Pioneers, the first of Cooper's tales to be published but one that portrays the protagonist Natty Bumppo as a weathered old man, Bumppo ${ }^{4}$ runs afoul of Judge Temple in a hunting disagreement. The Judge claims to have felled a deer, despite the obviousness of Bumppo's companion's fatal heart shot. The Judge seeks to exert judicial temperance into the situation: “'I would fain establish a right, Natty, to the honour of this death; and surely if the hit in the neck be mine, it is enough; for the shot in the heart was unnecessary — what we call an act of supererogation, Leatherstocking.'" (21). Bumppo, however, responds with precisely the sort of commonsense logic that fits the Redneck ethos:

"You may call it by what larned name you please, Judge," said the hunter, throwing his rifle across his left arm and knocking up a brass lid in the breech, from which he took a small piece of greased leather, and wrapping a ball in it it, forced them down by main strength on the powder, where he continued to pound them while speaking. "It's far easier to call names, than to shoot a buck on the

\footnotetext{
${ }^{4}$ Names shift for Bumppo: Aka Leatherstocking, aka deerslayer, aka Hawkeye.
} 
spring; but the cretr come by his end from a younger hand than

'ither your'n or mine as I said before." (21-2)

The conflict in action in this scene is far more than one of hunters determining rights to a dead animal. In this case Temple has no claim, since Bumppo knows four of the judge's five shots hit a tree and the fifth struck the man who actually shot the deer. The conflict is instead tied up in the designations of wilderness. More to the point, the conflict is over legal and frontier rights, whether or not a man like Judge Temple carries any power to exert justice over hunting laws that prohibit and control the free hunters of New York. In fact, it is in part through violation of these laws that Bumppo is later arrested, and it is through Leatherstocking's moral outrage at being arrested that he assaults an officer of the law and is, therefore, later convicted. The question at hand in these crises is one of the urbane versus the frontier. It is a question of definition, with America as the term yet unexplained. Bumppo lies on the redneck side, offering nongovernmental freedom as a model of the nation. The judge lies on the side of the future nation, where laws and restrictions govern the way citizens must operate, even in the wilderness; wilderness itself must be seen as part of the legal domain of the state. ${ }^{5}$

Intriguingly, even this early window into nascent Redneck ideology shows a keen attention to matters of race and, more particularly, to protections of whiteness. In Last of the Mohicans, Bumppo proclaims as much:

\footnotetext{
5 In this moment, Deerslayer also presages the interrogation of neoliberalism offered by Lisa Duggan, which I examine in more detail in Chapter Four.
} 
"I am not a prejudiced man, nor one who vaunts himself on his natural privileges ... though the worst enemy I have on earth, and he is an Iroquois, daren't deny that I am genuine white," the scout replied, surveying, with secret satisfaction, the faded colour of his bony and sinewy hand; "and I am willing to own that my people have many ways of which, as an honest man, I can't approve." (502)

More to the point, in Deerslayer Bumppo speaks with Hurry Hutter about his origins.

“You're a boy, Deerslayer, mislead and misconsaited by Delaware arts, and Missionary ignorance," he exclaimed, with his usual indifference to the forms of speech, when excited. "You may account yourself as a red skin's brother, but $I$ hold 'em all to be animals, with nothing human about 'em but cunning.... If you wish to be considered a savage you've only to say so, and I'll name you as such to Judith and the old man, and then we'll see how you'll like your welcome." (538)

Later in that novel, Bumppo confirms that he is very much not a "savage:" “'That's it that's just it. I am white - have a white heart, and can't, in reason, love a red-skinned maiden, who must have a red-skin heart and feelin's. No - no - I'm sound enough, in them partic'lars, and hope to remain so; at least, 'till this war is over'"' (617). The sum of 
these moments establishes Bumppo as prototype for the contemporary defense of whiteness that is exerted through Redneck status. Bumppo is an outsider, external to the law of the land just as a contemporary redneck seeks to be a free man and resister to The Man, but each is nonetheless undeniably and proudly white. He refuses to practice miscegenation, either sexually or philosophically, nor does he deny his whiteness in order to claim himself as Indian. Instead, his wild ways define him as an ideal white man, free of the boundaries of civilization. He can hunt as he wishes, and his final court conviction in Pioneers is both miscarriage of true justice and a moment that fixes him as permanent martyr for Charlie Daniels type redneck resisters, as the tragic liminal figure: the redneck mountaineer brought under control by the artificial demands of the law.

Even as Bumppo suffers conviction because of his refusal of propriety and law, it is crucial to consider that he serves as a savior. He is the man who understands both the wilds and the civilization. He's given up civility as a means to understand America at its heart, the forest and the frontier. His demise, and perhaps the demise of all who subscribe to Judge Temple's model of civilization, is to force away the core Americanness of the wilderness. In his proto-redneck form, Bumppo establishes a framework for American counter-civilized identity. It is by going to the woods to live deliberately or otherwise that Bumppo establishes the arc of American literary identity. Because he is at a crossroads, and because he claims himself to be of the forest, almost kin to the Indian, his is the quintessential American. Bumppo defends the nation and its 
people from the horrors of the Hurons while remaining apart from the too-English nature of law and military ways.

The mythological function of Bumppo relies heavily on the lack of centrality Henry Nash Smith identifies in that character. That is to say, Leatherstocking himself never functions as the center of the stories in which he appears. As Nash argues, Bumppo may be a "noble child of the forest" but he always maintains an inferior social status (64). Likewise, though he might operate as "by far the most important symbol of the national experience of adventure across the continent" (961) and become a symbol of "anarchic freedom" that leads to "sons of Leatherstocking" in the myth-making of the Wild West (81), he does so as a liminal figure stuck between civilization and wilderness. Bumppo is the frontier embodied, a vessel for the dangers of the contact zone and a symbol for the mighty exertion of American power. Thus, I argue that Bumppo's supporting roles in the Leatherstocking Tales point toward his function as prototype for the American Redneck. He has to be present for the stories to work, but he cannot be the main subject. He is simultaneously valorized as hero and downplayed as a lower-grade of person. His figure thus perpetually fights in a permanent state of frontier.

Just as Slotkin argues that the myth or idea of the frontier gives America a reason to push on, I argue that the never fully redeemable persona of Bumppo allows the frontier to mythologically push on. Both the frontier and Bumppo function as ready symbols to justify behavior as "American" or proper. The mythological presence of 
Bumppo satisfies and sanitizes American motivations of domination, but they also depend on the maintenance of a frontier and of frontiersman as entities to push against.

A mythological Appalachia and a mythological South becomes that frontier. These regions, by grace of the unabashed outsider mentality of the perceptual Redneck originating in Natty Bumppo, take on the mythological American power that has long resided in the cowboy and the West. As Frederick Jackson Turner problematically asserted, America through the lens of the pioneer relished "the ideal of individualism" as "the ideal of democracy." The pioneer "had a passionate hatred for aristocracy, monopoly and special privilege; he believed in simplicity, economy and in the rule of the people" (273). It is easy enough to substitute the word "redneck" for "pioneer" in this characterization. Moreover, precisely because Turner proclaimed the frontier closed, and precisely because both more contemporary history and the reality of development in the West has eliminated the "presence" of a Western frontier, a conceptual void lay ready for ideology. In response to that void, Appalachia and the South become a permanent frontier, albeit a conceptual one. The degradation of the redneck figure positions these regions as permanent contact zones between the civilized and uncivilized, make even the redneck individual an entity filled with that kind of frontier conflict. In turn, the actions of the "hero" Redneck are justified in American literary history. He battles perpetually at this margin. But it is through the Redneck's perceived degradation that he also can never win over that frontier - he must fight on forever, 
mythologically battling constructed enemies that threaten a constructed America. The terms of America change. The identities of the enemies change. But the frontier myth lives on in the Redneck - always ready to defend the core concept of American frontier philosophy.

As counterpoint and entry into the contemporary figure of the Redneck, I fastforward now some 100 years to the degraded South of Erskine Caldwell's Tobacco Road. If Cooper gave American literature a figure of proto-Redneck resistance in Natty Bumppo, Caldwell in turn presented a locale for such a figure's perpetual subordination. While the novel itself enjoys little popular attention these days, that was certainly not the case in the years after its 1932 publication. As numerous scholars cite, Caldwell sold extremely well, making a fortune while, in the words of the omnibus Encyclopedia of Southern Culture "creating characters who were amoral, shrewd, venal, and gullible, reflecting primarily the basic human impulses of lust and the urge for propagation, but who nonetheless displayed an almost mystical connection with the land" (876). More to the point, scholar Edwin T. Arnold argues that "more than Faulkner, more than Welty, more than Wright or Warren or O'Connor, Caldwell created the image of the rural South and Southerner, for good and ill, in the minds of readers worldwide during the first half of the twentieth century. You might not like what he wrote, but you can't pretend it never existed" (852). In discussing Caldwell's curious 
legacy, Arnold suggests a seriousness of purpose and a seriously negative portrayal of Southern poverty that blend to create trouble and a general omission of Caldwell in both American Literature and Southern Literature anthologies. That is to say, while the author himself might have sought to write realistically about the South, and while he might have sought to do so for the greater good of the Southern poor, his popularity, sexual explicitness, and problematic portrayal of the Lester family in Tobacco Road creates dissonance. ${ }^{6}$

Indeed, as the Encyclopedia of Southern Culture and individual scholars cite, Caldwell's books and in particular the on-stage version of Tobacco Road suffered accusations of pornography and subsequent censorship (Encyclopedia of Southern Culture 852 / Marlacher "'A Wallow in Slime'"). Still, the images of the novel version of Tobacco Road resonate and establish context for contemporary stereotypes of rural poverty. Consider that while the Oxford Encyclopedia of American Literature offers no entry for the novel or for Caldwell himself, the index of the Encyclopedia of Southern Culture links the term "Lester Family" with generalized discussions under the subheadings of “Economic Development and Southern Culture”; “Trees"; “Tobacco"; “Johnny Reb”; and "Poverty." Thus, Tobacco Road exists not at all even as it penetrates broadly.

\footnotetext{
${ }^{6}$ Scholars have had a similar on-again, off-again relationship with Caldwell. For a fuller critical examination of his work, see MacDonald's The Critical Response to Erskine Caldwell; Miller's Erskine Caldwell: The Journey from Tobacco Road; Cook's Erskine Caldwell and the Fiction of Poverty: The Flesh and the Spirit.
} 
Even though the opening scene of Tobacco Road is cited often enough in scholarship to border on cliché, it nonetheless offers perfect entry into the problematic identity that Caldwell establishes for the Lester family. Lov Bensey appears on the road in front of the Lester shack, home of his in-laws, carrying a sack of turnips. The hungry Jeeter Lester can't stop thinking about the turnips, while Lov can't stop complaining that his wife — Jeeter's twelve-year-old daughter Pearl — won't sleep in his bed. The action progresses slowly, culminating with hair-lipped Ellie May Lester scooting her naked backside across the dirt yard, thus drawing the attention of Lov to the point of copulation. Meanwhile Jeeter, his son Dude, the rest of the family, and a trio of black men watch the escapade in the yard. And in a moment that presages stereotyping Southern literature to come, Dude remarks of Ellie May: “'That old hound used to make the same kind of sound Ellie May's making, too. It sounds just like a little pig squealing, don't it?'" (18). The action is coupled with shot-establishing description of the shack itself: "The centre of the building sagged between the sills; the front porch had sagged loose from the house, and was now a foot lower than it originally was; and the roof sagged in the centre where the supporting rafters had been carelessly put together. Most of the shingles had rotted, and after every wind-storm pieces of them were scattered in all directions about the yard" (7). Tobacco Road thus appears in the contemporary mind as a hodgepodge of hillbilly and redneck disparagements. 
Across the scope of the novel, the Lesters are portrayed as sexually depraved, with Jeeter spying on his son Dude in the bedroom with new wife Bessie, who herself is passed along the male patrons at an Augusta flophouse while the Lesters otherwise sleep soundly. The Lesters have a ragged car rusting in the front lawn, and when Bessie buys a new one it is quickly reduced to scrap through a consistency of poor driving. Jeeter himself is described as too lazy to have Ellie May's hairlip repaired, and he is content to sit in poverty after his landlord closed shop on their cotton sharecropping setup. Thus a scholar suggesting that "Caldwell comes dangerously close to the pervasive stereotype of poor white southerners" (Vials 78) offers serious understatement. Indeed, Caldwell might have written the book to criticize the deleterious effects of amoral farm owners and potential redemption of cooperative farming: "Rather than attempt to show his tenants how to conform to the newer and more economical methods of modern agriculture ... he sold the stock and implements and moved away.... Co-operative and corporate farming would have saved them all" (63). But he does so in a manner that exploits and degrades the impoverished condition of the objects of his benevolence.

Contemporary scholars of Tobacco Road and Erskine Caldwell in general have been interested in what Louis Palmer calls the "interpretive quandaries" of the novel. They ask if Caldwell is 
a good-hearted social reformer, whose middle class revulsion at poor whites bleeds through his avowed zeal to change the conditions that led to their lives, or is he such an accurate "realist" that he defeats his own reformist purposes by demonstrating that the poor are incorrigible? Or is he an heir to the Southwestern humor tradition, mocking rural types from a bourgeois, urban perspective? (132)

Further, Palmer suggests that the portrayal of the Lesters goes far enough to raise doubt about the potential of agricultural reform on the condition of poverty presented (136). In essence, the portrayal of stereotypical hillbilly images creates such a dehumanized vision of the rural poor that the potential success of co-operative farming is outweighed by the negative, primitive nature of the Lesters.

At the same time, the novel does effectively force the reader into an uncomfortable relationship with the characters of the fiction. Certainly, the opening scene pushes the reader far away from identification, establishing the Lesters clearly as an exotic, dangerous, and depraved sub-human sort. So reader identification is postponed until the purchase of Bessie's automobile, where Caldwell presents two salesmen as a different sort of evil. These individuals offer connection to the readers of the novel, are in fact the "human" faces where readers would find the clearest reflection of self. Yet the salesmen treat Bessie and Dude poorly, questioning whether they're 
worth the time, then finally offer the kind of special deal no one wants from a car salesman. The car needn't be registered immediately if they wanted to drive it straight off the lot: "They winked at each other; every time they wanted to put over a quick sale they told that lie about the registration laws" (90-91). Caldwell has effectively criticized his readers here and elsewhere, showing them to be the source of the conditions that entrap the Jeeters in cycles of poverty. "'Then it will be the rich who put us there,'” Jeeter says of the possibility of having to leave the homestead for the poor-farm (115), and here "rich" and "reader" and "car salesman" collide. The middle-class readership of Tobacco Road is meant to suffer the depravity of the novel, to be aghast at the sexuality and violence bred by poverty and, therefore, seek to do something to change the conditions. More, the actions and results of "civilized" characters within the novel offer more lurid consequence than the sex and turnip scene that opens the novel. Caldwell offers, from one point of view, an effective and biting criticism of middle and affluent America.

Caldwell's criticism comes at great expense, though, as the fictional Lesters obviously come across badly. More to the point, the baseline of rural depravity in Tobacco Road continues to echo in literature. The pig-squealing of Ellie May returns in James Dickey's iconic Deliverance, and Dickey himself has been cited as an admirer of Caldwell's work (Arnold 853). Figuratively, Tobacco Road continues to hold sway in popular culture even if it seems to lack a hefty readership. Conservative writer Florence 
King, for example, made reference to "the descent of the Clintons back into the Erskine Caldwell novel from whence they came" in her National Review column (King 84). Perhaps more intriguingly, Tobacco Road checked in at \#91 in Random House's Modern Library list of the 100 Best Novels in the English Language, thus ranking Caldwell in the same list as writers like Saul Bellow, Wallace Stegner, James Joyce, Virginia Woolf, and fellow Southerners like Carson McCullers and William Faulkner. Faulkner's As I Lay Dying checks in at \#35, incidentally, a curiosity I cite because of thematic similarities to Tobacco Road.

My point is that despite early protests of the novel's sordid material, and despite uneven attention and unclear legacy among scholars, Caldwell's images of the Southern poor cannot be ignored as source material for contemporary redneck images. Caldwell's former popularity also cannot be easily discarded, largely because of the position of those who read him. Southern scholar Edwin Arnold writes that he came to Caldwell's novel not via his university education but, instead, from the working folk of his Southern homeland:

Had I read Caldwell? It was something I ought to do. And it wasn't just because of the sex, although there were plenty of jokes about that. It was the humor and the honesty that spoke to them, and that they commended to me. Caldwell made them laugh, but he also got it right. He understood the world they lived in, the limited options 
and inherent unfairness and occasional meanness and unexpected craziness. They pushed his books on me, telling me I would learn something by reading them. (855)

Arnold therefore presents a complicated aspect to the marginalization of the Lesters and future real-world Southern poor. Namely, Tobacco Road and subsequent titles appealed to the Southern working class because of a notion of truth and despite the stereotypes. Perhaps the hang-up of identity is a luxury of middle-class academia, as the reality of rough economic conditions seems to erase the specter of quick offense.

Still, when a pop columnist like King offers a quick strike at the Clinton family legacy by citing Erskine Caldwell novels, economic reality has been forgotten. The very real subjugation of impoverished individuals in the novels has been replaced by basic political rhetoric. In the same sense, Caldwell's stereotypes have become institutionalized as core definitions of rural poverty. The Encyclopedia of Southern Culture cites Caldwell as part of an entry on "Poor Whites:"

Many Americans blame the South's problems on the Jeeter Lesters (of Tobacco Road), degenerates and racists, shiftless wanderers, wifebeaters, drunks, and ne'er-do-wells. They believe that such people also furnish the Ernest Angleys, Jerry Falwells, and Marjoe Gortners of American religion. According to the conflicting images of American popular culture, the southern poor white can be the 
shrewdly innocent Jed Clampett of The Beverly Hillbillies or a Pentecostal haunted by incestuous lust, the sodomite of James Dickey's Deliverance, or the tough, poor-boy-made-good Paul "Bear" Bryant, who wrestled bears in Fordyce, Ark., because he could make more by fighting the beasts than by chopping cotton.

Caldwell continues to hold sway as part of the core concept of rural poverty, cited here as a means to clarify just what a poor white is.

By the same token, the 1974 edition of Tobacco Road pastes together the novel's texts with photographs of actual Southern poor. Scenes of real people in actual poverty run against the images of Ellie May and Lov rolling on the lawn. A crime against identity occurs here. The individuals captured in these photographs are permanently placed in comparison with the action of the fiction, each normalizing the other: if these are real people, then this must be real redneck behavior; if this is real redneck behavior, then these real people must be depraved themselves.

It is a relatively short conceptual voyage from Caldwell's southern Georgia to James Dickey's northern one, as portrayed in the novel Deliverance. The churning waters of the Cahulawassee River lead readers of Dickey's novel along a descent into wilderness and poor road maintenance. The trip to the river follows a progression from 
suburban strip-mall highway, to "blacktop state road," to a "badly cracked and weedy concrete highway of the old days," to a broken down concrete road "not worth maintaining at all" (52-53). In this way, Dickey traces disaffected narrator Ed's escape from the troubles of his Atlantan life, along with his equally middle-America friends Bobby and Drew, and wilderness aficionado Lewis. They travel into backwoods Georgia because of Lewis's desire to run the river "before the real estate people get ahold of it and make it over into one of their heavens" (4). The general plot of the novel centers on an attack by miscreant backwoodsmen and the city-goers' counter-offensive and escape. This plot now factors heavily in a popular, contemporary vision of the backwoods. Rather, images and sounds from the 1972 Academy Award winning film based on the book create the backdrop upon which contemporary Redneck America is projected. Ride into the woods in any collection of junior high boys and someone's bound to whistle the opening strands of the iconic "Dueling Banjos" tune that figures prominently in the movie. Such is the strength and permanence of malformed, backwoods imagery.

Consider the Atlantans' first encounter with the residents of rural Georgia in the film version. The scene is dominated by visuals of rundown, collapsing shacks, rusted out cars, and mud - images straight from Caldwell's Tobacco Road. The men survey the old-timers who stroll out to fill their gas tank, one of whom Bobby addresses: "Hey mister. I love the way you wear that hat." After a long pause, the "typical" rural 
Georgian — rail-thin, heavily weathered, beaten down and malnourished — responds angrily, "You don't know nothin'." Bobby looks concerned, then remarks to his buddies, “Talk about genetic deficiencies. Ain't that pitiful?" Soon after, Drew engages in the banjo duel with a child who appears unworldly, pale, perhaps mentally delayed. Elsewhere, Ed glances through a shack window to observe an old liver-spotted woman and a severely deformed child. The camera apparently shows viewers the way it "really is" there in the backwoods, a locale full of angry, pitiful, grotesque, simple people.

Not surprisingly, these sorts of images drew rather obvious arguments of exploitation and unfairness. Despite this criticism, the cultural work of Deliverance has been accepted, historically precedented, and complete. The film's images follow decades of previous backwoods imagery from Caldwell and others. As Ronald Elder argues, the mountain South "continues to languish backstage in the American drama, still dressed, in the popular mind at least, in the garments of backwardness, violence, poverty, and hopelessness once associated with the South as a whole" (ix). It is a place whose residents cannot shake the images that inspired and followed the film. Says Anthony Harkins: “The portrayal of southern mountain people as premodern and ignorant 'hillbillies' is one of the most lasting and pervasive images in American popular iconography, appearing continuously throughout the twentieth century in nearly every major facet of American popular culture from novels and magazines to movies and television programs to country music and the Internet" (3). As a result, 
viewers of Deliverance find little to quibble with in the images of the mountain folk, or with the portrayal of the violent and random rape of Bobby at the hands of two more "typical" hillbillies. Further, the revenge-flick atmosphere, as Ed scales cliffs to sling an arrow into the body of his attacker, fits an easy notion of necessity. The hillbillies of the film had it coming, are subhuman nearly to the degree of the zombies that populate a wide swath of early twenty-first century popular film and fiction. ${ }^{7}$ Each must be eradicated by reluctant and overmatched heroes, if only to defend the rest of the nation from the coming invasion.

Seen together, the film and novel versions of Deliverance offer competing narrative visions and complementary portrayals of hillbilly savagery. In some senses, the movie follows the novel faithfully. Plot, characters, and narrative arc are identical. However, the interpretation of the film diverges significantly from the book. At best, the film suggests the moral difficulty that Ed feels after being forced to fight for his life. In contrast, the novel maintains a more critical position. It offers both complaint about the loss of natural wilderness and, in nearly the same moment, complaint about suburban metaphorical excess. In the novel, Ed places the violent, anti-socialist Lewis on a pedestal of masculinity. He is an antidote to the suburban malaise that has descended

\footnotetext{
${ }^{7}$ As an interesting redneck-zombie intersection, Woody Harrelson's character in the 2009 film Zombieland goes into battle with a "redneck" zombie by a) luring him with a few banjo strains from the Deliverance soundtrack and b) quoting the Deliverance line that the zombie has "a pretty mouth." In other undead realms, the HBO series True Blood depends on Southern and redneck tropes, casting vampires in the role of racial or sexual minorities. Anti-vampire sentiment is played as a redneck value, and the vampires themselves fit a certain kind of hillbilly stereotype, particularly in their heightened and "deviant" sexuality.
} 
upon Ed's middle-aged doughiness. "We were not — or at least I was not — what we were before," Ed claims. "If we had had an accident and had to be identified by what we carried and wore, we might have been engineers or trappers or surveyors or the advance of commandos of some invading force" (35). For Ed, the voyage into the wilderness is a voyage away from self and into the identity of the macho-man. In leaving behind his suburban home, his suburban wife, his suburban job, he makes space for himself as an authenticated man, the same image he projects upon Lewis. The novel shows readers that this authentication is revealed externally. Someone finding Ed in the woods would see him as more than he knows himself to be. Similarly, he later sees a reflection of himself in the car window and adopts that outside view: I was light green, a tall forest man, an explorer, guerilla, hunter. I liked the idea and the image, I must say. Even if this was just a game, a charade, I had let myself in for it, and I was here in the woods, where such people as I had got myself up as we were supposed to be. Something or other was being made good. I touched the knife hilt at my side, and remembered that all men were once boys, and that boys are always looking for ways to become men. Some of the ways are easy, too; all you have to do is be satisfied that it has happened. (68-69) 
Ed sees himself now in the image he wants to become. His transformation is complete because he can now play the mountain man, albeit an action-film sort of mountain man; moreover, he can pretend to be the hardcore outdoorsman that Lewis appears to be.

The violence to come, the murder and coverup of the two locals who rape Bobby, is largely a self-fulfilling prophecy. The suburbanites want to kill, and screw, and be uncivilized. That they suffer so much in the offing, and that their trip into their imagined wilderness becomes a nightmare, critiques outsiders' views of Appalachia more than it functions as a stereotypical send-up of the region. That is to say, when Ed remarks that "there is always something wrong with people in the country" (55), he is espousing the suburban imagination. Thus the novel offers a criticism of the main characters, who have created iconic images of wilderness, of masculinity, and of hillbillies. They have to run the river before it's dammed, just as they must prove their masculinity in opposition to hillbilly violence. None of their preconceived ideas are accurate, and the horror of their canoe trip is their dream played out in the world. The violence happens because they want it to happen. After all, the famous rape scene seems instigated in the book by the Atlantans' assumptions and declarations that the men in the woods are moonshiners. The suburbanites have already assumed the position and identity of those in the wilderness, and so they merely receive in turn that which they've created in their minds. 
Of course, popular culture considers this reading of the novel far less frequently than it does the quicker, baser version of the film. On the screen, the men on the canoe trip suffer at the hands of the dirty hillbillies and must overcome the wanton violence inherent to the hills. Here, the audience approves and participates in the isolating perspective of civilized versus uncivilized: Ed and his buddies are forced into violence, have their peaceful trip disturbed by the miscreants who lurk in the woods. It comes as no surprise that the film's version of events is the version that lingers. The images contained within its reels adhere closely to the static portraits of the backwoods that have dominated hillbilly representations for decades. By combining the implications of the novel and the film, the dual-function of the American hillbilly icon becomes clear. Anthony Harkins describes this function as "the dual and seemingly contradictory purposes of allowing the 'mainstream' or generally nonrural, middle-class white, American audience to imagine a romanticized past, while simultaneously enabling that same audience to recommit itself to modernity by caricaturing the negative aspects of premodern, uncivilized society" (7). Thus Deliverance in total, film and novel, allows suburbanites to return to civilization broken, wounded, but reminded of the value of their own middle-American lives.

The closing image of the film evokes the American hillbilly message well. The men climb up from the river onto a blacktop road that disappears into the lake behind. An abandoned Church of Christ sits at the water's edge. The men walk up through the 
dam work, through heavy machinery and scoured earth, to retrieve their vehicles and head home. There, the local sheriff tells them not to return and not to ever do anything like this again. And as viewers of the film, readers of the novel, and consumers of the popular stasis of the mountain hillbilly, we surely won't make that mistake. Deliverance assures us that we should be happy with civilization, that the hillbilly will always lie in the wilderness, perpetually beneath the lake, ready to remind us that we cannot easily discard the civilities that govern our daily lives.

The degraded vision of Redneck cannot disappear, clinging tight to Jeeter and Lov and Caldwell and Dickey's Deliverance, even as the effect or intent of the identity shifts. Caldwell employs the identity to give attention to the plight of the Southern poor, while Dickey exploits backwoods savagery to criticize the state of suburban manhood. Redneck, in turn, operates closer to pure construct than singular identity, maintaining residues and gestures of the "pure" ideal of simplicity and the good ol' days in order to operate as a power-granting identity. In this, I would argue that the terms "redneck" and "hillbilly" are functionally identical from an ideological perspective. Each designates a rural underclass, and each is dependent on a fixed sense of geographic and historical specificity, even though the actual "meaning" of the terms constantly changes. Just as Henry Shapiro, Jerry Williamson, Richard Peterson, and Bill Malone point out, the uses and definitions of these identities move to satisfy national need. As such, the 
terms themselves become empty signifiers referencing ideas that correspond to no one. Yet they shift to allow the individual or group using the identity to shape the image into what is needed.

Even if the redneck or hillbilly cannot be considered extant in anything other than a theoretical way, the cultural valence of these rural figures remains strong and active. Popular images of the identity frequent contemporary country music and redneck-based comedy. Of the latter, the recent Blue Collar Comedy Tour has swept the nation, drawing large crowds of people who embrace their self-assigned redneck conditions. The peculiar result of that identification, however, is an audience that seems to be laughing both at themselves and at others who are somehow more redneck than they are. Simultaneously, the comics at work are telling jokes from the position of redneck while ridiculing the Redneck Other.

Scholars Sandra Ballard and Anne Shelby each take an ambivalent view of redneck comedy. Each suggests that redneck jokes are partly innocent but also part of a long history of rural stereotyping. Ballard finds the jokes funny, and can't quite find the anger that others feel. She suggests that, in one sense, the contemporary redneck joke must be placed in the historical scope of comedy, as a rendition of the long-standing fool or trickster. She argues that the Redneck Fool operates as a seeming rube who, in actuality, pokes fun at the evils of the greater culture surrounding it ("Hillbilly Foil in Literature" 141), a sentiment echoed in part by Bill Malone. But while I agree with 
Ballard that the redneck figures of The Beverly Hillbillies or even the Blue Collar Comedy

Tour function to a certain extent as cultural critique, there's something more at play when figures in power adopt the title. Despite Southern residence, the comics of the Tour are middle- to upper-class whites who have never suffered the negative epithet of "redneck" in quite the same way of the truly downtrodden Southern poor. Likewise, the audience who laughs at the jokes might wear the badge of "redneck" as an opposition to "civilized" America, but that same audience is likely rarely prevented access from goods, services, and capital. Instead, the white brushstroke of the audience echos the broader privileged identity of the nation itself. I argue that this adopted or exaggerated identity becomes self-insulating. It allows figures of power to maintain economic control over low-wage, working-class whites while also engaging the identity for hegemonic use. Worse, even the low-wage members of the audience are quick to apply this ideologically twisted version of Redneck to themselves. That act empowers the already powerful and subordinates the individuals trying to take "control" of the identity epithet. ${ }^{8}$

Shelby points out the hidden complexity of redneck jokes. She argues that the jokes allow the audience to participate and not just witness jeering. The jokes serve as an affirmation of culture, since attention is drawn to the figure of the working poor

\footnotetext{
8 Labels of Redneck function far differently than the liberating self-avowal of other subaltern epithets. "Redneck" works far differently, for example, than the emancipatory reclamation of terms like "queer" or "nigger." These terms have been re-appropriated by the very individuals who have suffered from their belittling use. As such, the very real power of those words to subjugate and denigrate has been at least partly defused by their reclamation. In contrast, the self-labeling of "redneck" works not to reclaim an identity but, instead, to assume one. The term hasn't been transformed by its use, only co-opted.
} 
(156). In this view, the audience laughs along with the jokes, as insiders to the follies of their own group. But she suggests also that for many in the audience, participation stems from an upward mobility. Audience members acknowledge that they used to be rednecks, can laugh at the jokes as insiders but have since moved on to better positions (156). I argue that this participation creates trouble. The audience is on one hand jeering at the crowd left behind, even as it celebrates its roots: Jeeter Lester is both a foundation to be laughed at and admired. Shelby's third view suggests that audiences may laugh simply because they're not the ones being made fun of, that the redneck jokes display that a class of whites exists that can be categorized below themselves (157). This schadenfreude offers a direct link to the long tradition of Southwestern humorists. ${ }^{9}$ Here, she echoes the roots of the hillbilly and white trash stereotypes identified by Matt Wray, Duane Carr, and others. Lastly, Shelby suggests that audiences might like redneck jokes because they at least offer someone available for ridicule: as many scholars point out, the status of the hillbilly or redneck or cracker leaves him or her open for the sort of ethnically and socially non-liberal ridicule that contemporary civil rights and polite society now condemn (158). Redneck jokes cannot therefore be separated from the sticky racial position of the redneck, who is simultaneously a degraded white and a last line of defense against non-whites.

\footnotetext{
9 "Laughing Over Lost Causes" by Andrew Silver presents a useful examination of how Erskine Caldwell fits into the scope of Southwestern humorists.
} 
Whiteness and white supremacy become entangled in the redneck identity formed by enterprises like the Blue Collar Comedy Tour. As I alluded to earlier, Duane Carr, Anne Shelby and others have pointed out how the construction and, particularly, the ridicule of rednecks and white trash comes about as a response to the "political correctness" of the post-Civil Rights era. When Larry the Cable Guy jokes about disappearing "as fast as hubcaps at a Puff Daddy concert" (Larry the Cable Guy: Git-RDone), he allows the nearly perfectly white audience to laugh at a racist joke with a certain sense of safety. After all, the audience laughs at Larry, the overly-stylized Redneck who makes the joke and who, more importantly, can't be expected to know any better. He's just a redneck after all. The laughter, of course, comes in no small part because the audience itself believes the root of the joke, that blacks are inherently larcenous and always suspect. But the audience knows also that it cannot initiate such racially charged humor without running afoul of the antiracist atmosphere of polite society. Larry as Redneck allows the audience to indulge its own racism and blame it on the redneck.

Harkins points out how popular 1960s television shows like The Andy Griffith Show, Green Acres and The Beverly Hillbillies allowed white Americans to revel in the splendors of white rurality without acknowledging the complex and violent racial situation in the American South of the time (175). Even though such shows were set in or dealt with people directly related to the regions that saw the most turbulent activities 
of the Civil Rights Era, the shows themselves were nearly completely white and never recognized the violence of the day. They allowed white Americans to whitewash the South, to ignore the toil of black Americans, and to pretend that nothing was really wrong in racist America. The Redneck image was put to use to conceal the racism of America, just as with Larry the Cable Guy it is put in use to maintain racist language under the guise of redneck comedy. For each, the images of the rural working class become aligned with the maintenance of white supremacy, which supports the stereotype that rednecks are inherently racist anyway. Crucially, the effect of that stereotype is to maintain privilege for non-Redneck Americans who nonetheless stand to benefit from such a structure.

Ideologically, Redneck identity offers a means to separate the individual from the ostensible corporate America. It reinvigorates the Fenimore Cooper notion of the noble outsider who refuses to be hemmed in by the rules of civility. For example, country singer Gretchen Wilson has found popularity with the song and, later, the memoir Redneck Woman. Each of these texts suggests liberation and freedom for any who accept their own Redneck title, but each also writes individuals back into the narrative of rural depravity from which the Redneck comes. The song hit the charts in 2004, launching Wilson to sudden fame after years of life as a bar singer, a background narrated in her memoir. In the song, Wilson offers unapologetic defense of her social position: 
Some people look down on me, but I don't give a rip

I'll stand barefooted in my own front yard with a baby on my hip

'cause I'm a redneck woman

I ain't no high class broad

I'm just a product of my raising

I say, 'hey ya'll' and 'yee-haw'

And I keep my Christmas lights on

On my front porch all year long

And I know all the words to every Charlie Daniels song

So here's to all my sisters out there keeping it country

Let me get a big 'hell yeah' from the redneck girls like me

(“Redneck Woman")

Wilson makes easy use of stereotypical redneck images, poking fun at the clichés of year-round holiday lights and the barefoot and pregnant redneck woman. She glorifies and defends the Southern working class from forced images. Thus she sings tongue-incheek in all but her request for hell-yeahs, the song becoming an anthem of support and release.

Wilson cannot help but enact the very conceptual shift that I seek to examine, even as she seeks to be satirical. She activates cliché images as a means to defend a class and race position that has hardly been threatened. The confusion of her Redneck 
position becomes clear in her memoir: "In many parts of this country, 'redneck' is an acceptable slur, along with equally acceptable put-downs like 'white trash,' 'trailer trash,' and 'hillbilly.' Low-income rural whites are about the last people in America who seem to be fair game for blatant stereotyping" (Wilson xv). Her sentiment seems at best naive or disingenuous, since these kinds of redneck stereotypes certainly aren't the only "fair game" out there, not when unilateral images of violent inner-city black men and job-stealing Mexican migrants are so quick to the contemporary mind.

In reality, Wilson's claim is a cop out and a defense against the rising tide of multiculturalism. She places poor rural whites or, more so, self-acclaimed rednecks, in a position of feigned inferiority. There, Rednecks enjoy the benefits of the downtrodden even as they have the capacity and position to be superior to minorities. By arguing that prejudice against the redneck is the last acceptable bias, Wilson deftly places the Redneck in a position of moral superiority. She makes space for the celebration of the identity and closes off the option for criticism. Redneck equates to minority, which therefore insulates Redneck from attack. So when the audience shouts out their hell yeahs in response to Wilson's song, they are both exercising pride of self and refusing to acknowledge that the "redneck" fans of Gretchen Wilson are far different from striking West Virginia miners, far different from Appalachian poor, far different from dirt farmers of the American South. The Rednecks in Wilson's audience enjoy the spoils of 
their created subaltern position, exercising tremendous influence on American culture and politics even as they lay claim to the image of the downtrodden.

Certainly the image of the redneck or hillbilly has been prevalent and important in the country music industry from its early years. As Malone and Peterson both outline, authenticating images of the hillbilly were used to create the idea of a simple, true America. The images helped form a musical genre that has increasingly become difficult to separate from American jingoism. But as each also point out, the images have been in constant flux. The title of "hillbilly," for example, implies several competing notions of authenticity. Early on, hillbilly costumes were used by otherwise non-hillbilly musicians as a means to show their position as country singers and, just as importantly, to identify them as practitioners of white folk music and not black jazz (Malone Don't Get Above Your Raisin'; Peterson Creating Country Music). Eventually, as negative images of the hillbilly appeared in the broader American culture, country musicians adopted the cowboy image. As Peterson points out, contemporary singers have taken to identifying themselves as hillbilly singers to designate themselves as different from big stage acts like Garth Brooks — thus the authenticity of the hillbilly image has come somewhat full circle.

As Bill Malone argues, notions of authenticity have always been crucial in country music (47-48). The musical genre has sought to align itself with the nostalgic power of rural America, to bolster its appeal by tapping into the American ideals of 
prairie houses, and Western ranches, and leather-stocking wearing frontiersman (at least ideologically for the latter, if not sartorially). As Malone and Peterson both argue, part of the country cowboy identity was shaped by the Grand Ole Opry, which forced its singers to present public images of piety and wholesomeness. Moreover, even though much of the root music of country extolled the virtues of "rambling" (Malone 119), the Opry image maintained a purity that allowed the genre to flourish. Still, as Malone argues, it was crucial that the music itself trumpet the merits of both sides of the moral coin — chasteness and hedonism were both sung about, as well as the beauty of working-class life and the allure of the middle-class. It wasn't until the 1960s that the protest music of the time created an inadvertent conservative champion in Merle Haggard. His Okie from Muskogee appealed to the slice of the American populace that resented the long hair and liberal politics of the protest movement (241). As Malone argues, mainstream country music became fixed at this moment as conservative, even though folk music has been and continues to be used as liberal anthems, and even as a contemporary liberal alt country music scene exists. Nonetheless, country became aligned with constructed values of America and, in particular, the rural South: pickup trucks, cowboy hats, hunting and fishing.

So just as the images of the hillbilly were employed to give country music life, and just as the images of the bootleggers give vitality to contemporary NASCAR, contemporary country music itself creates and maintains a certain image of redneck 
ethnicity. I would argue that through the growth of country and other rural enterprises, this has become a normalized ethnicity, a constructed base and history that defines a new American ethnicity. Since country music, like NASCAR, has become a multibillion dollar, multinational industry, it allows this new Redneck identity to be applied to big business needs. As a result, corporate ways become naturalized as the ways of the people and of the Redneck, thus erasing actual rurality from the equation. Country music's hillbilly and redneck images create an ethnic distinction that proves American validity for the individuals, companies, and governments that pledge allegiance to the Redneck identity.

The definition of "redneck" craters around its own complicated cultural identity. In Cooper, we see early notions of an outsider defending the purity of white manhood. In Caldwell we see the roots of the contemporary image. In Dickey, we see the stereotype used to explore a broader notion of contemporary male impotence. In contemporary redneck comedy — skewered in Family Guy and celebrated on the Blue Collar Comedy Tour — we see the economic potential of the identity. And in Wilson, we see how a contemporary illusion of downtrodden rednecks can be used to mobilize a distorted sense of oppression for a significant subsection of America. All of these identities can be claimed by individuals who want to be redneck without the element of poverty and by individuals who suffer from actual rural poverty. Wilson, for example, 
has authentic roots within the rural poor even as she now clings to the identity as a wealthy Nashville singer. Jeeter Lester, in the same sense, really is (fictionally) poor. But his depravity is also assigned by proximity to the individuals whose photographs pepper the pages of Tobacco Road. The Redneck is and isn't constantly.

The identity evoked in these texts and claimed by self-avowed Rednecks echoes the "national manhood" that Dana Nelson suggests function within colonial America. She argues for a fabricated joint identity that "has worked powerfully since the Constitutional era to link a fraternal association of white manhood to civic identity" (ix). Nelson argues that such an identity worked against the best interests of a socially unified nation, instead "conditioning [white men] for market and professional competition" and simultaneously creating "a series of affective foreclosures that block those men's more heterogeneous democratic identifications and energies" (ix). So it works with the Redneck nation, this homogenous definition of pride and American foundation that seeks to establish the very nature of American identity. Such definitions create competition for what I might label national Redneckhood, where an individual's level of adherence to Redneck identity determines that individual's capacity for inclusion in full American citizenship. The Redneck portrays itself as the tired and poor who come to America, work hard, and succeed. The Redneck takes over the economy, the government, even the cultural image of the country in order to close the door 
against other tired and poor who might seek similar inclusion. The Redneck exploits images of the actual rural poor for its own purposes, benevolent or, usually, otherwise.

An ideological Redneck identity defines the limits of American citizenship. The source of this contemporary American figure and evidence of its continued valence in the United States lies in our national literature and pop-culture. Here, identity operates with a certain fixed shiftiness, always changing in order to maintain a rigid dynamic of power and subordination. A broad American identity constantly reconstitutes the Redneck in order to serve not the underclass historically yoked with the title, but instead serve those who adopt enough characteristics to seem "authentic." This Redneck identity reassigns value to reinvigorate an empowered class against forces that might alter or eliminate the root sites of dominance. Thus, just as Cooper exercised what D.H. Lawrence called "wish-fulfillment" (61) in his Leatherstocking Tales, creating a fictional place to be both wild and aristocratic (58), the contemporary Redneck identity offers space for the dominant to fictionalize their own degradation. They map themselves onto the Cooperesque myth of the nobel outsider to feign superiority and demonstrated American purity. The wish fulfilled is one of native rights, one of permanent hegemony, one of unchanged national ideology.

This Redneck identity works to establish a baseline of normalcy for the broader American culture, in fact turns conditions of existence into values. The state of being white, or male, or heterosexual aligns with the state of being Redneck, which itself converts to a core value of American identity. To defend and practice these values is to 
establish one's membership as an American cultural citizen. Declaring oneself as Redneck is to declare undeniable American citizenship. Yet even those who don't overtly claim membership are subject to the philosophical parameters of the identity.

Crucially, in the Redneck model "redneck" ceases to be a pejorative classification of the rural, Southern, white working class, and instead becomes a new mode of the mainstream. The identity is simultaneously unbound by the very real pressures of class and status that defined the redneck or hillbilly even as it seeks to reify certain social situations inherent within a white, hetero, masculine America. The Redneck identity appears in obvious and shrouded forms, emerging as needed and with intent to forestall change. We see the Redneck in the obvious places, in mainstream country music and comedy and television, but even these unsurprising appearances function in subtle ways. We may see and recognize the comic or exaggerated stereotype, and we probably jeer at it as well, but the identity is nonetheless internalized. The constant presence and availability of this identity makes all Americans a bit like Peter Griffin from Family Guy. We are attracted to the identity and wish, somehow, to become a Redneck; however, we also laugh at Jack Donaghy when he looks for middle America in the rural, stereotyped South. Still, we can't help but believe he's right: just look at truck commercials, Monday Night Football, and other patriotic advertising.

Through the constricted identity of the Redneck, the conceptual frontiers of Appalachia and the South can never be closed simply because the Redneck has always resisted modernization. Since the hillbilly and redneck can be championed as glorious 
absences of sophistication, as Jeff Foxworthy tells us, they can also be championed as glorious resistors to the imposition of American mass culture. But because the interpretation of the identity itself has shifted from simple degradation, to potential resistance, to reification of the mainstream, the Redneck consumes this new frontier. In turn, the Redneck becomes a prime site of the reification of narrowed mass American culture.

This geographical shift of frontier from the West to Appalachia and the South, along with an interpretive shift of the frontier myth from the cowboy to the Redneck, allows rural white identity to become an uncontainable but vital American type. It follows Guy Debord's definition of ideology as the foundation of the thought of a class society within the conflictual course of history. Ideological entities have never been mere fictions — rather, they are a distorted consciousness of reality, and, as such, real factors retroactively producing real distorting effects; which is all the more reason why that materialization of ideology, in the form of the spectacle, which is precipitated by the concrete success of an autonomous economic system of production, results in the virtual identification with social reality itself of an ideology that manages to remold the whole of the real to its own specifications. (150) 
It is the Redneck as a simple shorthand for recognizable American identity. The ideological Redneck is very much a fiction of America, but it is also an image that has been consistently drawn and redrawn through the fictions of American literature. As such, it materializes as an identity to be claimed and controlled as a means to establish credibility as an American.

This representational groundwork spreads into more serious quarters, affecting politics and governance. The American presidency itself has seen three recent visions of the Redneck in office — Jimmy Carter, Bill Clinton, George W. Bush — each using different forms of the identity to achieve and maintain power (or not, for Carter). The move from Clinton to Bush, of course, offers the most contemporary version of the identity, the soft redneckism of Clinton giving way to the harder edges of Bush. In current politics, the broader scope of candidates for office must now court the identity. Redneck values have been aligned with conservative Republicanism, thereby luring rural Americans to vote against their own social position. As a result, non-redneck politicians must contend with the identity class in order to prove their merit. Hence John McCain picks Sarah Palin as running mate, and Barack Obama finds useful support from a group called "Rednecks for Obama." For Obama, that support implies both that rednecks typically would not support him — since his politics run counter to both the assumed racial and conservative positions of Redneck - and that approval from redneck groups matters. 
Maybe most importantly, the Redneck operates in absence as well, in the writingout of those who live and exist in the places iconized as Redneck America. When we think of a white trash literary figure, we think of an Erskine Caldwell character, even if we don't specifically know Caldwell's writing. We certainly don't think of the complicated redneck worlds of the actual regions being portrayed. Despite a bevy of contemporary literature from the South and Appalachia that offers dissonance in a monolithic concept of the regions and the identity, we cling nationally to the simplified vision of the Redneck. The body, actions, and words of Larry the Cable Guy consume reality and shut down the conversation before we even begin. The simplified vision renders America toward the Redneck, thereby holding back the tide of multiplicity included within actual Southern rurality, bricking the wall against the kind of national inclusion that threatens hegemony.

Patterns of American hegemony have long depended on such limitations of inclusion. As Charles Mills and David Theo Goldberg have pointed out in the complex coding of race, cultural systems have created an intricate web of identities and political structures in the United States. Racial constructions suggest a purely dichotomous and always-oppositional black vs. white system. The Redneck identity uses a version of whiteness, of masculinity, of sexual convention to establish a dichotomy between American and un-American. Just as whiteness seems to lose traction when a black President takes office, Redneck ideology hoists the falling flag to preserve the core values of white America, masculine America, and hetero America. Color, perhaps, no longer limits the boundary of whiteness, but ideology limits the scope of American 
inclusion. By tracking the development and maintenance of this Redneck identity, the girders of America's current identity position can be uncovered. Through constant flux in the external boundaries of Redneck identity, internal fidelity to the nation's limited white masculinity can be achieved. In the end, America defends the honor of the redneck, white and blue, ensuring that power remains firmly in the grasp of the very same individuals who have always clung so very hard to a limited definition of American citizenship. 


\section{Chapter Two: Redneck Masculinity, Burt Reynolds, and The Man}

Bursting into popular awareness and then receding in nearly the same moment, Robert Bly's "mythopoetic" manhood of the early 1990s offered a popular reassertion of masculinity for a swath of (mostly) American males seeking to regain something perceived as lost. ${ }^{10}$ Neither Bly specifically nor the movement generally sought to align masculinity with any sort of "redneck" values. Instead they emphasized a return to primal or animal instinct. Nonetheless, the brief popular exposure of the movement offers a precursor to the more contemporary exertion of Redneck. In particular, the "mythopoetic" movement sought to engage what Michael Kimmel and Michael Kaufman call "a widespread confusion over the meaning of manhood" (16) created by changes in the work and social spaces of the latter twentieth century that eroded the theretofore "normal" condition of white, hetero, masculine dominance. As these two critics argue, this so-called "manly" movement came in response to civil rights, women's rights, and gay rights, progression that led to "the cry of anguish of privileged American men, men who feel lost in a world in which the ideologies of individualism and manly virtue are out of sync with the realties of urban, industrialized, secular society" (18-19). The result, if not natural but at least unsurprising, was an organized movement that sought to defend the walls of constricted male hegemony against these invading hordes, political correctness be damned.

\footnotetext{
10 Entry into the critical context of Bly and the mythopoetic movement appears in Bly's Iron John and Kimmel's The Politics of Manhood; for a general background in American folk masculinity, see Bronner's Manly Traditions.
} 
In linking this relatively recent assertion of primal masculinity with the contemporary masculinity ensnared within the multiple definitions of "redneck" I have previously addressed, I reference a recurring American impulse to protect and defend a perpetually declining sense of manhood. As Kimmel argues elsewhere, American masculinity has a long history of perceived threat and, in particular, "flight from women" ("Born to Run" 116). More to the point, he suggests that anxieties about the feminization of American men have led to literary response since the early nineteenth century, where "men have sought the homosocial solace of the wilderness, the frontier, the west" (139). The notion of a declining masculinity and subsequent ameliorative need has coincided with the rapid urbanization of the nation. Going native offers an antidote to those pressures, clearing space for the man animal, for unfettered masculinity. ${ }^{11}$

More directly in relationship to my argument, the image of the manly redneck has offered an antidote to polite or feminized constructions of male behavior. As Raymond Rodgers suggests, in the 1970s previously pejorative redneck identities were refashioned as heroic, offering resistance and hope for the embattled hegemony (71). It is my assertion that the particularities of Redneck identification fit into an important space of contemporary American masculinity. The Redneck offers a specific mythic space for American identity, is more readily accessible and culturally acceptable than

\footnotetext{
11 Notions of "going native" have an additional, more literal effect in American culture, as men have long mobilized images of the American Indian in efforts to establish national and gendered dominance. See Deloria's Playing Indian.
} 
Bly's animalistic and mythic versions of masculinity. More to the point, the masculinity of the American redneck took an interesting turn in the 1970s, spilling out of the backwoods and honytonks to present a broader, national counter-cultural male icon. I engage this 1970s version of the Redneck because he offers an important nascent effect: the identity for the first time offered a non-pejorative position for followers. That is to say, in the 1970s the figure of the Redneck assumed the "heroic" qualities Rodgers suggests, functioning as a template for resistance to multiple threats. On one hand, the Redneck offers an intriguing counter-cultural, anti-government, libertarian manifesto. On the other, he reaffirms pre-existing conditions of white hetero-masculinity.

Just as this new form of Redneck masculinity must be recognized as a constructed position, and just as the term "redneck" comes with a multiplicity of definitions and implications, the regions that constitute the natural habitat for this figure offer an analogous artificial identity. Placed in the rural spaces of the South and Appalachia, the new 1970s Redneck relies on the long history of spacial construction that has imbued the American consciousness with images of inescapable "reality." To preface the examination of the change within Redneck identity, it is important to consider how conjuring images of the South and the Appalachia of the present requires a complicated act of negation. Each region must be seen as a construct, as theoretical entities that have actively and passively sought to reiterate, rebuild, and reinforce the 
social conditions of their pasts, often for strategic reasons that benefit only a small portion of the regional population. ${ }^{12}$

Further, for each region the construction of a unified identity has often played to the advantage of parts of America not actually located within the regions themselves. Thus a static notion of regional identity developed, fixing the historical and contemporary within a narrowed view. Crucial, here, is an understanding of the way that Southerners and Appalachians may or may not be involved in this construction of regional identity. In very real ways the ideas of the South and Appalachia have been built to serve narrow bands of the regional population — typically more affluent, culturally dominant business owners instead of laborers and the working class.

Likewise, the identity of the Redneck follows this pattern, where the identity has been put into play for the benefit of a narrow band of America: male, powerful, white. The construction of that identity shadows the construction of the regions, making use of its outsider status to maintain patriarchal power.

There's nothing new about this idea of static identity, of course, as the region of the United States broadly designated as "the South" ${ }^{13}$ has long been constructed as an Other. Even as the South is recognized as a discrete region, it has since the days of the

\footnotetext{
12 Insight into Appalachian construction and actuality lies at the center of texts by Billings, Harkins, Miller, and Shapiro.

13 Similar to the way "redneck" slips and slides with multiple definitions, so too does "the South." In a broad geographical sense, I include the region of Appalachia within a generalized definition of the South, as a large portion of Appalachia lies literally in the Southeastern United States. Still, as regions and identities, "The South" and "Appalachia" cannot be neatly tied together.
} 
American Revolution been seen in constant opposition to the North (Cobb 1). More importantly, it has typically been both lauded and criticized for a perceived stability of culture. As John Grammer notably argues, antebellum Southern identity relied on a dual focus of national pride and elegiac form. In developing a notion of "pastoral republicanism" (11), intellectuals and writers of the region sought to offer a stabilized model of America that worked as counterpoint to the perceived rapidity of change in the North. In the mid-twentieth century, the writers of the iconic I'll Take My Stand sought to establish the region as fundamentally different than the rest of the nation, as fundamentally steeped in the smaller-scale, romantic notions of an agrarian culture (Ransom et al). And most recently, Scott Romine has argued that contemporary Southern culture has come to constitute only a replica of imagined versions of "real" souths at work in the collective American cultural catalog (The Real South). More importantly, the North has rarely (outside the South) been considered as a region that necessitates a capitalized moniker.

That is to say, the North has typically been constituted through history as America itself, despite the potential for Southern national definition that Grammer identifies. Therefore the North needs no title to differentiate it from the larger national body. The North has been constructed as the normalized America, with the South seen as deviant, or backward, or simply as counterpoint, thanks to its different population, different mode of economy, different climate. Or as Sharon Monteith and Suzanne Jones 
put it, "region is usually applied to an area judged to be on the fringes; regional and regionalist, in turn, tend to be applied by 'us,' the members of a culturally dominant group, to 'them,' a group or area whose interest very largely stems from its not being at the center of things" (xiii). Certainly, the South has suffered the label of "region," its literature the classification of "regional," which is to say all things Southern are grouped as outside the American norm.

As Cobb also identifies, the South itself has been complicit in such constructions of opposition. The proponents of the New South, as well as the Agrarians, have sought to define the South as something different, something special, and something definitely not-North (116). Such practice continues today. As Amy Elias points out, contemporary travel marketing has sought to position the New South as a prominent American vacation destination, creating a brochure version of the South that seeks to burnish historical reputation while making a case for regional difference (263). In considering the magazine Southern Living, she explains how the glossy images within that text present a fixed notion of Southernness that appeals to both potential visitors and to mainstream Southerners. As a result, such image-making creates the contemporary South as much as it invites outsiders to visit an always (a)historical South. The region becomes a "a kind of postmodern hyperreality, one where regional characteristics are logos to put on T-shirts and bumper stickers rather than something rooted in the real habits, manners, customs, and history of geographic location" (264). Expanding the 
argument of construction to Southern literature, Michael Kreyling argues that the study of the region's writers has long ignored the way images of the South have been built. Ranging from the Agrarians to more recent critics, formulas of Southernness have been repeated, all of which deny the history of identity construction (xii). In failing to recognize, for example, the presence of African-American writers, and in perpetuating study of a largely white, largely male canon, the field has built a monolithic sense of the Southern historical past (3). History itself, Kreyling argues, is therefore revised through this literature, creating a sense of permanence that cannot be separated from Southern literature. But as with the Agrarians and other Southern definers before (and to those who helped construct identity from outside the region, as well), such a view of history serves as a means to seize and maintain power (5-6).

Here, applying Tara McPherson's concept of "lenticular logic" seems apt. McPherson explains this conceptual framework as akin to travel postcards offering two images, each of which can be viewed individually depending on the angle of vision. In this lenticular logic, McPherson suggests that multiple images are never seen at the same time, only as discrete entities that have little bearing on one another, neither affecting nor taking effect from the other (7). Applying the term to the South, and in particular to the racial history of the region, she suggests that such vision has allowed "whiteness to float free from blackness, denying the long historical imbrications of racial markers and racial meaning in the South" (7). Racial history appears 
uncomplicated and, therefore, works to reiterate the divisive and privileging forces of the region's past. For me, this idea of the lenticular offers ideal entry into considerations of the historical rigidity of Appalachia and the South, where a captured or constructed version of the past exists in the present. Redneck images become fixed in this frozen temporality. Masculinity in the South becomes frozen by the constructed terms of the region.

That idea of permanent or unchanging Southern history becomes crucial in considering both lenticular logic and the general idea of Southern identity construction. As Diane Roberts explains, the South has had a long history of being nearly gone, just as American masculinity has a long history of perpetual threat. She argues, however, that the brinksmanship of Southern historical construction has served as a means to rally defense around the status quo, an effort that has led (and continues to lead) to a hierarchy of whiteness (367). Often, such claims of doom invoke the past in a way that seems historical but that, really, responds only to present threats. As an example, she cites the decision in the 1950s and 60s by Georgia and Alabama to fly the Confederate battle flag over their statehouses (369). Even recently, calls to remove such flags were attacked with claims of heritage, that the flag is part and parcel of Southernness. But in considering when the flags were actually hoisted, she suggests they were more a white response to Civil Rights, an attempt to bolster whiteness against the growing threat of black rights (369). History becomes a tool, a nostalgic invocation that defends not 
heritage but a certain rendition of heritage dependent on a simulacrum of Southern history and experience.

In returning the argument toward masculinity — which I would also argue cannot be separated from the particular color of that masculinity - the constructed image of the Southern redneck works alongside the constructed permanence of Southern culture. As Jon Smith argues, authentic Southern manliness “has yielded since the sixties ... to more working-class emblems: the pickup truck, blue jeans, boots.... Southern or otherwise, when a bourgeois man who doesn't work with his hands affects a pickup truck or work boots, he generally expresses not an identity but a yearning for one" (83-84). For Smith, the great risk of the Southern male is the absence of a "viable middle-class southern white masculine identity" (87). The non-lenticular construction of the identity offers only the debased redneck and the aristocratic plantation owner. Since the latter comes with far too much contemporary baggage and is saddled with the residual guilt of slavery and dominance, the Redneck becomes the de facto Southern male identity. It offers the same sort of reasserted masculinity that 1990s males found within Iron John. The Redneck offers a defense of waning power and newly difficult hierarchical position.

At work within this cultural reception are the implied pejoratives of the South and the mountains as regional entities. Each region has been more than willing to accept that both person and place are safely and appropriately labeled as Other. As Jones and 
Monteith argue, the South has become an accepted marginality, that the use of the term "regional" in describing the literature, the culture, the economy is "to assign it a marginal status, the measure of its 'regionalism' being the extent of its deviation from the national norm" (xiii). Considered always as a region, as a subset of America, the racist practices of segregation, for example, could be explained away as the odd habits of an odd region. Thus, the South's long-standing position as "region" helped fix its barriers to progress.

Part of what is at stake in constructing and battering such barriers is the right to define identity, to fix a description of what it means to be "Southern" or "Appalachian" or, as is most apt for my work here, "redneck." In adopting "redneck" as powerful identity, masculinity seeks for itself a permanently debased but perpetually virile totem. Consider, for example, that the redneck stereotype of sexual depravity is dependent on unfettered sexual potency. Thus, adopting this apparently debased image simultaneously and covertly suggests power and core masculinity. Adopting a degraded image allows entry into the pro-minority conversation that the mythopoetic movement sought to more directly challenge. The redneck is a minority of sorts, thus he can come to the newly fashioned cultural table with the safety of his oppression successfully masking his never-diminished patriarchal power. 
In examining the interplay of constructed region and constructed Redneck masculinity, I return to the fictionalized Georgia wilderness of James Dickey's Deliverance. As much as the novel is steeped in stereotypes of the Southern figure, it is equally obsessed with a reclamation of a perceived failure of American masculinity. Main character Ed Gentry must face and overcome his suburban degradation to survive the horrors of the river valley. As Pamela Barnett argues,

Ed's crisis is contemporaneous with a host of national challenges to white male power ... felt most deeply in the Southern states. The stakes of the civil rights movement were more clearly defined in the segregated South, and Southern states are disproportionately responsible for the scuttling of the Equal Rights Amendment (ERA). As one of the nation's more conservative regions, the South was a microcosm of the nation's most anxious responses to civil rights, black nationalism, and feminism. (146)

Deliverance therefore remains an important subject of my project, since the text shows an early contemporary form of the resistance that has morphed in the latter twentieth and early twenty-first centuries. Namely, the supposed, constructed conservatism of the South has been refashioned as a hyper-real conservatism that can be deployed nationally. That is, just as the characters of the novel "fantasize about a masculinity built on hardship and modeled on the anachronistic and difficult lives of poor, rural, 
Southern whites" (Barnett 147), the text also reveals how "hard-scrabble Southern white men enjoy the autonomy of rural living, and their social order, based on kinship, seems to be relatively intact and uncomplicated" (147). The wildmen of the text offer for the suburbanites the very antidote to 1960s and 1970s pressures that threatened the kind of unchallenged masculinity that Kimmel identifies as the anxiety behind mythopoetic movements. In Deliverance I see the inertia of the Redneck pushing back against societal shift, masculinity seeking new and complicated space for itself.

In offering this resistance, Dickey makes liberal and problematic use of the kind of Southern construction I've been examining. He presents a decidedly non-lenticular and monolithic sense of the region, what Daniel Cross Turner calls "a kind of reptile brain or Jungian shadow for America in general, especially the Northeast, which has typically equated the southern backwoods with a profound and irreparable sense of cultural backwardness" (163). In this effort, Turner agrees with Steven Knepper's positive interpretation of Dickey, that he seeks in some way to fit into the scope of previous Southern literature and also offer critique of negative stereotypes. Knepper suggests that "[the novel's] treatment of the rural poor is correspondingly ambivalent. Scenes such as Bobby's rape certainly do vilify the mountain people, but there are also cracks in Dickey's narrative that invite a resistant reading" (19). Moreover, he argues that "it is instead symptomatic of how Ed processes the Appalachian poor in general, of an imagination that consistently substitutes stereotypical grotesqueries for individual 
particularities" (22). In this view — shared by several contemporary critics — the persistence of Deliverance jokes in our national popular culture is more an effect of poor reception than unfair portrayal, that "perceptions of the Appalachian rural poor have little to do with reality and much to do with personal preoccupations and phobias," and that "Dickey invites his readers to develop a more humanized and nuanced portrait of the mountain folk" (23). I disagree, mostly because of the over-generosity of such interpretations. Even if Dickey fits into the scope of Faulknerian Southern portrayal, as Knepper argues, he offers a domineering use of both Southern stereotype and traditional masculinity. The action of his novel, simply, cannot exist without the sexually deviant image of the conceptual hillbilly nor without subscription to narrow definitions of masculinity itself.

Both novel and film subscribe in many ways to the same kind of overphilosophized, unrealistic, romanticized notions of both the Southern backwoods and contemporary masculinity as the character of Lewis Medlock. In the text, Medlock is exposed as a poseur: he is both physically damaged by the river and rendered philosophically impotent by the failings of his professed machismo. And on film, this is a character who is portrayed by the iconic figure of 1970s hyper-masculinity, Burt Reynolds. In short order, the fame from Deliverance lead Reynolds into subsequent blockbuster movies, nearly all of which located him in the South as a Southern goodold-boy. Perhaps ironically, Reynolds becomes on film the redneck whose image 
threatened him so much in Deliverance, but funnier and certainly not homosexual. I find great significance in Reynolds's later redneck work, however, since it offers a response and resistance to cultural dominance in a populist manner. He becomes a man for other men, a redneck for other rednecks, a film star whose self-parody nonetheless offers an interesting shift in the limits of Redneck identity.

In Deliverance Reynolds offered nothing particularly Southern to the film beyond a slight accent and appeared as a more or less interchangeable Hollywood heartthrob. In his later work he became more specifically Southern, more overtly labeled as a redneck hero. In the early- to mid-1970s, Reynolds made a name for himself as a quintessential redneck figure. This is an odd trajectory considering his antagonist position in Deliverance: in that film, Reynolds appears only as a suburbanite seeking to play at wildness, not fully a redneck but certainly the sort of individual who sought to reclaim "lost" aspects of masculinity eroded by suburban life. In the coming years, Reynolds appeared in popular films like Smokey and the Bandit, Gator and White Lightning. In these films, Burt Reynolds forges a legitimate shift in the identity of the Redneck, portraying a decidedly counter-cultural figure who exists in opposition to rigid governmental control. He establishes the Redneck as an oppositional figure to The Man. At the same time, on film he presents characters that directly follow a personal philosophy quoted in the Saturday Evening Post: “'Most of my audience climbs down out of a truck to see the movie,' Reynolds has said. 'I understand these people. They're 
the people I grew up with and I love them'" (White 126). His film persona has actively sought to target and edify the same kind of redneck that Reynolds plays on the screen. The apparently progressive attitudes he presents in the redneck identity, in turn, posit a capacity for change within this previously pejoratively-constructed class. More, Reynolds's characters do this by appearing as rugged individuals dedicated to the resistance of totalizing governmental forces, a sort of updated version of Grammer's pastoral republican.

Consider the opening scene of 1977's Smokey and the Bandit, when a police car lurches to a halt beside a detained tractor trailer rig. The sheriff climbs from the car and addresses the trucker, a young, deferent man who appears fully ashamed to face the law. The cop demands that the trucker open the back of the truck and, more importantly, that he show his manifest, the official document that lists the contents of his vehicle. While we never see that manifest, only the anguished look of the driver, we do see the stacked beer boxes that fill the back of the truck. So too does the cop, who announces plainly enough: “Placin' you under arrest for transportin' alcoholic beverages across state lines without the proper permits. That means, you dumb cowboy - you know truckin' Coors beer East of Texas is bootleggin'. And this here is Georgia, son" (Smokey and the Bandit). From the get-go, the film establishes itself as a battle between the forces of the state and the forces of a downhome, working class ethos. The police, the manifests and paperwork, the rules that prohibit the interstate transport of a 
watery beer demonstrate how the state restricts the freewheeling life of Southern heroes. Smokey and the Bandit marks a moment when the power of the Redneck offered a kind of useful resistance to the Man and to the structures of power and government that lay at odds with the mythos of the self-reliant hillbilly and redneck.

In Smokey, the Redneck appears as Rodgers's 1970s and 80s country music antihero, as a counter-cultural icon who resisted the power of institutions. So it is in the film, where we quickly see that the sort of legal machine at odds with the Bandit is a flawed machine. It is embodied in the fattened, racist, unjust character of Sheriff Buford T. Justice, who spends the film chasing the Bandit largely because of the embarrassment of his son's exploded wedding. Our first vision of this Law comes beside an abandoned car that belongs to Carrie, the runaway bride who jilted Justice's son and who has been picked up by the main character Bandit during his bootlegging run. The sheriff finds a small group of local youth preparing to strip her car, and as a good lawman he steps in to stop the action. However, Buford quickly establishes himself as a vile, corrupt individual, manhandling the boys and setting the tone for the film. Even though the boys are breaking the law by pillaging an abandoned car, they are the innocents. It is the Law that steps in and over boundaries and displays its own corrupted nature.

Enter the Bandit, a trucker who was taken a bet to run a load of Coors from Texarkana to Georgia in 28 hours in order to win $\$ 80,000$. Teamed with his buddy Cletus - who actually drives the rig — Bandit uses his wits, charm, and Redneck 
purity to thwart the law and become a hero to the common man. He drives a Trans Am carrying a Confederate battle flag on the front plate, a marker of both his devotion to the South and resistance to the normalized structures of American justice and law. He marks himself as a rebel this way. Similarly his truck is emblazoned with an image of a stagecoach running the plains, an homage to the heroic nature of those who risked the danger and violence of the old West to bring hope and money to citizens of the nation. More importantly, the Bandit is a good kind of outlaw, carrying the "handle" of Bandit, as he explains to Carrie. This C.B. name evokes images of a counter-cultural, Southern Robin Hood. The Bandit is the good guy, slick, smooth, and clearly oppositional to the corrupt Buford who complains that Carrie "insulted my town. She insulted my son.... She insulted my authority. And that's nothin' but pure, simple, old-fashioned communism." Worse, after being blocked in his pursuit of Bandit by Cletus's skillful truck driving, Buford sums up the problem of Bandit, at least as far as The Man would be concerned: “What we're dealin' with here is a complete lack of respect for the law."

Of course, as viewers we already know who we're rooting for, and we know that the Bandit's lack of respect is actually a mark of his nobility. Later in the film, that audience identification becomes even clearer, as the already exaggerated vileness of Buford moves to racism. He can't come to terms with the fact that one of his fellow Sheriffs is black. "What the hell is the world coming to?" he asks softly to his son, after displaying an over-sweetened deference to his colleague. The law is two-faced here, an 
entity that gives lip-service to actual justice and equality while, in fact, harboring antijust patterns of racism and bigotry. On a theoretical level, this kind of double-view coincides with the inherent racism and white supremacy that David Theo Goldberg and Charles Mills outline, and that I've previously referenced. It puts on display an official world that is constructed of bigotry and backwardness even as it claims to work toward progress and inclusion. Such doubling reveals the necessity of the Bandit's opposition to corrupt Law.

Further, we see repeated scenes of the Law as a flawed entity of justice, both in the repeated and personal nature of Buford's pursuit of the Bandit, and through repeated scenes of other lawmen acting as less then stellar exemplars of justice. On a low-brow level, the film offers repeated scenes of small-town cops peeing out of their patrol cars, a coarse image that aligns the lawmen with a lack of civility and manners. More broadly, we also see numerous police officers from several states blindly join the chase of the Bandit only because of the requests of Buford. Here, the fraternity of the Law is revealed as at least ignorantly complicit in the exertion of injustice. Even the black Sheriff Bradford, the most upstanding of the lawmen and the one who suffers the most indignity at the hands of Buford, joins in the pursuit. The film clearly tells viewers that the Law cannot help but support corruption. Thus the Bandit, the Redneck, offers the audience the only hope for salvation and progress. 
In part, the film participates in a long-standing enterprise of image manipulation when it comes to the hillbilly or redneck. In fact, Buford and the Bandit each nod toward specific notions of the poor, rural white, a figure that has been divergently labeled as corrupt and degraded, or as noble and untouched by the soot of contemporary life. As Anthony Harkins has pointed out, though, these kinds of images have far more to do with the desires of those making the definitions than those who receive the definitions. Such images exert a strategic, if not overtly conscious, effort to respond to desires and anxieties within the broader American culture (3-4). More to the point of the film, Smokey and the Bandit makes use of the noble notions of the Redneck as a means to offer comment and resistance to the imposition of the State or of Law on the world. For example, the Bandit and Cletus face interstate communities of lawmen on their bootleg run: individual cops communicate via radio to pinpoint the location of the outlaws. During the course of the film, however, the Bandit transforms the medium of the State's communication into a tool for the common person. As the chase grows in intensity, a phalanx of supporters take to the same C.B. airwaves used by the police to offer support to the Bandit: other truckers, little old ladies, teenagers at the local burger joint, funeral processions, even mobile prostitutes. The salt of the Earth act in opposition to the corrupted Law and, more importantly, do so by transforming the very piece of equipment that the Law uses to monitor and control the people. 
As a result, the film evokes a vision of commonality, where people can come together under the Redneck rubric as one. We see regular old truckers, and Japanese truckers, and pretty young female truckers. We see black hearse drivers helping the Bandit evade the Man just as we see prim old ladies do the same. We see Cletus friendly and close with black gas pump operators and dive bar owners. The outlaw world of the Bandit offers a world of true inclusion and harmony, in opposition to the hypocritical oaths of justice offered by Law.

Similarly, the smarmy Big and Little Enos Burdette become a cautionary tale of those within the Redneck identity who would leave to join the corruption of a mainstream world of money and dishonor. It is the Burdettes who put forth the challenge of bootlegging to truckers, all of whom fail before Bandit takes the job. The Burdettes' motivations for the bet are clear: they have money to waste. But the Bandit's motivation is more profound and noble within the context of this idealized Redneck America. He claims he does it "[f]or the good ole American life. For the money. For the glory. And for the fun. Mostly for the money." Yet the viewer knows that his claims of financial impetus are not to be fully believed. This is eminently clear after the Bandit succeeds at the end of the film. He immediately takes a double-or-nothing challenge to race to Boston and back for clam chowder. The Bandit is untouched by greed, never takes the payday, and truly races because, as he claims earlier in the film, they said it 
couldn't be done. Moreover, the Bandit races the Law because someone has to offer resistance to such impositions on personal liberty.

This kind of "pure" motivation is presaged in the films Gator and White Lightning, earlier movies in which Reynolds portrays the title character of Gator as an individual again clearly stamped with the Southern redneck identity. He's a moonshiner who runs against the law, is devoted to his family, to cars, to Southern life in general. While the backstory of his life changes completely between the two films, these changes can be attributed to the needs for action-hero motivation. In the first movie, Gator hails from the Mississippi Delta, while in the second he comes from the Arkansas swamps. He is a macho, solo bachelor in the first film, and a macho father of a suddenly nine-year-old daughter in the second. White Lightning, the first film, is content with car chases, while Gator introduces the more exciting and exotic notion of a souped-up swamp boat chase. But the core remains the same. In each film, Gator is spurred to action by family threat or loss. In the first, his brother has been murdered by a crooked Southern sheriff. In the second, Gator battles a former friend turned Southern mob boss. Gator finds the kingpin distasteful in no small part because of the mobster's pimping of young girls; the hero's ire is raised by the victimization of innocents similar to his daughter. For each of these films, Gator follows a distinctly "Southern" and masculine devotion to family as the core of his action, as well as cliché impulses to act as champion or knight for the downtrodden. 
What I find most intriguing about these two films, however, is the way they make use of Southern redneck trope even as they seem to offer an updated version of the identity. Thus, just as Gator's motivations for action in the two films can be easily traced to a "known" Southern trait, so too can his violations of Southern stereotype be recast as, in fact, drawn from the rigidity of his identity. Here's the thing with Gator: in each of the films he works for the U.S. Government, going against his "own" kind.

In White Lightning, the feds spring him from prison to head South and uproot a crooked Sheriff who, as the film shows in the opening scene, has no problem drowning troublemakers in the swamps. The feds want Gator to do a Capone on Sheriff J.C. Connors. They want evidence of Connors's involvement in tax evasion through offbook moonshine kickbacks. Unable to find evidence linking Connors to the spate of murders in the region, the feds think moonshine will offer an enforceable offense. Gator, however, decides to go along with the feds only because a young man murdered in the opening scene happens to be his younger brother. That brother drew Connors's ire by protesting injustice and inequality, and by being a 1970s sort of rabble-rouser. Gator's involvement in a moonshine sting creates terrible ambivalence, however, as his own father suggests that plenty of good people will be on the list of names Gator gathers as he seeks to bring down Connors. "It's a bad thing, Bobby," Gator's mother tells him. Later, one of Gator's contacts echoes the issue: “What the hell are you if you ain't a damn stool pigeon?" Gator answers with a punch, establishing himself as neither a stool 
pigeon nor on the side of the feds. Instead, he is an individual using the feds to exact personal revenge on Connors.

The crucial issue here is the position of Gator as a redneck in relationship to the federal government. Gator identifies as an antagonist to the government, as someone purely opposed to the imposition of the Man. Further, as a new kind of redneck, Gator sides with the hippies who appear as casual characters in this film version of the South, in no small part because his brother has been cast as a student murdered for his "hippy" associations. Plus, Gator is drawn in stark opposition to Connors, himself both an antifed and anti-hippy figure. For example, when Connors finds out that stool-pigeon Dude has been working with the feds, he's outraged:

HARVEY. Washington's a damn dictator.

CONNORS. They gonna integrate our schools. They gonna get all our coloreds to vote. They gonna send all those long-haired, smart-aleck hippies down here. Communism, Harvey. That's what it is. That's plain and simple. That's as plain as the nose on your face. They're communists. (White Lightning)

In this quick scene, Connors makes his position clear. He represents the kind of solidified South that I've been examining, a region predicated on white racism, antifederalism, and crooked politics. Connors is on the take, looking the other way as moonshiners rake in the tax-free profit, all the while exercising his own tax in the form 
of kickbacks. Thus Connors becomes a version of The Man in the South, a clear example of authority at the expense of the people. Yet Connors nonetheless espouses the ideals of a quintessential freeman, Southern creed. In casting federal intervention as the coming of a communist regime, Connors draws himself as a noble patriot working to free Southerners from anti-state regulations. The U.S. government is the real threat, an imposition of the federal government on "private matters."

As a result, Gator becomes the only person capable of bringing Connors down. The feds can't do it, from a theoretical position, because they're just another version of The Man, flawed by grace of their position as part of the totalizing, anti-liberty state. It is only because of his middle-space as tough man and anti-Man that the redneck Gator can come to the rescue. He is fully masculine, fully Southern, and fully counter-cultural. Within the accepted and traditional concept of the South as antagonist to a centralized American government, Connors has a point. Federal influence in the South lies at the heart of the state's rights construction that operates in versions of Southern history and policy. But Connors is a bad Southerner, because he merely substitutes one violation of liberty for another. Thus Gator operates in the difficult third space of neither Man nor hippy — he works for the feds even as he does so for his own reasons, thereby exacting a perfect example of the ideal Southern masculine.

The second film in the series, Gator, offers a similar reading. The movie shows Reynolds's character as a figure who seeks to eradicate the imposition of the dictator in 
his own South. This time, Gator is forced to work for the government because his elderly father and young daughter have been arrested and held as collateral. They will suffer if Gator doesn't help bring down the mobster Bama McCall, who runs a drug, prostitution, and extortion ring in Dunston County, Arkansas. Gator, therefore, acts on behalf of The Man again, but does so for personal reasons. He's the reluctant redneck, assisting the feds only because his code of family honor requires that he do so.

Similarly, Gator comes to despise Bama because of the way the mobster violates codes of "traditional" Southern honor, running a whorehouse full of girls under the age of sixteen. Bama seeks to assuage Gator's concern on this matter by suggesting that their own mothers wouldn't have been much older when they got married - a revisiting of stereotypical Southern and Appalachian sexual backwardness. Gator isn't pleased, though, and the film shows a quick moral outrage burn through the hero.

Gator is, after all, a new kind of Southern redneck. After Bama tries to ply Gator with a young prostitute, Gator storms away.

GATOR. I want out. I wanna go home.

BAMA. Well Gator, there ain't nothing waiting for you at home but whiskey busts.

GATOR. I'll worry about that when I get home. I've seen your operation, Bama. I don't like what I see. (Gator) 
Reynolds portrays for the viewer a new version of the redneck, one who adheres to the moral fibers of his region, but one also willing to see the ills of those who might seek to identify with him. He's the kind of 1970s redneck that James Cobb suggests “began to convey a fierce and even admirable resistance to America's insistence of conformity" (Away Down South 226). In that, he's a purer version of the low-down, a melding of the Southern cavalier with the Southern redneck. He is an honorable figure who protects his home and his family with everything he has, but who refuses to give in to the domineering evils of history and hegemonic America.

It is at Gator's hand that Bama meets his downfall in a protracted and oddly dull final action sequence - let me be clear: this isn't a very good movie. But the implications of it are important. The 1970s has brought the Southern redneck into popular view, as a sort of counter-cultural patriot who is governed by immutable and inviolable Southern codes of masculine honor. Gator becomes the quintessential redneck because he operates in that middle ground, Othered as the region is Othered. He is not part of the greater American culture but nonetheless in support of and abused by federal effort. He's a regional character but a noble one; therefore, he is purely Southern.

In the end, Gator and the Bandit end up presenting non-lenticular Redneck visions of Southern culture similar to what McPherson examines in her own study of Southern tourism. For example, McPherson explains how such tourism and, in 
particular, plantation house tours work to rewrite history in the preferred romantic vein. Tours usually focus on the splendor of the buildings, of period furnishings, of the lavish lifestyles of the white elites who used to live there, all while omitting or quickly glossing the reality of the black slaves who made such lifestyles possible at their own expense. McPherson writes:

In this discourse of southern tourism, the houses are more than simple artifacts of the past. Rather, they serve to freeze the possible meanings of the South within a very narrow register, especially when yoked to the mythic figure of the southern belle or lady.... By reifying the plantation home as the privileged site of southern history and femininity and then coding this history as elegant and grand, such representations erase the history of oppression that such homes could just as easily symbolize and encourage a nostalgic form of southern history. (44)

I argue that Gator does the same thing in his films, serving up a sort of contemporary nostalgia of Southern masculinity. He operates within fully acceptable codes of Southern manhood but also does so with ostensible nods toward modernity: he defends women, hippies, and even in one moment seems to lament the maltreatment of Southern blacks. He offers an "update" of the redneck or bubba figure, but he does so with a clear superimposition of the past. Nothing's changed, really, with the core of 
Southern masculine identity. In this sense, Gator falls short of any actual shift in the visions of Southern masculinity. As McPherson suggests with several other pop-cultural texts (notably documentary-maker Ken Burns's Civil War), Gator fails to engage the history of America and the South without falling into familiar romantic tropes. Instead of seeking new narratives, Gator repeats the old ones with modest variation. And it's important to note that the progression of time limits the Reynolds Redneck as a progressive figure: while Gator is both resistant to official state entities and provisionally open to advances in women's and minority rights, the later-appearing Bandit is both more comic and less socially open, even if he remains counter-cultural.

Notably, this new Redneck variation remains steadfastly white, as black Southerners exist only on the periphery of the Reynolds films, even as black Southerners exist in reality as a significant portion of the culture and population of the South. But old tropes die hard, and popular culture portrayals of the South have long been infatuated with the tales and actions of white Southerners, genteel and base. Blackness often operates only as a vehicle for assertions of white compassion. In Gator, part of the "newness" of the title character's redneck persona is his discomfort in the shakedown of black bar owners, in his disgust at Bama's assertions that a sawed-off shotgun is used "to make them blacks easy" in negotiations. Gator's response works only for character development, however. His unease shows that he doesn't fall into the easy traps of racism, that he is, in fact, a "savior" to the blacks of the film. Veneer 
suggests this as a productive and progressive attitude, but the otherwise pure whiteness of the film displays the way blackness has been written out of even this contemporary vision of the South.

In a way, this discussion of Burt Reynolds and McPherson resonates with the charge of Anne Goodwyn Jones. She engages the issue of a de-theorized South and a theory-light academic focus on the region that "with the exception of those working on Faulkner, women, and African American writers...[is] a large, regional, and generally atheoretical industry" (173). For Jones, a recent growth of theoretical work in Southern studies offers hope for the disruption of historical constructs. Moreover, she also argues that even the de-theorized sense of the South was itself an act of theory. Certainly, she points out, the enterprises of slavery and segregation can be considered as nothing other than totalizing theoretical ideologies (174). Denying that, she suggests, is part of the problem, is essentially the same in my view as denying the way history is constructed.

In exploring different pop cultural artifacts, McPherson similarly shows how these artifacts fall into what I call spectre-theory. As mere spectres, the full truths of plantation houses or redneck characters present themselves as there but not quite visible. They are easily ignored if you whistle while hustling by the graveyard. Spectretheory therefore seems to not exist at all, even as it exerts significant and lasting effect on those who come into contact with its manifestations. 
To combat this latent apparitional function, scholars seek to re-theorize the place of the South and reveal how it has always been a place laden by theoretical constructs. For example, Paul Harvey identifies the actual religious progress of the Civil Rights era as the actions of individuals within the churches of the South who found a way to imagine a theory of Southern race relations that did not predicate itself on white supremacy. For Harvey, what he calls "racial interchange" (3) helped undermine the "theological racism" (2) that perpetuated white supremacy. He argues that formally and informally, blacks and whites began to mix in religious contexts, sometimes as white children going to black churches just to witness the "spectacle," sometimes through the growth of new modes of faith like Pentecostalism. This interchange lead to conscious political action that worked to break segregation and theological racism (4). An unfortunate side effect, Harvey notes, is that as certain churches gave up the indefensible position of white supremacy, they turned instead to contemporary defense of patriarchy (219): spectre-theory is a slippery thing, always finding a way to reassert old hegemonies.

For Gator, this kind of theory or racial interchange is limited at best. The spectretheory of Redneck identity holds him to narrow definitions of action, as he cannot shake the stereotypes of his position. As Redneck, his interactions with black Southerners, with women, with any sort of truly progressive Southern masculine identity offer a 
paucity of effect. He may be against The Man, but he remains committed through lack of engagement to a whitened, masculine version of the contemporary South.

The idea of a freshly theorized South is, at heart, an idea of possibility. Instead of reiterating the old modes of being, such a perspective seeks to identify hidden tropes like Gator's new-old masculinity and therefore open the world for the kinds of new theories present in Harvey's racial interchange and McPherson's lenticular logic. Or, put another way, these efforts seek to retheorize the idea of Southern place, which has always been central to definitions of the South. As Scott Romine argues, it might be better to think of place itself as a theoretical idea, and not a geographical locale. That is to say, Romine seeks not to argue against the notion of place as important in Southern literature and culture, but that the specificity of space is not:

Because of place's conceptual instability, what stability it does possess can be ascribed almost exclusively to how it has been used.... "Sense of place" has usually signified positive orientation toward the determinative texture: place located you, told you who you were, and did so in a way that provided comfort and security (if occasional restlessness). At worst, "place" is what you were alienated from, or what you loved and hated simultaneously, with the love running just a bit deeper. ("Where is Southern Literature" 23-24) 
As means of explanation, he offers Richard Ford, who as a Southern writer has written about the non-Southern, non-place of suburban New Jersey in The Sportswriter and Independence Day. He argues that Ford maintains a rigid focus on place, and therefore follows the tradition of Southern writing. But by removing his characters from the South itself (and even, generally, from any Southern markers of identity other than origin) Ford reimagines the importance of place to Southern literature. Place becomes a simulacrum, which itself reflects the way that the "real" South — the place of focus in other Southern writing - is also more or less a simulacrum of itself.

So Gator, White Lightning, Smokey and the Bandit and Deliverance become part of that simulated space. Rather, they are exposed as functioning within the simulated space of a rigidly defined sense of what the South was and is, but that really is and was neither. And, truly, the geographic South of contemporary America cannot easily be imagined without this idea of simulation. Baudrillard's concepts of simulation function as a fitting framework in light of the long tradition of Southern historical simulacra I've been addressing. As John Shelton Reed explains, the South itself must now be called the Southeast, since points west of Mississippi are now clearly part of the Southwest and not the South (145). More, other explanations of the South might label it the Sun Belt, the kind of constructed tourist destination of Amy Elias's Southern Living. In the end, pointing to the true South becomes an impossibility, precisely the kind of disruption that the theorization of the South seeks to create. 
Once the South can be conceived of in these multiple ways, as divergent real and constructed places, the trans-(a)historical presence of the romantic South or backwards Appalachia can begin to fall away. That rupture opens the regions to their own definitions. But portrayals of the South and Appalachia fail to do this. They instead refuse to allow the regions to emerge free from their designations as merely regional, aberrational, and stuck in pasts that, really, no one quite remembers the same way. Similarly, the figure of the Redneck remains fixed as aberrational and regional, as masculine and retrograde, thus limiting the social progression that even its 1970s heroic turn seemed to suggest.

This is the sticking point of Burt Reynolds in all of the films I cite. On one hand, he seems to offer the potential for a re-theorized notion of both place and masculinity. But on the other, he's merely reiterating codified scripts of masculinity. Sure, Gator is not as overtly sexist as Bama, but he nonetheless successfully beds the feminist character of his film. This new version of redneck sensitivity serves the same hyperhetero-masculinity that was in place before Burt Reynolds.

In this effort, the scope of Reynolds's film work that I reference fits neatly into the normalizing effects of Dickey's Deliverance, that "in a novel that casts Southern, white, suburban life as emasculating, this camping trip from hell is, curiously, the protagonist's dream come true" (Barnett 145). As Barnett argues, Ed restores a manhood threatened by a dull job, a dull life, and domineering hillbilly rapists through his violent 
actions. The novel "explicitly blames white middle-class life and suburban domesticity for Ed's ennui, but femininity is the real culprit: while women, according to the novel, are always at 'fault' when men feel fettered and unfulfilled, the more pressing problem is femininity categorically, as it insidiously resides in the male self" (145). Toward the beginning of the novel, Ed himself seeks to have sex with his wife in a "primal" way, entering her from behind as a way to convince himself of his manhood after a feminizing day at the office (28). Moreover, his pleasure at seeing his doughy, hairy self rendered in guerilla fashion (68-69) offers a visual suggestion that he can, indeed, be the virile male that lies within.

Throughout the novel, Ed seeks the solution to the problem scholar Angela Farmer presents: "How does American culture represent and therefore begin the hegemonic sorting out of men who are perceived to be manly and men who are not? More importantly, how does American culture encourage masculinities believed to be 'proper' and discourage what is believed to be 'unmanlyness?'" (105). Moreover, the catalyst for Ed's "manly" reactions of hunting, murdering, and the stashing of bodies is the threat of homosexuality. He responds as he does because "the buggering hillbilly lies at the intersection of cultural and cinematic discourses of class and sexuality. He is abnormal, sexually and socially deviant, monstrous, representing the boundary of civilization and savagery. He is the epitome of Dickey's representation of rural folk as 
abnormal and aberrant" (Madden 198). As several scholars have pointed out, ${ }^{14}$ the threat of homosexuality looms large in the text as a threat to masculinity, and therefore Deliverance reaffirms the necessity of that anxiety. Since Ed successfully defends and reaffirms his masculinity in no small part because he avoided rape and because he exacted revenge on those who sought to feminize him, he offers a retrograde defense of normative heterosexuality. So it is with Gator, as well. While that character offers a freshened version of the redneck as semi-sensitive male, he nonetheless maintains full masculinity by "conquering" the feminist threat in the bedroom. The South, America itself, remains safe for masculinity.

Still, even as Burt Reynolds on film offers protection to old-style masculinity, he also offers dissonance within the Redneck identity. He presents a moment of potentiality when the masculinity of the position teetered between the degraded stereotypes of cultural history and more contemporary exertions of neo-conservatism. Smokey, along with Gator, exists as a character willing to side with the hippie, or at least as a character who participates in a broader resistance to the restrictions of the mainstream. It's not a full or successful resistance, of course, since Smokey — again like Gator and like the characters of Deliverance — offers plenty of "traditional" heteronormative womanizing to go along with his limited progression. In fact, this failed

\footnotetext{
${ }^{14}$ A fuller background on the homosexual anxiety of Deliverance appears in Barnett's "... Nightmare or Dream...", Wrede's "Nature and Gender...", Entzminger's "Come Back to the Raft Ag'in, Ed Gentry," and Madden's "The Buggering Hillbilly."
} 
progression is inevitable, since the Redneck figure cannot escape the kind of constructed limits I've been exploring.

Consider the comic descent of Burt Reynolds, from serious masculine figure in Deliverance to conflicted action-hero redneck in White Lightning and, less-so, in Gator, to the fully-comic Bandit in Smokey. Since these characters cannot escape the comic constructions of the hillbilly/redneck trope, they cannot ever fully escape marginalization, must always be the butt of the joke in some way. Even critical attention to the redneck on film cannot help itself. Scott Von Doviak offers a fairly exhaustive, if not critically deep, overview of the redneck cinema infatuation of the 1970s. But he opens his book with a joke about "redneck credentials":

I don't play the banjo or drive a pickup truck. I own no guns. While I drink my share of cheap American beer, I also have a fondness for that foreign microbrew stuff. My CD collection contains a handful of Johnny Cash and Willie Nelson albums, but they sit side-by-side with the works of Prince and They Might Be Giants. No one has ever referred to me as "Bubba," but in the early Nineties I sported a mullet, and for about three months in the summer of 1998 my facial hair resembled that of Dwight Yoakum in Sling Blade. (5)

This tonal posturing must be considered as crucial to the cultural position of the Redneck: the identity is always approached with a wink and a joke. This is true in 
popular film criticism and in otherwise sober academic tomes like the Encyclopedia of Southern Culture - remember that it defines the redneck, among other things, as a nonskier (1140).

And that's part of the power of Redneck identity. It can't be taken seriously, must always be assumed to be a punchline and as part of a great American comedy. As a result, the background cultural work that the Redneck offers, as a reifying site of American hetero-masculinity as I argue in this chapter, works more efficiently. If it's funny, it can't be insidious. Yet, of course, that's the point. That the serious rape scene of Deliverance becomes a permanent pop-cultural joke reveals how the "threat" of homosexuality to masculinity becomes normalized as an unserious issue. Traditional masculinity becomes so firmly entrenched via the mechanism of the Redneck identity that countering images are simply discarded as low-brow humor. That, too, is part of the power of the identity: it creates a veneer of powerlessness, harmlessness, for whomever adopts it, so the work of hegemony operates without resistance.

Even when the 1970s receded into history, the forged masculinity of the Dickey model continued to hold sway in the literary backcountry. As a bridge into more contemporary writing, I return to the woods, this time to the Southern West Virginia of Lee Maynard. Published in 1988, his coming-of-age novel Crum relies on the same hard hewn masculinity that helped usher the protagonists of Deliverance though rural 
Georgia. The novel depends heavily on the same kinds of constructed versions of Appalachia that have long been assigned to the region. The novel opens with an epigraph,

When all the goodbyes are said I want to be the one who is leaving And it's going to be good to be gone.

Crum follows that sentiment clearly. The narrator recounts in a more or less picaresque way his childhood goings-on in the muddy town of Crum, West Virginia. The tales tend toward the sexual, explicitly so, and include plenty of the promiscuity that has come to be expected from backwoods tales. "There were three things that most every kid in Crum High School had in common — poverty, ignorance, and fucking," Maynard writes. “We were dirt poor and didn't know anything about anything outside the Tug River Valley, but we all knew about fucking. Everybody fucked somebody" (16). Thus the novel recounts the narrator's observations of life in Crum, a "place located deep in the bowels of the Appalachians, on the bank of the Tug River, the urinary tract of the mountains. Across the flowing urine is Kentucky" (1). Maynard spends an inordinate amount of time in the first chapter recounting the visual appearance of the town, described negatively in ways common and familiar within Appalachian trope. The effort effectively implies that locale is person, that the people of Appalachia are nothing more than their place, indistinguishable from the natural, and unfortunate, landscape. 
In many ways, reading the novel feels like the long set-up to familiar West Virginia jokes. The punchlines are all there, the source material for the kind of negative humor that continues to portray Appalachia as a toothless, morally-deficient, sexually questionable wilderness. This vision becomes clearest mid-novel, when the character of Benny exposes himself to a new English teacher, Miss Thatcher. Benny has been drawn through the novel as a creature of habit, as a boy who relishes the fondling of his penis and who enjoys doing so in front of others. In turn, other kids seem to enjoy the rise such a display evokes in the adults of the novel. In this scene, however, the shocked Miss Thatcher doesn't rage against the display. Instead she quietly walks out of the classroom and is never seen again. The narrator laments the loss: "The delicacy of the Miss Thatchers of the world could not stomach what we were and so they closed the door and left us" (106-7). On the surface, this line seems to suggest that Appalachia has once again been left and ignored, simply because of ways uncommon and uncomfortable to the rest of the nation. But the "ways" of this scene are unquestionably horrific and sexually abusive. They are not the sort of thing worth sticking around for. Benny and the narrator emerge in this scene as culpable predators and this moment, as with all of the sex in the book, seems to support and play to the negative stereotypes of the hillbilly as sexual miscreant. Thus, even if the outsider is being criticized, the criticism cannot stick: Miss Thatcher's response is reasonable. 
On one hand, Crum can be considered an exploitative book, one that uses the shock value of stereotypes to boost sales. And in that sense, Maynard functions as a purveyor of the negative stereotypes of his home state. Yet from another perspective, Crum functions as a purposeful exaggeration of the stereotype, as a response to the negative image of the region. It seems to say, You think we're hillbillies? I'll show you hillbillies. It becomes a criticism of the reader. The degradation of Miss Thatcher becomes a reflection of the degradation bestowed upon the region. Moreover, as the novel continues, Maynard offers a biting critique of his own narrator, which in turn continues to cast suspicion on constructions of regional identity.

Later in the novel, the narrator makes love with the beautiful Yvonne, a character who had taken to showing her body to the other boys for cash. She declared, upon the narrator's questioning, that she'd have sex with anyone for five dollars. So after the love-making scene, written to be tender and sensual (though coming across as cliché and chauvinistic), the narrator acts in kind:

I think she saw the money from across the room but it didn't really hit her, didn't really register, until she was standing in front of me. But she saw it then, for certain.

"Oh, God," she said, "oh, God, you've ruined it. You've ruined it. Oh, God..." 
Her voice trailed away and the tears came, pushed down her face by deep, throbbing sobs. I reached out to her. She stepped backward, quickly, sharply, not wanting me to touch her, not wanting my hand to contaminate her, not wanting to admit that I was alive. (125)

Yvonne snatches the money from the narrator, angrily declares that he'll never be able to afford her again, then storms off. When he returns home, the narrator finds the fivedollar bill fixed to his door with a rail spike. If there's redemption for this book, it's here, when the narrator's understanding of the world is shattered. His actions hurt someone he cares about, which resonates within him. Here, the character shows for the first time thoughtful response to poor behavior. It's hard to say if Yvonne really becomes, or ever was, a prostitute, as the narrator elsewhere claims. But it's clear she made love to the narrator here out of love, thus the shock of the five dollars. The payment offers a criticism of our understanding of Appalachia. It suggests that America functions like the narrator, thinking of the place as its own caricature without stopping to think about the real emotion underneath. It is also a criticism of those within Appalachia who are more than happy to live within the guidelines of their own stereotypes, who turn Appalachians into "prostitutes" as readily as do outsiders.

So it comes as a welcome surprise that the narrator climbs the hill outside of town at the end of the novel and is struck by the vision he witnesses: 
It was beautiful. The sun was directly overhead, flooding the valley with a sort of liquid illumination caused by the heat and the shimmer from the valley. The scene was more than I had ever known to look for. It was like a perfect toy. The lanes of the town were perfectly straight and didn't have a bump in them. The river was crisp and sharp, a deep green color that looked pure and wholesome. The tiny houses on each side of the highway were put there by elves who were laying out a village around which to build a fairy tale. I couldn't believe it. I stared at the scene until my eyes hurt. (143)

We see the narrator's folly here. With perspective Crum looks beautiful. It very much is beautiful even if the narrator has always failed to appreciate the town, just as he failed to appreciate the love of Yvonne. Mired within Crum, he can't understand it. Still, the narrator bears witness to the reality of the town that isn't pretty, that the river runs muddy, that the people can be crass and unfair. Within this multiplicity of knowledge, through experience and romantic overhead views and the myopia that comes with lack of perspective, we are left to see how place becomes inescapable in Appalachia and the South. The narrator of Crum still leaves, still wants to get out. But we see, as well, that he likely would not have hated either himself or Crum so much if he hadn't clung to the stereotypes foisted upon the region. 
Hilltop perspective is exactly what the 1970 s redneck I've been examining seemed to offer. Positioned as a resister to the force of national power, he appeared alongside other counter-cultural figures to offer an apparent new way of being within a decidedly masculine identity. However it is the "seems" of that position that eventually failed, since the residue of masculine construction clung as tightly to the redneck as the baggage of regional stereotypes has weighed down the South and Appalachia. In a sense, there is no walking up the hill behind Crum for the redneck. There is no easy escape from rigid conceptions of the South and Appalachia. There is no evading rampant sexual masculinity. The inherent theoretical images of the regions and the figure remain firmly planted within the minds of all Americans.

Having been built so very long ago and lying at the heart of literary descriptions of the South and Appalachia, the simulacra that surround Southern masculine identity create their own seeming reality. That is, of course, the thing with simulacra: they don't seem fake at all. In that perceived reality of monolithic region, of singular masculine way of being, the Redneck and his environs create the conditions that allow him to take shape and do his cultural work. They short-circuit the possibility of lenticular view before the complications of multiplicity reveal true complexity and potential. And as literary history moves forward into the late twentieth and early twenty-first centuries, the foundational work of narrative ancestors opens space for the Redneck to rectify losses within more mainstream hegemonic contexts. With the weight of its constructions 
pulling the 1970s redneck away from his liberating potential into reactionary response to the social progress of women, gays, and minorities, he gains the capacity for reinvention as the very Man who Burt Reynolds seemed to resist on screen. Just as suburban Ed Gentry hunted down his nameless hillbilly attacker on the Cahulawassee river to allow for his own safe return to Atlanta, the force of normalizing American hegemony brings Gator, brings Crum, brings the South and Appalachia back under control to allow for the safe emergence of new, more contemporary redneck figures. Larry the Cable Guy waits in the wings. 


\section{Chapter Three: Redneck Electability}

On the surface, George W. Bush offers the perfect visual presentation of the American Redneck. He is in fact from Texas, an unquestionable site of "authentic" Redneck culture. But Bush is a newcomer to Texas. He comes from a familial line of Northeastern aristocracy and boasts a personal biography punctuated by graduation from clearly non-Redneck institutions like Harvard and Yale (WhiteHouse.gov). Yet because Bush adopts an exterior rural identity, and because he does so with plenty of apparent authenticity, he is Redneck despite his background.

For Bush, actions speak louder than heritage; that is, Bush enacts a perfect Redneck spectacle. He offers the kind of image that Theodor Adorno argues as the great force of mass culture: "Wrenched from all context, detached from thought, they are made instantly accessible to an infantile grasp. They may never be broadened out in any way but like favourite dishes they must obey the rule of identity if they are not to be rejected as false or alien. They must always be accurate but never true" (74). The Redneck is an easy image, one Americans are familiar with from pop-cultural icons. As a result, the decontextualized Redneck can easily be applied to individuals who lack the necessary rural background but who offer apparent fidelity to the expected stock images. Thus Rednecks appear accurate, whether or not they are rural at all.

Moreover, the alignment of Bush and Redneck is obvious. It takes no heavy intellectual lifting to realize that he, first of all, fits the stereotype and, second of all, is 
on some level faking it. It is the very obviousness of Bush's Redneck identification, however, that makes him successful. His identity cannot be rejected as "false or alien" simply because it is so obvious. Since the President unflaggingly maintained the feigned identity, the image kept him in line with Redneck identity and in control of his own power.

For example, in Bush the trivial practice of cutting wood takes on mythical status. That manly act offers the "accuracy" if not the reality that appeals to Adorno's infantile grasp. Conservative columnist Dave Shiflett writes about the importance of this image: "Long ago, a wise woman suggested to me that instead of asking a person what he does — the standard opening line in Washington — one could gain deeper insight by asking, ‘What do you like to do?'” (28). In this column, Shiflett offers a detailed and positive analysis of Bush's free time. For Shiflett, cutting wood equates to moral strength:

For one thing, clearing brush is not the sort of thing the president's father was fond of. The elder Bush was devoted to tennis and golf — and pitching the odd turnip on a head of state — which is what one would expect of a New England patrician. He also did a spot of fishing and horse-shoe tossing, perhaps to convince us he was a regular guy, but any brush-clearing at his estate was left to the help, who perhaps undertook the activity in aprons and bowlers. That 
disconnect from common tasks was another manifestation of the first Bush's isolation from common folk and common concerns, which in turn made him susceptible to ruinous policies advocated by similarly insulated elitists. Raising taxes comes to mind.

Connecticut Bush's demise was sealed on the pruning fields of Kennebunkport. (28)

In offering this analysis of brush clearing, Shiflett relies heavily on the perceived superiority of hands-on manliness. He equates physicality with political wits and the failure of that ability with inefficacy. He likewise employs important rhetorical choices, contrasting the "ranch" of the younger Bush with the "estate" of the father, activating anti-elitist impulse despite the similarity of size and property value in the two tracts of land.

Most importantly, however, Shiflett suggests that the clearing of brush reveals that the younger Bush is "truly of Texas" (28), where real men ride fence and defend their stock from "the lurking coyotes that lust after spring calves" (28). As interpretation, Shiflett argues that "[t]he swinging of the ax and the singing of the chainsaw delight this type of soul, and this is exactly the kind of disposition one would hope for in a wartime president" (28). And in explaining how the desire to cut and clear land relates to political prowess, he offers an example of presidential action: the president sizes up the situation and says, "You're mine, sucker." 
Not only that, he will probably saw up the victim's body and feed the pieces into a fire, smiling as the flames dance before him. This is the sort of fellow you want in your corner not only in wartime, but when it comes time to stand up against tax hikers. (29)

This sort of analysis offers little subtlety and isn't particularly difficult to unpack. Simply, it aligns manly activity with necessary strength, strength with rural redneck values, and those values with a mandate to lead the nation.

Bush is the kind of president America needs, Shiflett argues, precisely because he's the kind of man who likes to work the land, and precisely because we "would have a hard time imagining Bill Clinton clearing brush, and not only because he owned no property until very recently. Clinton was not the type to undertake activities that might leave calluses on his hands (or at least none that bear mentioning)" (29). And most to the point, Shiflett argues that "[t]he hand that swings the ax, it seems, fits nicely on the tiller of the ship of state" (30). Better yet, in contrasting the younger Bush to the elder, Shiflett establishes authenticity for the brush-clearing president. Fishing may be cited by the father, but fishing doesn't compute to actual redneck values. It can be a put on, which the hard labor of land clearing cannot. As such, the authenticity of sweaty labor confirms the authenticity of George W.'s rural identity, which supports the authenticity of his leadership skills.

As Ryan Malphurs explains, the political identity of George W. Bush has from the 
beginning relied on the kind of cowboy images that have "served as fundamental archetypes in the development of this nation" (185). He further argues that Bush's image has stayed within these narrow cowboy constraints even when the former president has chosen not to actively employ the identity (196). Clearly, Bush's redneck image seems so natural, so permanent, and so important that it need not be trumpeted or argued for: it simply is. Bush fits neatly and unquestionably into the Redneck paradigm, despite origins outside of Texas, despite financial conditions far beyond the means of the rural working class. The image of Bush consumes his elitism and renders him legitimate as populist leader, as the kind of guy voters would enjoy having a beer with, as was widely reported in the elections of 2000 and 2004.

Bush's crucial Redneck position remains an obvious exaggeration, though, and the equation of brush clearing and statesmanship is an obvious stretch. I imagine even Shiflett wouldn't suggest that the ability to cut scrub automatically qualifies someone for national office. Instead, Shiflett's belabored metaphor demonstrates the necessity and power of image. Even if the image is obvious and clearly shaped, it fits the proper national spectacle well. In maintaining a personal image that depends heavily on his role as self-acclaimed Redneck, Bush creates an ideal Debordian spectacle: no substance but full effect. The symbolic work of Bush's declarations of brush clearing normalize his position, making him both suitably masculine and suitably rural, despite a heritage that would seem to prohibit his entry into the Redneck class. As Country Music Television 
chief Brian Philips has said: "There's a real dichotomy between the raising of the son, George W., and the way most of our audience has been raised. But God bless Karl Rove if he was able to connect those two and make people feel like he was one of us" (Willman 111). Certainly Rove did just that, as the Bush presidency offered a finely rendered contemporary Redneck presidency: strong, male, hawkish, anti-intellectual. And because these components of his identity could be so clearly aligned with the codes of Redneck character, Bush stayed in office despite disastrous domestic and foreign policy.

More importantly, the function of the Redneck spectacle might best be explained as a sort of Althusserian hailing. Self-assignation as Redneck comes about because of the interpellation enacted by ideological state apparatuses, creating an "imaginary relationship of individuals to their real conditions of existence" (162). So individuals who are not of the marginalized working class recast themselves as such. More, the constant reiteration of Redneck values that circulate in pickup truck commercials, country music videos, and redneck comedy merge with core American notions of the rural outsider to create a cultural apparatus that aligns simulated Redneck experience with American identity. The function of the apparatus demands that would-be members of the class act along the prescribed lines that govern properly inclusive patriotic behavior. That is to say: don't criticize a wartime president. Importantly, George Bush must be considered as equally hailed as other individuals in this scripting. His 
presidential policy was similarly restricted by the ideology of the Redneck. He had to follow the guidelines of white, Christian, masculine America. To prove his validity as leader of the United States, he must act within the ideal, thereby offering both model and defense of citizenship.

The exertion of Redneck identity I am suggesting here functions to aid already empowered Americans in the consolidation of dominance. They use the identity to claim membership in the core American identity of Redneck, but they control the identity instead of having the identity control them. Social elites use Redneck as a way to seem common, often obviously so, which offers a way to exercise power without resistance. Thus rural people accept socially elite individuals into Redneck status even as their own degradation is put to use by those who maintain social structures that support economic and social disparity. The elite Redneck pretends to be philosophically downtrodden as a means to maintain the position of the literally downtrodden.

It is not coincidental that the formation of Redneck image centers on presidential perception. A chief requirement for that highest American office is an indefinite presence of "electability," a quality matched in its lack of specificity only by its very real power to determine political success. To gain purchase on the term, I suggest that electability itself relates to Guy Debord's concept of "spectacle." A candidate must have 
it, even if "it" seems to resist definition. In what I would term "Redneck electability,"

Debord's spectacle acts at the very core, as it

is both the outcome and the goal of the dominant mode of

production.... It is the omnipresent celebration of a choice already

made in the sphere of production, and the consummate result of that

choice. In form as in content the spectacle serves as total

justification for the conditions and aims of the existing system. It

further ensures the permanent presence of that justification, for it

governs almost all time spent outside the production process itself.

(Debord 13)

Thus in the 2008 Presidential election season, Democratic nominee Barack Obama found himself with a necessity of justification. He did not fit the overt, outward image of a white masculine Redneck that Bush offered to America, so he had to otherwise find credibility within the framework of the existing Redneck system.

For Obama, that support came from a self-titled, small-time group called "Rednecks for Obama" (Leibovich). Growing from the efforts of two men, Tony Viessman and Les Spencer, the group enjoyed some national attention, printed evocative T-shirts, and helped usher Obama into the White House. At the very least, this group attracted attention from a mainstream media that found it surprising or newsworthy that "rednecks" would come out in support of a black presidential 
candidate. And though the group's website — rednecks4obama.com — has passed into oblivion since the election, the existence of the group still marks an interesting moment in both the specific election of 2008 and the general notion of redneck functionality in American politics. Boiled down, Obama probably could not have won without at least a veneer of support from this segment of America. Moreover, contemporary American politics seem unable to get over the redneck issue. Whether constructed or otherwise, the Redneck identity must be handled by each and every candidate as it both attracts attention and invites interpretation.

As a functional ideology, the Redneck identity works within the framework of what Michael Rogin calls "countersubversive tradition" and "political demonology," the "creation of monsters as a continuing feature of American politics by the inflation, stigmatization, and dehumanization of political foes" (xiii). Rogin argues that presidential politics require the construction of an enemy who can then be exploited as a mandate for leadership. More importantly, Rogin argues that the growing ethnic diversity of America creates an easy site for these invented demons, as "racial conflict placed the paranoid style at the center and origin of American history, made it hard to argue for a happy, pluralist outcome, and broke down the easy distinction between interests and fantasies" (277). The office of the presidency in turn becomes the nexus for the management of these images. It is the space where the symbols of America exist most overtly, perhaps most readily demonstrated by the Presidential Seal that is applied 
to all presidential items, whether desk or ashtray. More importantly, the office becomes the representative space where American symbols in general must be accounted for. The president must both be America and represent America. For election, Obama needed the support of groups like Rednecks for Obama because they offered external validation of his power. That group designated Obama as the champion against Rogin's demons instead of as demon to be resisted.

Because of his race Obama needed a way to fit the Redneck spectacle without violating his own heritage. He could not simply abdicate his racial identity by claiming himself as redneck by wearing a Confederate Battle Flag lapel pin, perhaps while clearing some brush. Obama instead needed Redneck validation in order to both maintain his personal identity and fit into the national white paradigm. Or as Rogin puts it:

To win, in the countersubversive tradition, is to be an Englishspeaking white man. To lose is to fall back among the undifferentiated mass of aliens, women, and peoples of color. Countersubversives desire the submergence of separate identities within an ideal America, but they also enforce divisions because they are threatened by boundary collapse. That oscillation between a fear of the breakdown of all difference and a desire for merger lies at the core of American political demonology. (279-280) 
Obama entered politics as a foe, symbolically cast as the Other of American politics black, intellectual, progressive. Redneck spectacle, applied externally, offered a way to fit the standards of his desired office.

Hailing from the North, Obama could not automatically assume the label of Redneck, as Democrats Jimmy Carter and Bill Clinton could before him. More, Obama's racial position presented an obstacle for support, since racism lies at the heart of the expected range of Redneck ideology. Worse, a widely-publicized comment about rural Americans "clinging" to guns and religion seemed to doom Obama within the redneck caucuses of white Appalachia. At the very least, those comments revealed Obama's limited understanding of politics, identity, and the rural poor. London's Sunday times offered this critique: “Obama's historic candidacy holds much of the world in thrall. Yet there's one significant sector of the U.S. voting public that has so far proved resistant to the Democratic candidate's charms. The great American redneck — that rifle-toting, Bible thumping, truck-loving caricature devoted to beer and motor sports " (Allen-Mills and Berman). Or as that same newspaper later put it, "suddenly the rednecks are being taken seriously. In the unique arithmetic of this year's presidential election, the white rural working-class vote has assumed huge importance, and nowhere more than in the Appalachians, the great spine of mountains that stretch 1,000 miles from southern New York to the middle of Alabama" (Macintyre). 
This swath of geography offered a corresponding block of voters who presented what pundits called Obama's "Appalachian problem." In analyzing Obama's loss to Hillary Clinton in the West Virginia primary and his general lack of support in Appalachia, reporter Jonathan Tilove suggested that Obama's failures lay within the very origins of the people in the region: "Obama appeals more to whites like those in New England..., who inhabit the lands first settled by the more intellectual and moralistic Puritans, and the places from the Great Lakes to the Pacific Northwest where those New Englanders migrated" (“Obama's Appalachian Problem”). Or, from reporter Dee Davis, the failures stem from Appalachians as "a special set of Democrats, white, low income and undereducated," who have lost historical importance in the Democratic party where, "in the minds of some, 'Coal Miner's Daughter' has been supplanted by 'Deliverance'” (“Why Don't Those Hillbillies Like Obama?”).

Inherent in these analyses of Obama's Appalachian "problem" are the very same narrowings of Redneck culture that I've been exploring in this project. That a certain kind of "intellectual" white settled in the north while a baser version wound up in the mountains follows the same line of reasoning that has always considered the hills locales of monolithic degeneracy. The suggestion, really, is of an unchanging region. Appalachia figures differently in politics because it is what it always was (that it never was) and will always be: Appalachia hasn't so much traded "Coal Miner's Daughter" for "Deliverance" as it has been reduced to the merest set dressing of that latter film. 
Meanwhile, the icon of the Redneck looms large in these constructions. Because he carries such weight in elections, he must be contended with. Obama needed in some way to appeal to the stereotypes of the Redneck, and not just appeal to the actual social needs of the rural poor. Thus, his criticism of the icon of guns mattered deeply, because he insulted the circulating images of the Appalachian identity. Obama violated the Redneck code by criticizing one of its hallowed ideas, even if his politics would seem more in line with the needs of the region. Conversely, Bush had easily appealed to that Redneck code despite politics antagonistic to rural issues. Redneck codes matter more than redneck policy. Moreover, these codes depend heavily on the recirculation of Redneck stereotypes and the narrative of rural degradation. Without the circulating images of America's incomplete comprehension of Southern and Appalachian identity, the political function of the Redneck would yield little affect. But because the American Redneck is such a familiar type, it becomes easy political shorthand.

On the opposite presidential ticket, newspapers made much ado about the background of Republican vice-presidential nominee Sarah Palin, whose identity skewed undoubtedly toward the redneck. ${ }^{15}$ The implications of the 2008 election press coverage is clear enough, that rednecks mattered in the election and that the regions where the rednecks lived mattered as well. Moreover, as Douglas Kellner argues, Palin

\footnotetext{
15 Notably, coverage of this "fact" was certainly widespread but seemed, also, to carry particular sway overseas. Though citations for Palin's redneck identity could fill pages, I've noted Antonowicz, Dickinson, and Harnden because of their particular emphasis on the redneck proclamations of the fiance of the daughter of the candidate.
} 
brought to the McCain campaign the sort of spectacle that has become increasingly crucial in presidential campaigns. The mere shock-value of a Redneck vice president offered an early boost to the Republican ticket until the too-redneck hyperboles of Palin's family began to backfire (709).

John McCain selected Palin as running mate likely to bolster support within the same sector of redneck Republicanism that found great significance in Bush's brush clearing and complaint with Obama's critique of gun ownership. For critics, however, “Palin's redneck identity became ... a matter of dysfunctionality through which her conservative politics could be attacked" (Darling 20). Moreover, scholar Eliza Jane Darling argues that Palin's

self-construction invoking genuine rural authenticity became a ready-made foil for the liberal counter-construction, invoking dystopic rural pathology in a clash of discordant tropes: the folksy Rockwellian countryside marred by the unsightly spectacle of ramshackle rural poverty, down-home commonsensical wisdom discredited by parochial ignorance of the world, the good mother debunked by the vaguely incestuous trailer trash slut. She became less a collection of policies than a collection of symbols. And through Palin was all of white rural America essentialized and indicted, aided and abetted by its own widely circulated 
expressions of bigoted right-wing hatred: Obama effigies hung

from trees in Oregon and Kentucky, small-town gatherings

evincing suspicions about Obama's Muslim heritage,

demonstrations articulating rage against the very idea of a black

American president. (20-21)

Regardless of politics or actual political prowess, Palin's identity as self-professed

Alaskan redneck in the end undermined her potential for power. The problem was, again, one of image. Palin was too "authentically" Redneck, too close to the actuality of the degraded stereotypes of American literature, and therefore was more than spectacle. Palin revealed the actual suffering and poverty that lies beneath the iconic Redneck image, which uncomfortably demonstrated the limitations of that icon.

Her "truth" added unwanted dissonance to the purity of the image. Essentially, Palin's identity problem was that she wasn't pretending to be a redneck. As a result, she might accidentally call attention to the actual existence of the struggling rural poor. Further, as a potential commander-in-chief she failed to offer the "substance" of strength necessary for the office, as was clear enough in the popular criticism of her foreign policy experience as commander of the Alaska National Guard. Without someone to actually bomb, Palin came across as huff and image. Bush could appear more authentic as a Redneck, despite looser genealogical credentials, because he got to bomb the Middle East. Without such clear evidence of overt strength, Palin appeared 
too much like a less-slick version of Jimmy Carter, a potential redneck in the office who really couldn't be trusted with the keys to the missile silos.

Obama's Appalachian problem and Palin's too-redneck background, in turn, relate to the complicated narrative space of the American redneck. It is reviled and revered in the same breath, in need of defense by liberal policies but extolled by conservative imagery. The Redneck is attacked by its liberal defenders just as it is functionally ignored by conservative big-business legislation. The destruction of Palin thus reveals the impossible, though necessary, political position of the Redneck: it must be accounted for to win national support, but it must also be ridiculed if the identity is more than a put-on. Political success depends on the successful playing of Redneck, but not on the actual living of the identity. This was Palin's particular problem. Like the Dixie Chicks, she broke the narrative. But Palin did it by being too uncomfortably like the actual rural working class. Bush played the role better than she did, simply because he actually had to play it. For the social elite, it is the assumption of feigned Redneck identity that matters, not the ascension of one who carries the actual identity.

Still, for Palin the outsider Redneck continues to function as evidence of political viability, if not electability. In the first years of Obama's presidency, she has become a totem for right-wing politics, arguing that "(w)e need a Commander in Chief, not a professor of law" (Zernike). And in her memoir, she aligns herself with images of Americana at the Alaska State Fair to open the narrative, where she breathes "in an 
autumn bouquet that combined everything small-town America with rugged splashes of the Last Frontier. Cotton candy and foot-long hot dogs. Halibut tacos and reindeer sausage. Banjo music playing at the Blue Bonnet Stage, baleen etchings, grass-woven Eskimo baskets, and record-breaking vegetables grown under the midnight sun" (1). She casts herself as a critic of big government, as a radical who fits the strict images of neither Democrat nor Republican but who is nonetheless steeped in classic American images and values. She casts herself as outsider Redneck, which offers her narrative force as critic of the political status quo. And she casts America as in need of a leader who can be narrowly defined within these constraints. She calls for a leader who can operate within the actual guidelines of Natty Bumppo's libertarian wilderness. And she denies the validity of a leader who would resist the lawlessness of the Redneck outsider. More, Palin has begun to portray a more iconic and less bona fide version of Redneckism. In the years following her defeat, she has shaped herself more as a representation of the Redneck ideology than as a representative of the rural poor, which makes her a more viable political threat.

This is how the Redneck spectacle works. Bush's successful outward fidelity to Redneck image lends him credibility that Obama and Palin cannot easily grab. Bush succeeds because he is not redneck but can convincingly pretend to be. Palin and Obama fall short of the image for varying reasons, but they must still attempt to fit the mold because, as Adorno argues, "anyone who fails openly to parade their freedom, 
their courtesy, their sense of security, who fails to observe and propagate the established guidelines is forced to remain outside the pale" (79). Moreover, an individual "incapable of talking in the prescribed fashion, that is of effortlessly reproducing the formulas, conventions and judgements of mass culture as if they were his own, is threatened in his very existence, suspected of being an idiot or an intellectual" (79). This is precisely the challenge of those who are not immediately counted as Redneck, and this is precisely why Obama must mitigate his image through the support of Rednecks For Obama. Easily criticized as an elite intellectual, or as a lawyer-in-chief, he requires a way back into the ideological mold: that's the crux of the Appalachian Problem, which is not so much a problem of voting patterns but a problem of national identity.

Consider a brief timeline of American Redneck presidency, which moves from the overt Southern identity and geography of Jimmy Carter, to the actual geography but constructed identity of Bill Clinton, to the fully constructed rurality of George W. Bush, with important interventions along the way by Ronald Reagan and Richard Nixon. While these latter two presidents might not fit the specific exterior parameters of Redneck that the others display, their role in shaping an ideological basis for Redneck "values" cleared the path for a divergence between redneck reality and Redneck philosophy. In the cases of Carter, Clinton, and Bush, their positioning of identity displays two divergent lines of image making. One path follows decreasing Southern 
heritage, with Carter as fully Georgian and Bush as an interloper to Texas. The other line ascends from the minor identity constructions of Carter to the full construction of Bush. Thus the office of the presidency, as site of American symbol, becomes more Redneck even as its occupants become less bona fide in their redneck credentials. Each of these presidents, nonetheless, had to contend with Redneck identity.

Carter conforms by proclaiming how his memoir, Keeping Faith, is his "own work," how "( $t$ )here were times ... when I yielded to the temptations of my nearby woodworking shop or a convenient fishing place, but I have spent most days and nights of the past year on this project" (xiii). These words establish a core credibility for Carter, that he both possesses within himself straightforward Southern honesty — the book is his own, not the work of a ghostwriter — and pursues typical Southern pastimes. Carter works with his hands and fishes, so he's a man of the people. More importantly, Carter writes about establishing himself as a Southern candidate for the presidency by, curiously, invoking the name of one of the region's most infamous leaders:

In the panhandle of Florida during the primary election campaign, I'd had my first real understanding of how much it would mean to Southerners to have one of their own elected President. Governor George Wallace had told Floridians that a vote for him would "send a message to Washington." A vote for me, I told them, would send a President there. At that time, Southerners had some messages to 
send to the world, and I listened to them. The most important was that we in the South were ready for reconciliation, to be accepted as equals, to rejoin the mainstream of American political life. (22)

The effect of this episode is twofold. On one hand, Carter shows how he sought to position himself politically as a Southern figure, since that was so crucial to his support in his home region. On the other, he implicitly aligns himself with Wallace without directly supporting that governor's policies, nonetheless pandering to the same sort of Southern (un)sensibility that Reagan later did by announcing a "states' rights" platform in the Southern town that hosted the murder of three Civil Rights workers (Kneeland, A11).

As Reg Murphy and Hal Gulliver argue, Carter's campaign relied on code words like "Wallace" to lure the racist vote despite the candidate's progressive politics (186-187). Further, Carter documents this alignment with Wallace in his memoir long after the fact of his Presidency. Simply, by the time his memoir was published Carter neither needed Wallace supporters on his side, nor should he have overlooked the implications behind such an invocation. It is through the lens of time, however, that Carter reasserts the tired old construction of the South as a land removed, as different and in need and ready "for reconciliation." In these moves, Carter successfully establishes Southernness for himself but, more, establishes it for external, non-Southern viewers. He uses the tropes of the South in order to clarify how he fits the simulacrum, 
which makes his alignment to Wallace, to the past, politically useful. Carter is both authentically Southern and a conscious manipulator of his own Southern image.

This kind of image grooming becomes even clearer in Carter's later writing, particularly in his 2002 memoir of childhood, An Hour Before Daylight. In this work, Carter painstakingly establishes himself as a crop of the South, as an individual literally connected and immersed in the soil of his homeland."My most persistent impression as a farm boy was of the earth," he writes. "There was a closeness, almost an immersion, in the sand, loam, and red clay that seemed natural, and constant" (15). Later, he extolls the virtues of shoeless farming: "I preferred to plow without wearing shoes, and I remember vividly the caress of the soft, damp, and cool freshly turned earth on my feet. The burning surface sand and the ubiquitous stinging nettles were brushed aside by the plow blade that I was following down the furrow" (166). And as he writes elsewhere in the book, he goes unshod even at risk of the ubiquitous hookworm (80).16

In these memories, Carter makes an argument for himself as part of a certain kind of Southern gentility, establishes himself as an Agrarian even if he happened to be a social liberal. Thus, he fashions for himself a soft redneck identity that proves useful for a president. He is undeniably Southern, of the people there, of the land there, which mitigates the threats his social progressivism pose to established patterns of white patriarchal dominance in his region and his country. Similarly, his attraction to the soil

\footnotetext{
${ }^{16}$ As its own history of construction, the supposed proliferation of hookworm in poor Southerners echoes the Redneck identity. For commentary on how hookworm rhetoric has been used in maintaining rigid social divides, see Wray's Not Quite White.
} 
seeks to establish commonality for Carter. He argues simplicity for himself, denies any perceived elitism, whether economic or intellectual. Thus it fits that in running for office, "Carter's campaign was deliberately more roughhewn, even to the point of selecting a less than flattering billboard picture of Carter....Carter's approach won him support among lower-middle-class and blue-collar workers" (Murphy and Gulliver 188).

In appropriating this soft, Agrarian Redneck model, Carter increases his viability as a candidate and penetrates the conservative curtain that, in the 1970s, had already locked in the South for the Republicans. ${ }^{17}$ Carter isn't too Southern to be president and is thus electable. Soft agrarian Carter ameliorates the supposed Bible-thumping that cartoonists and pundits mocked before he took office (Keeping Faith 22). That's the message of the Redneck. The values inherent within the identity made Carter a viable President. As merely a man from the South, he would have been suspiciously regional. As a self-styled redneck farmer, he became presidential.

In contrast, Bill Clinton opens his exhaustive autobiography with a scene straight out of the Southern Gothic:

Early on the morning of August 19, 1946, I was born under a clear

\footnotetext{
17 Southern identity politics must contend with the long history of the Republican Party's Southern strategy. Through that conscious effort to eschew the black vote and support racist policies to win the white vote, the region became a foundation for conservative politics. For more background on the Southern strategy, see Earl and Merle Black's The Vital South, The Rise of the Republicans, and Politics and Society in the South; Bass and de Vrie's The Transformation of Southern Politics; Applebome's Dixie Rising; and Greenhaw's Elephants in the Cottonfields. For background on Southern politics and the "solid South," see Key's Southern Politics in State and Nation.
} 
sky after a violent storm to a widowed mother in the Julia Chester Hospital in Hope, a town of about six thousand in southwest Arkansas, thirty-three miles east of the Texas border at Texarkana.

Clinton offers quintessential Southern tropes here, setting the scene for himself as a character living within a narrowly defined version of the South. And versions, for Clinton, are important simulacra: his life is difficult to pin down in any absolute way, is difficult to divorce from construction and image manipulation. Or, put another way, the effect of Clinton's 1,000 page autobiography comes across in exactly the same way as an elaborate, detailed story that through its length seeks to convince the recipient of its truth despite an utter lack of final believability. Just as his opening line evokes the gothic, with lightning strikes filling the air, then softening to calmness as a single mother gives birth, the bulk of Clinton's narrative presents an overly-rendered claim to Southern heritage.

More, the book takes place in the actual South with only nominal discussion of the region itself. Scanning the book's index reveals as much, as it includes nearly two pages of entries with "Arkansas" as part of the heading. But none of the entries references life in Arkansas, or a childhood in Arkansas. Instead the entries link to passages on the "Arkansas attorney general's office," or the "Arkansas gubernatorial election," with multiple entries on 1978, 1980, 1982, and 1990, as well as an overarching 
general reference to Arkansas elections (vi-vii). Arkansas, the South, a rural upbringing, all of these things exist in shorthand. Clinton relies on predetermined Southern images without making any particular case for any specific Southernness. Moreover, Clinton writes his life story with a Southern setting that depends throughout the autobiography on the representational work performed by his opening line. While Jimmy Carter's life writing seeks to analyze his Southern roots, Clinton's does not. Clinton's book is political, a moment-by-moment account of a man who ascended to power, who happened to do that while growing up in rural Arkansas.

By creating a curious absence of Southern identity, Clinton demonstrates the necessity of a simulated political Redneck. The setting of his book doesn't matter at all. By choosing to foreground the book with a hyperized "Southern" moment and by providing references to rural life throughout the narrative, Clinton plays the part of the Redneck even as the actual conditions of that identity matter not at all to his life story. It may be true that he was born to a single mother, that he grew up with an alcoholic stepfather, that all of this took place in Arkansas, but the function of that truth is not related to the conditions of working class, Southern rurality. That is to say, Clinton's life is not redneck, cannot be related back to the soil of Arkansas in the way Carter's can be to Georgia. There, even if Carter's construction of Southern identity serves a political purpose in aligning him with core values that appeal to voters, the writing offers the necessary ring of truth. 
Clinton, in contrast, lives a fully simulated life of Redneck identity. He was born within the economic conditions necessary to claim inclusion, but he manipulates those conditions in a totalizing way. Clinton wants or needs to be a Redneck to bolster his liberal, defender-of-the-working class political credentials, even if his actual politics led to NAFTA and, in fact, a catastrophic undermining of the employment of the Southern working class, whose jobs shifted beyond the borders of the nation. As Shawn and Trevor Parry-Giles argue, Clinton's "presidentiality" works to "shape and order the cultural meaning of the institution of the presidency, ideologically defining the office and its occupants" (3). They argue that Clinton carefully walked the line of femininity and masculinity, portraying himself as sensitive but womanizing, for example. Likewise, Clinton played both ends of the dichotomies of war and peace, black and white, public and private. I argue Clinton also walked the fine line of Southern and notSouthern, using his heritage as an ideological mask for the reality of his political ambitions. Put another way, it is more than a symbolic coincidence that Clinton's home state of Arkansas is also the home state of Wal-Mart, the poster corporation for the decline of viable working class life in America and the globalization of consumptive commerce.

Metaphorically, the economic policies of Southern retail giant Wal-Mart offer a fine lens into the separation between redneck reality and Redneck image. Journalist Joe 
Bageant criticizes politics that leave behind the working poor and, in particular, the typically conservative claim that hard work always yields results: "The American bootstrap myth is merely another strap that makes the working poor privately conclude that they must in some way be inferior, given that they cannot seem to apply that myth to their own lives" (9). Such myth could serve as shorthand for the arc of Clinton's memoir — Southern boy from single-parent household makes good. Such myth also figures into the advertising rhetoric of Wal-Mart, which claims to slash prices to help working families. Bageant, however, undermines the seeming truth of the myth by addressing the hemorrhaging of jobs at Winchester, Virginia's Rubbermaid plant. Its workers became victims of Wal-Mart's predatory price-cutting and rigid demands on suppliers. Wal-Mart demanded that Rubbermaid sell containers to the chain at lower prices, so "savings" could be passed on to shoppers. However, Rubbermaid couldn't lower prices to meet Wal-Mart's demands without hurting workers, and the company sought to do right by its employees by refusing to cut prices. Wal-Mart, in return, dropped Rubbermaid products and made previously obscure company Sterilite its container purveyor of choice. Rubbermaid lost business, had to lay off workers, then later lowered prices to get back onto Wal-Mart shelves (53-115).

The story offers a cogent and important consideration of the way working class Americans are forced into complicity with the very institutions that help deepen their plight: the Rubbermaid workers now have to shop at Wal-Mart because it's the cheapest 
way to go, but Wal-Mart policies have also led to the erosion of pay and opportunity. The object of all of this criticism aligns closely with Jefferson Cowie's argument about working class politics:

The greatest political illusion today is that the "liberal elite" are the great and powerful level-pullers hiding behind the curtain. The genius of this political construct - and the brilliance of much of the rhetoric of the right today — is its ability to tap into an endless well of rage at those supposed "elites" (more accurately, "elitists") without touching the major form of power and privilege in America: capital. (9)

Wal-Mart and Clinton successfully make use of Redneck image to defuse accusations of elitism, even though the company is obviously one of the economic superpowers of the world and the former president a member of the political elite. Image suggests otherwise, and leads the rural poor to shop at WalMart and vote for politicians whose policies do little to help them.

The foundation for this shaped image lies at the heart of the shaping of the Redneck identity. Suitably, the origins of Redneck political viability originate in the celluloid cowboy actions of Ronald Reagan, in tandem with cynical political maneuvers he helped crystallize. The rise of the contemporary ideological Redneck was made possible by the Republican "Southern strategy" that has seen 
that region more or less steadfastly support conservative candidates since the Strom Thurmond and Barry Goldwater 1960s. In brief, as Peter Applebome explains lucidly, the Southern strategy offered a way for Republicans to assume power in the South by ignoring the black vote. While the contemporary vision of Southern conservatism may be most closely associated with fundamental Protestant Christianity, the Southern Strategy relied on the activation of white racism. Moreover, by actively aligning itself with white Southerners and implicitly (at the least) racist policies, the GOP successfully shifted a traditionally Democratic region to one that now more or less computes as the home turf of Republicans (Dixie Rising). ${ }^{18}$

As a result of this effective strategy, the GOP established the conditions that led to the 21st century political designations of Red States and Blue States, with Red serving as code for conservative, rural middle and Southern America. As Charles Bullock and Mark Rozell explain, "Partisan change began in the Deep South immediately after the 1964 Civil Rights extended federal protections to public accommodations" (3), with Barry Goldwater publicly decrying such legislation as violations of states' rights. A few years before that, in an oft-cited speech, Goldwater declared, "We're not going to get the Negro vote as a bloc in

\footnotetext{
18 See Earl and Merle Black's The Vital South, Jack Bass and Walter de Vrie's The Transformation of Southern Politics, and Wayne Granshaw's Elephants in the Cottonfields or more background on the Southern strategy. For background on Southern politics and the "solid South," see V.O. Key's Southern Politics in State and Nation.
} 
1964 and 1968, so we ought to go hunting where the ducks are" (Bass and DeVries 27), establishing the racial undertones to the strategy: pander to white racism, shift political support to the right, win the South. Or as Reg Murphy and Hall Gulliver put it, "It was a cynical strategy, this catering in subtle ways to the segregationist leanings of white Southern voters — yet pretending with high rhetoric that the real aim was simply to treat the South fairly, to let it become part of the nation again" (3). In implementing this strategy, the Republican party successfully relied on tropes of the fallen South as much as it relied on the support of racist whites, implying a need for regional reunification that simultaneously relied on the anxiety of whites facing the reality of Civil Rights. The strategy successfully affixed Southern pride to stereotypical southern racism, preyed on the resistance of anxious whites in order to gain power in portion of the country that didn't immediately identify with the big government policies of the Republican Party, nor with its famed historical icon Abraham Lincoln.

In fact, this Southern strategy has led to more than a mere political refashioning of the South. The political changes have also laid the groundwork that allows a certain aspect of Southernness to consume the cultural conversation of the rest of the nation. As Applebome puts it, "the most striking aspect of American life at century's end — in a way that would have been utterly unimaginable three decades ago at the height of the civil rights era - is how the country looks like the South" (6). In defining America as 
newly Southern, Applebome suggests that the nation has adopted a prevailing point of view that is "bitterly antigovernment and fiercely individualistic, where race is a constant subtext to daily life, and God and guns run through public discourse like an electric current" (8). In essence, Applebome classifies his Southernized America as the swatch of the nation I label as Redneck. And while I cannot agree with the hyperbolized idea that America has assumed a totalized Southern identity, I do echo his suggestion that the stereotypically Southern attitudes he references hold greater weight in public political discourse than they did even thirty years ago. But just as importantly, the rigidity of perception that defines Southern culture allows Applebome to see these broad American attitudes as somehow uniquely Southern without question.

Ronald Reagan figures prominently in the development of Redneck political agency in part because of his explicit role in the Southern strategy — consider the "state's rights" comment I referenced earlier in this chapter — and in part because of his presence as a phantom president. On this latter point, I mean to suggest that Reagan both relied on the power of images to gain political capital and himself was, in effect, mere image. Richard Slotkin argues that much of Reagan's power drew from his use of American myth, from borrowed film slogans uttered by cowboy icons like John Wayne and Clint Eastwood, and from images of an idealized version of 1950s America (Gufighter Nation 643-644). According to Slotkin, "these patently celluloid backgrounds and gestures seemed both appropriate and authentic as settings for candidate and 
President Reagan, because they were icons of movie-America, and that imagined space was indeed the historical setting in which Reagan matured and acquired his public identity" (644). Reagan the president functioned in very much the same way as Reagan the stage actor. He lacked definable and stable identity and relied, instead, on performance. As Michael Rogin has pointed out in Ronald Reagan the Movie, Reagan often appropriated lines from his own movies, collapsing his own physical identity into the remembered performance of his acting life. In extension of that merge between film and reality, Reagan also created fictive memories of presumed threats to drive his politics as President: Star Wars, Iran-Contra, the Cold War in general. The very political identity of his presidency was predicated on the faulty memory of cinematic Inertia Cannons as real-life missile defense systems. But since Reagan's memory of his film roles functioned alongside the non-celluloid world, he stood fast when real-world facts threatened to undermine his political aims. It mattered little, then, that the Star Wars missile defense system was neither practical nor possible. He believed in the memory of the Inertia Cannon, and by clinging to that belief nonetheless bankrupted the Soviet Union, which was forced to develop a real response to the impossible Star Wars program.

Pertinent to my discussion of Redneck political ideology, Reagan offered a nexus of image and locale that lent credibility to the feigned Southern image and power to the public exertion of counter-liberal rhetoric. Since Reagan was not of the South and only 
an obvious actor of cowboy identity, he could safely echo George Wallace's overt Southern racism in claims for states' rights. At the same time, he offered newly empowered legitimacy to Wallace's own arguments that, as quoted in a 1968 Time article, "intellectuals are 'overeducated ivory-tower folk,' or 'pointy-headed professors who can't even park a bicycle straight.'" Reagan avoided the too-literal — and too pointedly "hillbilly" — tactic of criticizing his opponents in dismissive ways, but he instead offered a carefully rendered image of action. Wallace presented a certain way of thinking that appeals to the contemporary limits of Redneck philosophy. He spoke back against intellectuals and others out of touch with the land, rhetorically raising up individuals who have felt themselves ignored in national conversations. Quite directly, and with strong Redneck accent, Wallace spoke back against the social elites that contemporary Republican philosophy positions as opposed to the "common man." From a national perspective, Wallace could only voice an opinion that got heads nodding, however. He lacked viability as a candidate because he was too clearly and too stereotypically "Southern." Reagan's great move was to somehow tap into the anti-elitist undercurrent of Wallace's words without casting himself directly as another version of racist Wallace. Redneck politics demanded an actor capable of merging Redneck philosophy with palatable image, and this was precisely what the celluloid cowboy brought to the party. Voters understood that he was an actor, but that didn't matter. The artifice could be safely applied to the narrative of Reagan's life, which in turn aligned 
his political ideology with the very specific images of the Southern redneck without suffering from a too-Redneck persona.

Through this representational move, Reagan became almost more fully Southern than his opponent Jimmy Carter, whose identity was a bit too tied up in images of rural agrarianism. Reagan defeated Carter by adopting a feigned Southern persona, predicated on the coded assertion of the "normal" terms of Southern policy established by Nixon's Southern strategy: conservatism, racism, whiteness. In turn, Reagan made possible the non-Southern Southernness of Bill Clinton and the over-baked good-oldboy pretenses of George W. Bush. Reagan gave a picture to American political presence, and that picture was drawn in the inescapable shades of the Redneck.

As I am arguing in this chapter, the narrative shaping of political Redneckism provided electable identity for Carter, Clinton and Bush via feigned identity made possible by Reagan's own feigned political presences. Carter casts himself into the category of Redneck to assuage his too-weak sensitivity, just as Clinton casts himself into the category to render himself narratively Southern, just as Bush allows himself to become fully the category by grace of his cowboy brush clearing. But these are images that rely on category and not actuality. They are identities that fit neatly into prepackaged parameters of Redneck status. They are boxed and available for use. But the original qualifications of the term "redneck" were not ideological, were neither prepackaged nor even desired. Instead, the 
conditions that defined "redneck" were purely economic and decidedly subordinate to other American figures. In gaining power as a force of politics and social (un)change, Redneck drops its economic realities and refuses to allow into the conversation the people who still suffer under the conditions of rural poverty.

The situations of Barack Obama and Sarah Palin illuminate a different sort of problem with the assumption of Redneck identity. While Carter, Clinton, and Bush each offer a version of the Redneck spectacle to solidify their mandates for leadership, each also does so from a nominative position of power. They are white men, the very identity for which the Redneck works to maintain dominance; these three merely apply versions of Redneck symbology to the already symbolic office of the president. For the others, preset conditions of exile demand the application of the Redneck identity. As a woman, Palin did not fit the expected parameter of masculinity, despite rural experience. As a black man, Obama does not fit the expected parameter of whiteness, despite his masculinity. Therefore, each draws around her- or himself the cloak of the Redneck in order to deal with the circulating ideology that makes that identity central to American mass culture. But each also faces significant resistance because of incomplete applications of that cloak. Palin becomes too easily aligned with the negative stereotypes of the degraded redneck to be taken seriously; Obama cannot become Redneck himself without a full denial of his own racial identity. 
But all of the individuals I offer in this chapter must contend with the Redneck identity in some way, because it is through the spectacle that rigid American culture maintains itself. Since the limits of citizenship are threatened by the growing fracture of homogenized American identity, the Redneck works to mend those cracks. Life and globalization threaten to rupture American trope, and the concept of the Redneck steps in to fill that space. In a sense, that's what the liminal figure of Hawkeye offered for early America. That character becomes both frontiersman and Indian to make the frontier safe for settlement. That's what hillbilly stereotypes do: Deliverance resists the threat of masculinity; Smokey and the Bandit resists the threat of feminism; Larry the Cable Guy resists polite racial harmony; the office of the president resists the erosion of white hegemonic power. The constant recirculation of redneck stereotypes works to de-voice potential resistors to the ideological norm. Yet for people who actually live in Appalachia and the South, issues of poverty and representational degradation remain daily conditions. There, the voice of the Redneck ideology does not speak for reality. Instead, the people who live in the regions claimed as representative site of the new mythological American frontier offer their own voice. It's just not quite as Redneck as ideology might imply. 


\section{Chapter Four: Normal Rednecks, Normal Americans}

In September of 2006, World Wrestling Entertainment's Friday night

"Smackdown" debuted a new, image blurring character, a Korean-American redneck introduced as Jimmy Wang Yang. His presence reveals a distorted sense of racial equality within the category of redneck, as Jimmy simultaneously occupies positions inside and outside of the Redneck identity. Appearing first in a series of short promo clips instead of in actual wrestling action, Jimmy offers to audiences a Southern nasal drawl and a series of redneck-defining short films. Jimmy's image also offers an apparent entry into the Redneck nation for minority figures, and his presence on Smackdown suggests a gentler liberalism within the Redneck identity: if a Korean can be a Redneck, then the rigid racism of that icon has finally been broken. In action, however, he offers none of this.

When Jimmy announces himself to the world in his introductory clip, he engages the Korean ethnicity that would seem to prohibit his entry into the redneck world. But Jimmy suggests that he isn't what he seems:

Howdy. I know what you're all thinkin'. Now I reckon you're all a little confused out there. But I'm not what you think I am.

[He pauses to put on a black cowboy hat].

I ain't no foreigner. I ain't your stereotype. I ain't no Kung Fu

fighter. And to me, chopsticks are just a piece of wood. Mattera fact, 
there ain't no yeller about me. But there's one color about me. A little red. That's right. I'm a redneck. My name's Jimmy Wang Yang. And I'm your boy.

Giddyup. Yee haw. (wwe.com)

The message is unmistakable, substituting one stereotype for another but clearly aligning the wrestler with the Redneck instead of the foreign suspect. He marks himself visually as part of redneck culture, dressed in the videos in jeans, with a black hat, standing in front of a pickup truck. He wears a black leather vest emblazoned on the back with the Confederate battle flag. In the ring, he wrestles in a white tank top and blue jean-like tights. He wears a Fu Manchu mustache that presents an odd duality. Such facial hair suggests the ethnicity of the Far East, calling to mind stereotyped images of the Mongol warriors or Chinese Kung-Fu masters that Yang denies as his heritage. But the Fu Manchu also reads as a stereotypical marker of the good old boy. On Jimmy Wang Yang, the mustache could lend either way, reinforcing his Korean ancestry or helping to mark him as the redneck he claims to be. It is through his profession of Redneck identity, however, that his appearance becomes unambiguous. He is a Redneck as he proclaims because he adheres to the expected, stereotypical parameters of the redneck. More he substitutes — or in the case of the Fu Manchu, transforms - the stereotypes of the Asian with the stereotypes of the white Southern 
good old boy. In so doing he eases anxieties that might appear because of his position as a minority within wrestling.

I invoke Jimmy in order to outline the completed shift of contemporary Redneck identity. While the 1970s version embodied in Burt Reynolds certainly reveals core masculinist and retrograde normative impulses, that earlier version still contains an aspect of real resistance. At least at first, the Reynolds Redneck stood in outward opposition to the broader national, governmental power, even as this version of againstthe-Man redneckism bore close resemblance to the non-normative stereotypes of the redneck and hillbilly. But just as the Reynolds version of the redneck failed to offer a full shift against the normative restrictions of America, and just as it offered a defense against the pressures that threatened to liberalize the nation, the twenty-first century Redneck displays the full failure of resistance. In fact, this contemporary Redneck version has come full circle to support national social and political conservatism. Moreover, it presents a mechanism to bring back under control non-normative identities that threaten hegemonic unity: like Jimmy. The Redneck becomes The Man and The Man assumes the cloak of the Redneck as a way to codify authentic American identity. Therefore, membership becomes aligned with common values instead of actual social position. Viewed externally, Jimmy ought to be excluded from Redneck identity since his racial position places unwanted pressure on a newly purified American Redneck. 
But in rendering himself at the service of the Redneck image, Jimmy writes himself into that identity, and thus back into America.

Most important, here, are the limits of Redneck inclusion, not the authenticity of the actors themselves - at least not exactly. The trick of the Redneck identity is that it does not require actual membership in the impoverished rural social class. The crucial phenomenon is the capacity for individuals to assume the role of Redneck despite socioeconomic, racial or even geographical locations that would seem to nullify their inclusion. For example, in another video Jimmy wonders why Asians are always thought to be good at math, why they are thought to set the curve. "Only curves I know is from my old lady," Jimmy says, etching a silhouette in the air with his hands. In twenty seconds, he abdicates his role as stereotypically intelligent Asian, substituting instead a persona of the stereotypically chauvinist redneck. He thereby enacts the properly anti-intellectual strain of the Redneck and proves that he is not claiming citizenship as anything other than American.

As a visually obvious minority, Jimmy Wang Yang would not immediately fit the standards of the Redneck identity without these "credibility"-establishing videos. His status as minority places him in an always tangential citizenship, but he ameliorates his position and guarantees his "naturalization" as American citizen through images that reinforce his desire to be American. He proves through actions his willingness to be not not-American. Significantly, prior to assuming the identity of Jimmy Wang Yang, the 
man in the role wrestled on Smackdown as Akio, an "evil" Japanese wrestler whose unmediated Asianness proved his outsider status and guaranteed his reputation as bad guy.

Certainly, race is strongly in play with the case of Jimmy Wang Yang, and just as certainly race is one of the most crucial issues in play with Redneck identity. Since the identity depends on the stereotypical racism of Southern culture, it must account for the growing multiplicities of race in contemporary America, as well as resist the growing acceptance of non-white racial identity. Scholars like Lucy Jarosz and Victoria Lawson see the construction of the redneck stereotype as a means for middle and upper class whites to deflect the guilt of racism: white racism is explained as "redneck" racism (11). I argue instead that the self-assignation of Redneck so readily apparent in the case of Jimmy Wang Yang serves as a way to manage racism, to allow for it without accepting guilt. That is, the Redneck script exacts a strategic move that furthers the agenda of white dominance without accepting blame. Characters like Jimmy Wang Yang don't so much reinforce stereotypes as maintain them, allowing whites to feel distance from "real" racism since it's Jimmy, after all, doing the stereotyping. But since Jimmy is doubly stereotyped as Asian and redneck, he becomes part of the group, becomes a whitened version of the stereotyped minority. In this way, the Redneck identity maintains the power and prominence of traditional white values. By adopting the stance of "minority," or by showing how a visually obvious minority can be included in 
the category, the Redneck can safely assume power without notice or critique. The identity category is "open" to multiple ethnicities even as it demands that those ethnicities cast themselves as properly white. The Redneck becomes both an achieving "minority" and a permanent holder of power.

The Confederate battle flag on the back of Jimmy Wang Yang's leather vest becomes a visible marker of his acceptance of the Redneck identity and a crest of its power. Certainly, the contentious nature of the battle flag has been explored in detail in other scholarship, where scholars engage claims for the flag's historical "merits" in contemporary culture. Moving somewhat obliquely from that complex discussion, I argue instead that Jimmy's vest fits into an interesting post-symbolic space. The image cannot be viewed directly as a claim for racism or history, since the wrestler's minority position fits into neither genealogy. Instead, the flag here operates as a marker of a certain kind of Southern identity, fixing Jimmy's Southern credentials as the "white Confederate southernness" that Gerald Webster and Jonathan Leib argue as the limitations of that flag. ${ }^{19}$ The flag has literally applied itself to the body of Jimmy Wang Yang, marking him as part of that limited definition of Southern whiteness and subject to the group's dominance. Jimmy cannot be a redneck if he peels the flag from his body,

\footnotetext{
19 Newman offers interesting and important studies of how the Confederate battle flag works as a sporting symbol in football ("Old Ties There are not Forgotten") and NASCAR ("NASCAR and the 'Southernization' of America"). Reingold and Wilke present an obvious but quantified explanation of the racist aspects of the flag in "Confederate Symbols, Southern Identity, and Racial Attitudes."
} 
since his visual ethnicity works in contrast to normally accepted standards of the identity.

Similarly, applying the label places him into the very specific scope of redneck imagery that I've argued serves as the nominal foundation of the identity. In order to be accepted into the group, Jimmy must become a Southern white, must fit into the limits of the category. So just as the ideology hails whites and encourages them to follow the scripts of America, it hails outsiders and shows them the way to find membership in the nation. Adopting and accepting the demands of the Redneck identity earns acceptance and national citizenship. Proof of American identity is therefore predicated on proof of Redneck participation. And increasingly in American culture, failing to demonstrate status as ideological Redneck means failing to demonstrate worthiness of full inclusion in national cultural citizenship.

Jimmy turns me toward whiteness, since it is through the application of the Redneck identity that he is able to ameliorate his suspect racial position. Moreover, it is through his Redneck whitening that Yang can be absorbed into the scope of "normal" American identity. He need not wrestle as an explicitly Asian character but, instead, can participate as a fully realized American. Crucial, here, are the notions of normality that intersect with typically unspoken requirements of whiteness.

Julian Carter offers a useful introduction to American normality through an examination of two marble statues created in the 1940s. These statues were presented as 
the result of painstaking research that sought to measure and determine the shape of the average or normal American. Thus, the final proportions of the statues were based on an amalgamation of physical data, which were therefore offered as a definitive physical display of America (1-2). Carter argues, however, that as physical symbols of normality or even perfection in the American mold, the statues worked both to display the undercurrents of whiteness in America and to put on display the aspiration of whiteness to the populace.

As Carter explains, the "normality" of these sculptures must be considered suspect. Even though the statues were formed based on data gathered from a crosssection of the nation, Carter identifies that cross-section as coming from a predominantly upper-echelon white portion of the population (34). As a result, the "normality" of these figures only shows a normality of a dominant class, even as the figures are trumpeted as generally normal and average. As Carter argues, normality itself becomes raced as a white ideal. People of color and even white Americans from ancestral stock dissimilar to the cultural elite of that time period are immediately cut off from inclusion in the discourse of normality. The figures present an obstacle to minority and immigrant inclusion, rendering American normality as a permanently elite state unreachable by most Americans.

Such is the hidden power of whiteness, as it establishes baselines that seem beyond interrogation. The baselines are presented as absolute facts of normality. As 
Charles Mills argues, this perception of factuality is predicated on "an agreement to misinterpret the world. One has to learn to see the world wrongly, but with the assurance that this set of mistaken perceptions will be validated by white epistemic authority" (18). Thus Norm and Norma become acceptable as representations of "average" American bodies because the viewers of the statues were already determined to see the world within this narrow definition of normality. The statues' claims to normality need not be interrogated because the viewers already believe that whitened version of averageness to be true. Viewers of the statue have bought into Mills's "inverted epistemology" wherein "global cognitive dysfunctions" produce "the ironic outcome that whites will in general be unable to understand the world they have themselves made" (18). Moreover, white viewers of the statues will be unable to understand that these sorts of models in fact make the world.

Without close inspection, the privileging in play maintains an invisibility that nonetheless replicates itself throughout the culture. Or, as Richard Dyer puts it, "there is no more powerful position than of being 'just' human. The claim to power is the claim to speak for the commonality of humanity. Raced people cannot do that — they can only speak for their race. But non-raced people can, for they do not represent the interests of race" (2).

Jimmy Wang Yang finds a way to efface the visible marker of race, and that is by adopting Redneck identity. In so doing, he opens up space for himself within the 
limitations of American identity. He forges a position as majority even as he comes from the outside. In essence, he puts to action through his declaration of Redneck identity the nationalization that David Theo Goldberg suggests collides with notions of race, that "race pushes to its extreme the logic of national identification; hence the gratuitous ease with which racism and patriotism seem to intersect" (81). Thus the simplistic but familiar notion that "redneck" is more or less synonymous with "racist" offers tremendous value in the de-racification of Jimmy. If he can become a Redneck, can in fact participate as a member of the very class of American popularly perceived as quintessentially racist, then he instantly and simultaneously ceases to be a minority. After all, a minority surely could not be accepted within the racist Redneck rubric. Jimmy cleans up the category: since it opens up to accept him, the category implies a specious multicultural acceptance.

Jimmy's twang and self-presentation align him with a long tradition of Southern identity. He reasserts what Grace Elizabeth Hale calls the locale's status as "central to the erasure of the whiteness of American identity" (282). She suggests that the contemporary effect of Southern history — or, at least, of a simplistic and narrowed vision of Southern history as a racialized dichotomy — has been to create a narrative for a fully national reinvigoration of whiteness. Segregation, for example, has been deployed as a means to unite white identity "across lines of gender and class" (9). 
Jimmy and the Redneck image create a further blurring of lines, as they bring white identity across previously explicit racial lines.

In blurring racial lines, Jimmy must be viewed as complicit within the "racial contract" of Charles Mills, and in particular within the shifting terms of the "contract" that alter "the criteria for who counts as white and nonwhite" (78). Such shifting criteria function in "making explicit its political foundation. In a sense, the Racial Contract constructs its signatories as much as they construct it. The overall trend is toward a limited expansion of the privileged human population through the 'whitening' of the previously excluded group in question" (78). Jimmy seems to propose a broadening of the categories of inclusion in popular American discourse and, in particular, an inclusiveness within the Redneck category of whiteness I see as fundamental to American cultural identity. But Jimmy does not, and cannot, truly expand those limits because he is, even in his inclusion, a visible marker of difference. His inclusion, which itself must be considered permanently tangential, is predicated on his proper redneck coding — the flag, the hat, the misogyny, the failure to achieve intellectually. The result is, in fact, a limitation of the category of whiteness and, indeed, of America: instead of opening the doors for diversity or multiculturalism, Jimmy reminds the viewer that American identity has long been closed and will continue that way. The Redneck portrayal reveals that Jimmy cannot be fully part of America if he identifies as Asian. Instead, he must cease to be Asian and fill the resultant space with Redneck. In this way, 
he writes his way into American identity, but only at the expense of multiplicity: the Man still holds all the power, and he likes to pretend he's a Redneck, too.

Both Mills and Goldberg offer the theoretical framework through which Jimmy must be viewed. In unearthing whiteness as a raced position and not a mere lack of race, these scholars examine how whiteness functions within a systematic structure of institutional privilege. For Goldberg, a chief concern is the way that liberalism tends to conceive of racism as an irrational response to the world. To the contrary, Goldberg argues that racism is a rational response, but that the definition of Western rationality itself has been from the start imbued with racist ideology. Racism must be viewed as inherent within the institutions and structures of culture, as it is foundational to the way of thinking that has created Western modernity (92). As he points out, modernity argues increasingly against the relevance of race - likely a move driven by supposed antiracist motives - at the same time that racial awareness is itself multiplying. As Goldberg writes, "race is irrelevant, but all is race" (8). Similarly, Mills argues that white supremacy is an unnamed political system that has created the modern world. He argues that despite its lack of presence in philosophical or political textbooks, white supremacy has nonetheless operated as the most influential ideology of modernity (1). In fact, he suggests that modern whites have tacitly signed on to the "Racial Contract" that favors whiteness over all other racial positions. Much like Goldberg, Mills argues that moves toward general liberty in contemporary culture are doomed to succeed only 
as a veneer of liberty, since the Contract itself has pre-set the conditions of white supremacy (122). Again like Goldberg, Mills argues that "rational" European structures and systems govern our current structures and systems. These structures lead only to the reiteration of old systems of rationality. All of these systems favor European civilization, which itself favors whiteness by conceiving of non-European (or nonWhite) culture as pre-cultural or sub-cultural (122). Jimmy Wang Yang, in turn, becomes culturally American, becomes white, becomes cultural at all by grace of his declaration of whiteness. He's given up on the Asian identity that might be labeled as substandard and, in so doing, pledges allegiance to American Redneck identity. Whiteness, meanwhile, dives beneath the surface of his Korean skin, hiding under the familiar and obvious guise of color even as it exerts itself in expression and power.

Elsewhere on television and stage, a new image of the mainstream Redneck appears within the mega-popular Blue Collar Comedy Tour. This cultural artifact aligns itself clearly with the poor or middle class, rural, working white people of America. The first, self-titled DVD of the tour opens with a clear evocation of the imagined symbols of this America: the four comedians sitting in a boat, fishing and telling stories. And when they reach the stage to tell their jokes, they do so in front of a set that includes a country store, a windmill, mailboxes, gas pumps, the whole Americana deal, nostalgic and clear. Jeff Foxworthy, the most famous of the comics when the tour started, and one made 
popular by a string of "You Might be a Redneck" jokes, defines Redneck, and perhaps the general sense implied by the tour, as "a glorious absence of sophistication." And that seems to be the operative image of the group, even if two of the comics - Bill Engvall and Ron White - seem only nominally redneck, and even if the bulk of the comics' jokes have nothing whatsoever to do with rednecks, or rurality, or sophistication. Nonetheless, the image is evoked, and "blue collar" itself is presented as an image of the Southern working class. By grace of that limited geography of identity, millions of working Americans in areas outside the South and racial categories outside of purely white are cut out of "blue collar" status. The racial homogeneity of this version of "blue collar" is clear enough in the crowd shots shown on the DVD, as well as the collection of comics who have chosen to take on the label.

Larry the Cable Guy, a prominent figure in the first Blue Collar Comedy Tour, takes a more prominent position in The Blue Collar Comedy Tour Rides Again. He has since released his own self-titled DVDs and stars in several feature films. He's the clearest redneck of all these comics, a slightly overweight man in a sleeveless, untucked plaid shirt and a mossy oak camo cap complete with Confederate battle flag. He brandishes a guitar painted with that same flag. On his first solo DVD, he opens the show with a gaybashing joke, proclaiming himself to be "happier than Jim Nabors with a wheelbarrow full of butt holes," then continues for an hour and a half to offer a litany of anti-gay, anti-minority, anti-progressive jokes. Larry is "madder'n a queer with lockjaw on 
Valentine's Day"; "madder'n a legless Ethiopian watchin' a donut roll downhill"; has "disappeared like a set of rims at a Puff Daddy concert"; and has been as happy as "a retard in a room full of bouncy balls." His crowd madly cheers following these jokes, then cheers even louder when he offers his frequent mock apology: “Lord, I apologize. Be with the starvin' pygmies in New Guinea. Amen." After the crassest of his jokes he declares, “I don't care who you are, that's funny right there," or "If you don't think that's funny get the hell outa here, cause that's funny." Every line is delivered with a strong hick accent, as authenticated jokes from an authenticated Redneck.

The popularity and influence of Larry presents difficulty. Momentarily accepting Larry as some kind of "actual" redneck, he can be viewed as the sort of individual who through most of the scope of American history would fall under the category of what Matt Wray calls "stigmatypes." These are "boundary terms that simultaneously denote and enact cultural and cognitive divides between in-groups and out-groups, between acceptable and unacceptable identities, between proper and improper behaviors" (23). Larry, of course, falls onto the negative side of that equation, as the contemporary iteration of the rural fool. He is the base and valueless country bumpkin that has long been discarded or, more, has long reminded struggling white Americans that at least someone has it worse off. Conversely, Larry also fits into the pattern of characters that warn Americans about the danger of discarding capitalist ethic. Jerry Williamson identifies this function of the hillbilly image: "[I]f, in other words, capitalism has indeed 
learned to control our collective imagery for our own good ... then clearly the hillbilly fool is a warning, a keep-away sign enjoining us to avoid the rocky rural edges outside the grasp of the urban economy" (27). Larry would then be reinforcing the role of the hard worker, tacitly encouraging the audience to leave the show and get back to the office or job site.

Corporate support isn't fully the case, though, as the audience on display in The Blue Collar Comedy Tour clearly identifies with Larry instead of viewing him as a warning. They aren't him, exactly, as Larry's clearly an exaggerated version of the Redneck, but the audience nonetheless laughs alongside him. The comedian is an actor, the identity a hyperbolic put-on, and this is a position the audience likely understands. Yet the artifice on display nonetheless invites them to participate in the comic ideology. Many of those in attendance wear the same Confederate battle flag hat that Larry does, and many sport his ubiquitous "Git'r done" slogan on their shirts. To take a generous view of this audience identification, Larry could offer a counter-cultural image for rural Americans. He offers a means of resistance to standards of decency, middle-class values, and political structures that work to oppress the rural working poor. More realistically, Larry fits into the kind of persistent redneck image that Duane Carr identifies, that of the redneck racist, the anti-civil rights figure that offers an explanation and support for continuing racism (8). That role explains the ubiquity of the battle flag on Larry's hat and guitar, and it explains why the more-or-less exclusively white audience likes to 
laugh at his jokes. Larry makes it safe to support racism and deny other "politically correct" values, since Larry's the one making the outlandish statements. Championed as the mighty Redneck resistance against the dangers of an America gone soft, Larry speaks the "truth" that the audience wants to be able to utter in their daily lives.

Just as he serves as unfettered vocal id for his audience, Larry also presents the possibility of identity. He models a middle-class masculinity that Jon Smith calls "an attempt to alleviate a bourgeois sense of having no (masculine) identity at all. There has never really been a viable middle-class southern white masculine identity ... so that class has been forced to to ape the signifiers of those above and below it" (87). Moreover, as Bill Malone argues, the contemporary redneck comic figure offers a way for a contemporary generation of former rural poor to reconnect: "More and more, the children of southern working folk ... live in suburban areas and preserve their rural contacts by purchasing from the L.L. Bean and Land's End catalogues, by taking occasional camping trips in state parks, or by driving Land Rovers or other SUVs" (204). In the case of Larry, an individual adopts the harsher identity of a stereotypical, hateful (but jolly) redneck comic creation. Certainly, a fundamental geographic difference lies beneath the choice to wear L.L. Bean field pants and to don a Larry the Cable Guy ball cap: the first reads as particularly Northeastern and the latter as particularly Southern. Still, each exposes a desire to artificially connect with a perceived history of rurality. Malone's argument adds an intriguing layer to the search for common identity. In 
suggesting that suburban Southern individuals might adopt symbols of Northeastern upland hunting in order to participate in rural history, he also suggests that Southerners representationally link themselves to the North. As the geographic region that lies at odds with Southern regional identity, such a Northeastern identification forces the middle-class to accept the power of the North over the South.

Larry offers an apparent antidote to that contradiction. His identity and sartorial choices are clearly not Northeastern. Those who adopt his image are clearly not the kind of elite weekender of the L.L. Bean model: Larry models "Southern" in a narrowed but clear way. Larry, in fact, combines several identity motivations at once. He offers identity as rural, as working class, as Southern. As a bonus or, in fact, truest motivation, he reasserts the racial superiority of whiteness and the societal dominance of longstanding hegemony. Larry is The Man, dressed in a ragged sleeveless shirt.

What I find most intriguing about the Blue Collar Comedy Tour is the way that this limited vision of both the working class and of Redneckism itself speaks to a narrowed interpretation of mainstream America. Consider the stage set, positively redolent in the residue of "normal" American nostalgia. This is the America we're all supposed to wish for, the idealized past that may never have been but that nonetheless we should all strive to recover, an America explicitly cast within the prairie hues of a flagrantly mainstream whiteness: this is the America of the Redneck ideal. But since this version of America is also portrayed as a rendition of the blue-collar America, it also suggests that 
the American working class comes from the same imagined space. Thus the stage set and comics of the Blue Collar Comedy tour show how "'working class' is code not just for ... any culture but specifically white, male culture. The working class is, objectively, a multicultural and gender neutral rubric, but, in both the public mind and most of the history of organized labor, it is sadly a term largely limited to white guys"' (Cowie 11).

Further, even while labor critics recognize the limitations of this narrowed view of "blue-collar," the humor of the show belies its ideological work. Critic Anna McCarthy suggests that the stage show and subsequent TV program demonstrate a "lack of access to the social power associated with white privilege" (136). She interprets the popularity of the show as a response to a perceived powerlessness within the identity category presented on stage: the blue-collar rednecks of this program are not empowered by whiteness. The concealment of power, in fact, is the greatest trick of the show. Blue Collar Comedy carries the power to align white privilege with a narrative history of rural poverty. The seeming lack of sophistication of the humor lets the comics off the hook. The seeming innocence of fart jokes conceals the strong social work the show does in reifying the "redneck" version of real life. Yes, Larry's a stereotype and a send-up, but he also becomes a model. ${ }^{20}$ People do kind of want to be him. Or at least do kind of want to say what he says. Since we discard the validity of the show and

\footnotetext{
20 It is both interesting and significant to note that "Larry" is actually a full-time character for a comic who formerly performed as Dan Whitney. As Whitney, he presented a peripatetic but mainstream identity; Larry was only part of the performance. The role's viability eventually led to the consumption of Whitney's actual persona by Larry. Footage of Whitney is available on YouTube. CBS's 60 Minutes offers a good overview of the Larry phenomenon.
} 
assume it's just bumpkin, low-brow humor, the Blue Collar Comedy Tour can effectively aid the Redneck identity's assumption of power. In this sense, Larry the Cable Guy works in opposition to even the faux-populist moments of Burt Reynolds's Gator, offering not even a veneer of gender or racial equality.

Larry criticizes the Dixie Chicks, for example, attacking their opposition to George Bush directly on his DVD saying, “I think they're pretty girls. I think they're good singers. But I think the little fat one needs to shut up, is what I think needs to happen." His crowd loves the sentiment. Those in attendance cheer still louder when Larry explains that the problem with the Dixie Chicks is that they fail to understand how their country music crowd doesn't appreciate anti-American argument.

Suffice it to say that Larry is right: his criticism receives such applause precisely because the Dixie Chicks didn't act as they were expected, didn't follow the conservative guidelines that Bill Malone has recognized as firmly entrenched in country music since the 1960s (45). But for Larry the criticism takes an interesting twist. In a way, while the audience takes his criticism as indignation at the horror of the Dixie Chicks's personal philosophy, Larry instead may be criticizing their business acumen. The Dixie Chicks failed to understand how the redneck image he portrays is in fact at the service of a particular agenda of national identity: jingoism, patriotism, patriarchy, and all that is dear to this new, negatively idealized Redneck nation. Or, to grant theorist status to punk / country singer Hank Williams III: “'They say Nashville, 
Tennessee is Country Music, USA, but I don't hear no Merle Haggard or George Jones or Johnny Cash or any of the legends on the radio anymore.... All they care about is money — that's all it's about, really. Nashville is putting out a bunch of shit" (Azerrad 38). While I will suspend detailed discussion of the Dixie Chicks's criticism of Bush until a later chapter, Larry's criticism of the band engages the crucial economic motive of America's new pro-Man version of the Redneck. The identity is not just a way to fit into an American racial majority; it is also a way to fold that identity into profit. In tweaking identity to maximize profit, Larry's version of the Redneck ignores the full scope of country music to emphasize that which is most economically useful. His criticism of the Dixie Chicks relies on a narrowed view of country music as only conservative, only masculine, and only "patriotic" in the ways of the Man. The real complexities of both rural identity and country music identity would introduce distracting dissonance to the sort of Redneck image Larry sells. So Larry's Redneck rewrites history to ignore such inconvenient multiplicity.

Larry functions as a way to maintain the narrowed scope of the Redneck identity. He reifies the status of the white, hetero male while demonstrating the cultural valence of the redneck image. But he adopts this persona because it is financially viable, just as politicians and country musicians, wrestlers and average Americans have become selfidentified Rednecks because it is politically and culturally viable, which is to say financially lucrative. As Robert Hauhart argues, "the (Blue Collar Comedy) Tour is, at 
heart, a consciously engineered, demographically targeted, commercial vehicle" (274). This profit motive for the identity category aligns with the 1970s model redneck, since Burt Reynolds movies were certainly made for cash and not high art. And it is this profit motive that, in fact, helped push the progressive potential of the 1970s redneck into the corporate, nationalist, conservative contemporary version of Larry the Cable Guy. As Jefferson Cowie has argued, the labor strikes of the 70s were complicated by the gender and race pressures of the era (12). The rigid identity positions of masculine America disrupted the potential for economic liberation. Faced with the perceived pressures of feminism and growing civil rights, the male dominated core of working America balked at continuing progress. As a result, the sort of contemporary neoliberalism that Lisa Duggan argues has been the fundamental political philosophy of the late twentieth and early twenty-first centuries found the means to establish new American values of big business, privatization, and winnowing social democracy. Duggan argues that neoliberalism "organizes material and political life in terms of race, gender, and sexuality as well as economic class and nationality, or ethnicity and religion" while also working to "actively obscure the connections among these organizing terms" (3). This move toward regressive neoliberalism opened the door for the assimilation of the redneck category as a tool for conservative economics and general hegemonic reassertion. Double pressure links the shift of the anti-Man redneck to Redneck as Man. Since the American working class male was fighting the power of big 
business on one front and the infiltration of their ranks by women and minorities on the other, the conflation of the Redneck and the Man became easy. The revolutionary power of the underclass activated the anti-progressive undertones of race and gender, allowing for an easy shift to a pro-Man Redneck form that fought gender and racial equality and economic liberation.

The shifting allegiance of the Redneck identity echoes the form of Richard Hoggart's foundational examination of mass culture. While Hoggart argued that English working-class culture offered authenticity through its grounding in the lives of workers (The Uses of Literacy), the Redneck identity applies a sheen of authenticity to the very mass culture infiltration that Hoggart decried. In fact, the shift of the Redneck identity I have been tracing in this chapter allows mass culture to appear in the clothes of the working class and therefore more easily create disruptions in the autonomy of the actual working class. Hoggart's cultural elite pose as the Redneck, which in turn allows Duggan's neoliberal agenda to function seamlessly: adopting the low-brow form of the Redneck lets the amorphous social-political normality of America sell itself as intrinsically basic and, therefore, part of national culture. Redneck normality appears blue collar, creating an authentic simplicity for the values being sold. But Redneck normality comes about through the act of power pretending to be powerless. As a result, the Redneck urges every American to pretend to be basic, and in so doing he encourages every American to adhere to the social constraints of the stereotypical 
redneck. Figures like Jimmy Wang Yang and Larry the Cable Guy function as agents of mass culture, pretending to be working class rednecks while silently espousing the retrograde social standards that maintain the status quo of American hegemony.

The "blue collar" of the Blue Collar Comedy Tour further reveals itself as misleading in the context of working class economics. As Cowie argues, the deeply-entrenched world of blue-collar conservatism works for one simple reason: class in America today is a cultural category not an economic one. It's Marx on his head. In political and popular discourse today, the American working class doesn't have an economic identity as much as it has one defined by culture, race, and gender. It is swirling in a galaxy with guns, God, whiteness, NASCAR, flags, country music, and war, all mobilized to give the illusion of an attack on privilege and power. (10)

So the comedy of the Blue Collar comics doesn't so much offer the audience a way to, as Hauhart argues, "look down on those socially below them while inoculating themselves from competing for social and cultural positions above them — which, they know, will forever elude them" (278), but instead offers a facsimile of this sort of underclass. The audience isn't really powerless at all, just as the characters of the comics aren't really downtrodden rednecks. Instead, the Blue Collar Comedy Tour makes the Redneck the purveyor of authenticity and political power. 
The history of "Redneck" as a term or even looser concept is tied up in notions of this kind of authenticity. As Anthony Harkins argues in relationship to country music, the allied label of "hillbilly" has shifted through time from a phrase intended to debase music as inauthentic to a contemporary declaration of freedom from commercial influence (101). Moreover, as Richard Peterson suggests, "identification with country music today is like identification with an ethnic group.... Indeed, being a fan of country music and its associated way of life may serve as a way that millions of people of mixed ethnic identity can express their imagined place in society against urbane corporate ways and in distinction from other nation- race- and religion-based ethnic identities" (218). I'm extending that phenomenon beyond country music, beyond wrestling, beyond popular comedy to complicate the very notion of American authenticity and inclusion. In fact, the very idea of "country" — in music, visage, comedy — becomes synonymous with a core ideal of American identity. The state of being country, of being verifiably Redneck becomes a new normalized economic ethnicity. As with Larry the Cable Guy's criticism of the Dixie Chicks, this new Redneck form sublimates issues of race, class, and sexuality. As a result, long-dominant modes of whiteness, wealth, and heterosexuality are constantly reasserted as natural states. Here again, the function of Larry the Cable Guy follows the tracks of Duggan's neoliberalism: hegemony is carefully maintained by pretending that minority issues are being dealt 
with by the state, leaving the door open for Larry to help the state reassert convenient power structures.

Through this neoliberal lens, being Redneck does not so much open up the doors of inclusion and national participation to members of varying ethnicities but, instead, suggests a route through which individuals can abdicate their memberships or identities as visibly minority ethnicities to adopt the ethnicity of America. The Redneck consumes the foundational American of Natty Bumppo to equate purified citizenship with a heavily-accented, crass, anti-progressive. In this new form, Bumppo would not fight the British alongside the American Indian but would, instead, pretend to be an Indian in order to help the British assimilate the natives back into the royal brood. Moreover, the contemporary Redneck identity cinches whiteness to all racial and economic categories, preserving for America a baseline of racial purity and presenting resistance against the influence of outsiders. Further, the identity naturalizes identity, diminishes the divide of rural versus urbane because the Redneck ceases to be a rural construction. Urbanity itself falls under the umbrella of the Redneck, ruralizing all of America and offering a tangible link to the imagined past of a mythic frontier nation.

In this sense, the idea of the Redneck — of Jimmy, of Larry, of Burt — harkens back to resistance, to a refusal to play the game of polite America. It offers an exterior vision of the outsider, of the noble individual refusing to play by the rules of the oppressive state. Redneck therefore suggests a rugged American individualism. Yet the 
identity functions in precisely the opposite way, making use of the toil and uncertainty of life as a "real" redneck — of the life of the rural poor — to transform privileged middle- and upper-class white America into a protected realm of ideology. The Redneck adopts the troubled but now sanitized past of the rural poor to support the modern ideals of Redneck America, to insulate itself from the criticism of conservatives who would find suspicion in the allying of an individual so clearly in need of public assistance. Conversely, the Redneck makes itself immune to the criticism of liberals, since the Redneck is positioned as a member of the downtrodden working poor. In one fell swoop, the Redneck becomes a liminal figure who can work in the best interests of the status quo. The Redneck becomes an idealized history functioning in the present, a living testimony to the hardscrabble life that never was. More, he has been reconceptualized as a noble struggler against the strictures of the British colony on the frontier, against big government, against loose radicals like the NAACP, the Democratic party, and any who seek general social justice. 


\section{Chapter Five: Normal, Side Two}

When Natalie Maines spoke into her microphone in the spring of 2003, the crowd at London's Bush Theatre responded with cheers. Said Maines: "Just so you know, we're on the good side with y'all. We do not want this war, this violence. And we're ashamed that the president of the United States is from Texas" (Shut up and Sing). Uttered in the middle of the build-up to Iraq War II and its concurrent patriotic swell, the perhaps inevitable American public response struck Maines's group, The Dixie Chicks, from the top of the country music charts. The response also drove them from the good graces of country music fans across the United States and lingered for years in the form of reduced attendance and weaker album sales. Opponents were incensed that Maines, and by extension the full trio of the Dixie Chicks, openly criticized a wartime president. Vocal critics saw the comment as nearly an act of treason, particularly since the words were spoken abroad to an audience who likely needed little encouragement to disagree with the policies of George W. Bush.

From a broad and simplistic cultural perspective, the Dixie Chicks's anti-war stance seemed to lay in stark contrast to the implied common values of the dominant conservatism of the country music market segment, and the musical group was therefore villainized for failing to adhere to those ideological standards. Moreover, at stake for the vocal opponents who effectively barred the Dixie Chicks from country music radio and who discarded or destroyed old albums en masse was the nation itself. 
Criticism of Bush extended to criticism of the war extended to criticism of the troops. And that, in turn, suggested a chink in the thematic armor of patriotism that previously had seen more or less unbroken popular defense in mainstream country music. The Chicks's criticism of George W. Bush implied a weakness within the resolve of a citizenry who in turn demanded immediate and sure response. Thus the Dixie Chicks were figuratively cast out of the nation of country music, were stripped of their citizenship and recast as dangerous outlaws, but not the good kind that popularized country music in the $70 \mathrm{~s} .{ }^{21}$ In fact, even as the The Dixie Chicks returned in 2007 to sweep the Grammy Awards, winning in five categories including Album of the Year and Best Country Album, it is notable that their success did not come within their "home" community of the Country Music Awards. The outlaw Chicks had not been with the president and were therefore against America; worse, they were not with mainstream country music and were therefore against the dominant philosophies and codes of action that function within contemporary Redneck America.

On stage in England, the Dixie Chicks likely exercised a moment of real reaction: Natalie Maines truly felt embarrassment at the actions of her president. But the followup reaction to her comments quickly returned to a baseline of artifice that functions within contemporary culture, a fake reality that Guy Debord argues "presents itself as an immense accumulation of spectacles. All that once was directly lived has become

\footnotetext{
${ }^{21}$ No book offers better background on this "outlaw" surge in country music than Jan Reid's The Improbable Rise of Redneck Rock.
} 
mere representation" (12). More directly, the reactionary expulsion of the Dixie Chicks demonstrates how that spectacle appears at once as society itself, as a part of society and as means of unification. As a part of society, it is that sector where all attention, all consciousness, converges. Being isolated — and precisely for that reason - this sector is the locus of illusion and false consciousness; the unity it imposes is merely the official language of generalized separation. (Debord 12)

The collective response of the Dixie Chicks's critics organized under the demands of the false consciousness of the Redneck identity. A vocal segment of America struck back against the perceived threat of the music group precisely because the Chicks presented a fracture in the constructed unity of the Redneck national model. Country music serves as an anthem for this version of America, as the form outwardly celebrates and shares the common ideals that the Dixie Chicks apparently defied.

In failing to follow the limits of Redneck spectacle, the group similarly failed to adhere to the parameters of an idealized America. As Andrew Boulton puts it, "Country music's representation of 'heroic Americans' is part of a wider context in which American foreign policy is, on occasion, reduced to the level of the individual and understood in terms of personal objectives/bravery/integrity evocative of broader national values" (382). It is by following that mode of external patriotism that 
individuals enact citizenship and prove their fidelity to the nation, and it is through these images that the U.S. sees itself. More, overt patriotism allows the U.S. to separate its citizenry between the proper and the suspect. Under this system of classification the Dixie Chicks, of course, are suspect.

Up to this point, I have argued a progression of the Redneck icon in American culture that is traceable through literary and cultural artifacts. I have argued that the image itself has undergone a subtle shift that leaves intact the most visible signs of identity. As a stock image, the redneck is one of America's most enduring and most easily recognizable icons. But over time, the functional interpretation of that stock image has undergone tremendous ideological shift. Working from a baseline of the degraded rural poor, the Redneck became a champion of resistance in the 1970s, whose hegemonic inertia collapsed back toward the mainstream in the twenty-first century. As such, the contemporary exertion of the Redneck aligns easily with the requirements of a longstanding cultural dominance, and it offers a way for the American hegemony of mainstream masculine whiteness to maintain primacy in the national culture. In this chapter, I turn to the rigid control that the Redneck makes possible. Thought the texts I examine here are explicitly feminist and the control enacted to prevent feminist action, I do not intend to engage already familiar patriarchal arguments. That is an American condition long ago proven. Instead, I employ these texts as a lens to consider control itself. The key idea is how the Redneck defends hegemony, and not how that hegemony 
has come to pass. Simply, all individuals must acknowledge, deal with, and in some way follow the Redneck image in order to access or inhabit unquestioned American citizenship.

This mutable Redneck image is undoubtedly a function of mass culture. It is a figment created by an amorphous cultural system to address equally spectral hegemonic conditions. Theodor Adorno presages the Redneck construction when he discusses cultural production:

As a focus of regression mass culture assiduously concerns itself with the production of those archetypes in whose survival fascistic psychology perceives the most reliable means of perpetuating the modern conditions of domination. Primeval symbols are constructed on the production line. The dream industry does not so much fabricate the dreams of the customers as introduce the dreams of the suppliers among the people. (80)

The Redneck is, in fact, American primevalism. Imbued with power by its relationship to an American literary icon, the Redneck functions as an obtainable dream to the masses. It is a dream sold to Americans, who take up the identity because of its attractive national image. Yet while the Redneck is supplied with power by stereotypes that align with core American individualism, it is also controlled by its baser aspects. Anyone who claims to be a redneck therefore accepts status as a degraded individual. 
In turn, degraded individuals must submit to domination by some great unspoken "better" American or America. Individuals are attracted to the Redneck identity because it is not the mainstream, but in assuming it they become beholden to the mainstream. ${ }^{22}$ By adopting an external or internal allegiance to the Redneck, individual Americans become cultural seams of humanity ready for mining by the corporation of hegemonic stasis. Or, as Adorno tells us, "the commercial character of culture causes the difference between culture and practical life to disappear" (53). In becoming ideologically Redneck, Americans abdicate the right to make the kind of authentic critique that Natalie Maines uttered at the theatre near Shepherd's Bush. Staying Redneck requires unflagging attention to subordinate positions.

This ideological function is exactly what the Dixie Chicks threatened to destroy. The band battered the solidarity of a Redneck Ideal by acting from within the downtrodden culture in opposition to the leader of the feigned Redneck culture. Martie Maguire of the Dixie Chicks read it best: "It had to be somebody or some group that seemed like the All-American girls. It was perfect. It had to be the unlikely voice from what looked like the conservative heart of America saying it. That was perfect" (Shut Up and Sing). Their greatest threat to the Redneck identity was to disrupt the ideological image, to prove that the so-called "conservative heart of America" was a constructed

\footnotetext{
22 Adorno also presages the way a degraded vision of the American redneck becomes a national icon: "Sometimes such stereotypes are disguised as national American traits.... This way of reasoning is an insult to the American spirit. High-pressure publicity and continuous plugging to institutionalize some obnoxious type does not make the type a sacred symbol of folklore" (149-150).
} 
heart. They revealed just how the nation hails its citizens and dictates a particular way of being. That an All-American girl group could, in fact, break from the typical standards of Redneck decorum revealed the artifice of the spectacle, which in turn called into question the accepted parameters of citizenship.

Interestingly, even as the Dixie Chicks create that disruption, they cannot help but be bound by the spectacle. The documentary Shut Up and Sing chronicles the group's actions following their controversy and is clearly intended as a remediation of their image or, more, as defense of their position. But it also places the women in the group inside a feminine ideal. Each is portrayed as mother, as wife, with many family scenes prominently featured. The point seems to be that the Chicks were unduly cast as rabble-rousers, that they actually fit the American ideal. Such is the power of the spectacle: even those who break free from it find themselves inescapably written in. Those who threaten the illusion must be written back into the Redneck narrative.

In revealing the constructed nature of America's rural icons, the Dixie Chicks also violate the representative history of popular country music that has long been aligned with definitions of "true" America. ${ }^{23}$ These core concepts are entrenched in the wide open spaces the Dixie Chicks sing about, as well as with a baseline simplicity perceived as core to American identity. As Bill Malone suggests, "ruralism linked country singers to the nation's most cherished myth, the deeply held belief that our country began its

\footnotetext{
${ }^{23}$ See Richard Peterson's Creating Country Music and Bill Malone's Don't Get Above Your Raisin'for a more extensive examination of country music and its identities.
} 
existence as a republic of rural virtue" (23). Moreover, he suggests that even while performers haven't always embraced the rural iconography and identity that the industry's marketing has relied upon, the genre has nonetheless continued to do heavy theoretical work for the consumers of the music: "Although increasingly regionless, classless, and suburban in residence and values, these young, affluent, mobile listeners wanted a music that seemed to embody the qualities in which contemporary America seemed deficient: community, family values, and down-to-earth simplicity" (86). Similarly, Richard Peterson argues that early country music from the 1920s fit into a broader cultural response to "a widespread fear of the loss of white Anglo-Saxon Protestant hegemony in American political life and culture;" thus the genre was put to use in the effort to popularize and reinvigorate a traditional white stranglehold on American cultural capital (59). Seen together, these two elements of country music history suggest a genre that is hard to separate from concepts of American normalization. That is to say, the music itself offers plenty of protest and progressivism, but the music functions as a barrier or alternative to the growth of less quintessentially "American" forms. More, a certain notion of America is reflected in this narrow version of country music.

This is the version of America that the Dixie Chicks threatened through their criticism. This was their gravest violation of the American Redneck spectacle. Viewed in this context, the issue of patriotism looms largest, both overtly as a mechanism for 
displaying one's allegiance to a national power and covertly as a sign of acceptance of the ideals of the less-tangible Redneck identity that defines contemporary American political/patriotic discourse. Maines violated patriotism and America by choosing to be "not-with" the nation.

The spectacle I'm suggesting requires fidelity to the national power as evidence of membership in the ideological Nation, just as full citizenship in the Redneck discourse predicates unwavering allegiance to the U.S. government. It is therefore unsurprising that in the wake of $9 / 11$, several country stars released hyper-patriotic songs that tapped in to the general American sentiment of shock, anger, and even warreadiness: Clint Black's "Iraq and Roll," Alan Jackson's “Where Were You (When the World Stopped Turning)," Darryl Worley's “Have You Forgotten," Chely Wright's "Bumper of my SUV," and of course Toby Keith's aggressive "Courtesy of the Red, White and Blue". ${ }^{24}$ Each of these, in its own way, followed the accepted guidelines of the Redneck identity, as each song conveyed a message that expressed emotions and reactions proper for the idealized American citizen.

The shock, anger, and latent desire for retribution fit the national zeitgeist perfectly, just as it fit the acceptable conservative parameters of the Redneck spectacle in operation. Keith, in fact, became an anthem-writer for the American troops. His melodic desire to stick a boot in the collective terrorist ass was soon adopted as an unofficial

24 See Chris Willman's Rednecks and Bluenecks for a more detailed explanation of these songs and their function in country music's patriotic reaction to $9 / 11$. 
fight song for the nation. Keith himself seemed plenty willing to wave the flag, support the troops, and act the part of the ideal, masculine, aggressive, hetero citizen — an angry white man ready to do battle for the good of the nation. Significantly, Keith and Maines fell into a war of words after the Shepherd's Bush incident, further confirming Keith's patriotism and the Chicks's treason. Keith understood that the great violation of the Dixie Chicks was to ignore the way that the nation's enemy is defined, in country music, both as a place in the world, out there, separate from America, and in more human terms as groups of individuals and a set of values, differentiated from Americans and American values. The "place" of the War on Terror — the enemy — in post $9 / 11$ country music is not, however, just "out there." Simultaneously with America's enemies being brought to justice abroad, there is a battle at home too. (Boulton 377-78) The Dixie Chicks spoke out publicly against the battle "out there," which immediately cast them into the category of those who needed to be battled on the home front in order to preserve proper Redneck patriotism. Even as support of the ongoing war in Iraq declined, the determination for "true" Americans to support the troops, to display fidelity to the homeland, to emphasize and defend good old-fashioned American values, remained steadfast. Put another way, Chevy truck commercials were (and are) still on the air, a country music soundtrack in tandem with waving American flags. 
The greatest function of the Redneck spectacle emerges because of a seeming validity to its standards and limits. It is crucial to note, however, that this validity is only apparent. There is only seeming fidelity to a seeming set of standards. That is, some Chevy truck commercials now use John Mellencamp as soundtrack, and he is a figure associated with actual progressive rural politics like Farm-Aid. But the ads seek to evoke a patriotic response ("this is our country") aligned with Toby Keith flag-waving and pro-war jingoism instead of government and private help for struggling family farms. Similarly, Keith himself is a more complicated figure than the apparent simplicity of his pro-war image would suggest. He's a Democrat, thus at least nominally liberal and not wholly in line with the pro-Man Redneck forces.

On an on, then, the "seems" of the Redneck spectacle works to conceal the hidden complexities of the world. Country music isn't necessarily conservative, for example, its history not really locked up in mass-market conservatism. But the Redneck spectacle makes it seem that way, conceals the complicated, multifarious, and diverse catalog of ideas and individuals that make up the genre. The spectacle encourages the knee-jerk reaction, seeks to flatten the world to dichotomous responses. You support the war, or you support the terrorists. You wave a flag, or you're unpatriotic. You drive a truck, or you're a pansy city-dweller. In the world beckoned by the Redneck spectacle, divinations of citizenship are easy. The inherent complexity of reality is riven to feigned 
simplicity, with a seeming purity of Redneck imagery left in the rubble. Standards are clear: you're Redneck or you ain't.

Prior to Shepherd's Bush, the Dixie Chicks fit just fine into the standards of the Redneck spectacle, precisely because they professed their fidelity to it. The Dixie Chicks offered apparently feminist anthems like "Goodbye Earl," a song that claimed "that Earl had to die" because of his spousal abuse. The song outlines the violent reaction of a woman stuck in a cycle of abuse, but the group's gender politics could be ignored because of the careful exertion of Redneck image. Prior to the 2000 release of "Earl," the Dixie Chicks had already established their properly feminine credentials. Their debut video "Cowboy Take Me Away" offered little of the sly undercutting of trope present even within the band's name. That video offers steady images of the women in the group as somewhat interchangeable objects of masculine desire. The lyrics themselves participate in an invocation of traditional gender role, with Natalie Maines crooning that she wants to "sleep on the hard ground in the comfort of your arms," and calling for a mythical cowboy to take her away from the tall buildings of a nameless city. At once, the song taps into an urge to seek in rurality the freedom lost in urban life, a longstanding use of country stereotype, and the desire for a subservient female figure in need of a strong man.

More importantly, the images of the video do nothing to suggest subcultural resistance. The first shot is a close up of a blue eye, giving way quickly to hot pink boots 
stepping into a puddle. Throughout the video, the singers smile at the camera and invite all viewing cowboys to, in fact, take them away — not-so-veiled invitations to take the singers as feminine possessions. Furthermore, camera angles offer frequent cleavage shots of Maines, who wears a red bra trickling out from the edges of a low-cut black sweater. There's little subtlety in this invitation. The escape from the city to the country aligns with a desire to escape from sterile feminism to the excitement of sexualized cowboy lover.

By the time "Goodbye Earl" arrived on the airwaves a year later, the preceding images of sexualized femininity, of pretty girls singing pretty songs, had established an ameliorating normalcy to the Chicks's image. So even while the lyrics and themes of "Earl" call for violent reaction to spousal abuse, the band's image mitigated the song's potentially unsettling resistance. If that wasn't enough, the stylized presentation of the associated music video works to render safe the worrisome notion of feminine revolt. The video foregrounds its fantasy by opening with titles and actor credits, which include familiar faces: Dennis Franz as Earl and Jane Krakowski as the abused Wanda. Thus the video immediately casts itself deeply into the category of fiction, softening the tones of the song. Further, the video puts on display a series of hyper-stereotyped white trash images: Earl wears an artificial mullet, sports a sleeveless sweatshirt, and drives a Dodge Charger that echoes the campiness of TV's Dukes of Hazzard. Wanda, for her part, dons a tacky airbrushed hoody while walking around the couple's trailer home. The 
exaggeration reaches a crescendo in the hospital room when friend Marianne witnesses the violently wounded Wanda. Here, the overly peppy gait of the actors coincides with saturated colors to soften a truly grotesque bruise on Wanda's face. This, notably, is the moment when the women decide that "Earl had to die."

The Dixie Chicks complicate their image in this video, as its overblown feel certainly invites a reading as commentary on the way spousal abuse is typically given less credence than it deserves. Likewise, the video shows the women braless in front of the police, where their overt display of sexuality seems to defend them against deep investigation of Earl's whereabouts. The Chicks may indeed be, perhaps likely are, tweaking the pretty girl image of their first video. They show how the restriction of sexuality can be reactivated by the subordinate figure to exert resistance. However, the final moments of the video short-circuit the full critique of patriarchy, as Earl literally cannot die. In the final super-camp scenes beside a roadside stand, Earl's corpse dances around zombie-like, neither alive nor dead. Significantly, he cannot be removed from the scene, since that would suggest that the Dixie Chicks really were supporting violent resistance. A truly dead Early would defend a version of femininity that could imagine itself as free of masculine presence. Instead, Earl's permanence in the video simultaneously renders safe the revolutionary lyrics of the song and reasserts the lingering presence of patriarchy. The Dixie Chicks in this song sing about real strength in resisting abuse, present winking resistance in the campy nature of the lyrics and 
video, and exert redneck justice through law-in-your-own-hands response. But because of their prior body of work, the Dixie Chicks still seemed safe enough: the dancing corpse makes it okay for women to "joke" about murdering an abusive husband.

But then came Shepherd's Bush. Even as the Dixie Chicks's feminine presence, mainstream beauty, and maternal status fit the proper conditions of the Redneck identity, in going off-book by criticizing the president and his desire to go to war, the band exposed themselves as actual deviants in the Redneck nation. Their resistance immediately called into question their status as citizens. They were quickly condemned as poseurs to the Redneck identity and summarily evicted once their comments proved their failure of ideological adherence. Since the "spectacle is not a collection of images" and is instead "a social relationship between people that is mediated by images" (Debord 12), the previous credibility of the Dixie Chicks fell aside at the moment that they violated the accepted social contract of Redneck America. The spectacle must at all times support the maintenance of preexisting conditions. The Dixie Chicks sought to offer a counter-narrative incompatible with the Redneck spectacle; therefore, they had violated the social relationship of that mediated image. So they had to pay.

As much as the popular criticism of the Dixie Chicks revealed a heavy dose of Redneck norming within a narrow definition of the limits of American country music, 
stock car racing offers an immediate and obvious external allegiance to the strictures of redneckism I have been engaging. It is an intriguing branch of NASCAR-branded Harlequin romance novels that offeres finest example of how Redneck identity works to normalize long standing power structures. In their mere existence, these NASCAR romances imply a crossover popularity of stock car racing that defies the boundaries of mere fandom. More importantly, the novels show how Redneck identity works to keep in check the prospect of social renewal. The greatest threat the Redneck poses is to fulfill the promise of the 1970s resistance embodied in Burt Reynolds, or to gain national power and prominence as viable country feminists in the vein of the Dixie Chicks. But NASCAR romances reassert standard gendered lines to put back into line those who would otherwise offer a threat. As with Larry the Cable Guy's criticism of the Dixie Chicks, economic savviness links the genre to "traditional" values. The maintenance of these values implies the maintenance of economy. Thus, NASCAR romances help contain the potential resistance of people who might actually be considered "actual" rednecks. The books are one way to inculcate "proper" behavior in a potentially vital underclass. They are a way to prevent "real" rednecks from acting like the Dixie Chicks. Consider the base plot of Abby Gaines's 2008 Teaming Up: scientist Kim Murphy faces debilitating and potentially fatal kidney disease and, therefore, decides to follow a list of "10 Things to Do Before I Die" written in high school. Chief among those is the command to "Date a jock." As a result, she finds herself in a love affair with Wade 
Abraham, car chief within the Fulcrum racing team managed by Kim's crew chief father. Just as Kim finds love surprisingly (or not) blooming with Wade, Fulcrum coowner Isabel Rogers finds herself falling out of love with Kim's father and into love with the race team's main sponsor.

As far as romance plot lines go, Teaming Up offers little surprise, which is to say that it follows the clear guidelines of its genre. As Janice Radway identifies in her important book Reading the Romance, stock plots offer readers a way to quickly understand and participate in the narrative traditions that define the genre and, in fact, aid the reader in "the process of sign production where the reader actively attributes significance to signifiers on the basis of learned cultural codes" (8). Part of that process, in turn, allows romance novels to function as cultural capital, as primary sites for the ideological construction of individuals as gendered subjects, especially female ones, in male-dominated heterosexual couples. By producing the female subject as complemented and completed by her relation to a male partner, patriarchy naturalizes sexual identity, masking the cultural construction of the feminine, thereby continually reproducing women in a subordinate position. (Ebert 19)

While scholars like Tania Modleski have suggested that the subordination of romance novel heroines offers at least some possibility for the limited discarding of gender roles 
("The Disappearing Act"), ${ }^{25}$ it is the reproduction of subservient women that makes

Teaming Up a useful choice for my examination. Kim Murphy, as heroine, is clearly portrayed as less-than-fully female until she learns to participate in coded gender behavior. That, in fact, is the function of her list. Her growing understanding of properly feminine behavior functions beyond mere traditional gender coding. Instead, the book places Kim back into "traditional" roles as a means of maintaining the steady control of working class America. Just as Jimmy Wang Yang secures whiteness for the category of Redneck, Kim secures patriarchy. Each of these figures demonstrates how dedication to the Redneck identity yields social and economic benefit. And in so doing, each of these figures urges individuals to bracket their personal experience within the limits of proper Redneck behavior.

From the first moment of the novel, the reader learns that Kim will and must undergo a radical epistemological change. Immediately preceding the narrative beginning, Kim has been informed of the dire status of her kidney disease, and contrary to her apparent typical behavior, she has sought to deny rationality: "There's nothing to tell. Because for the first time in her life, Kim had chosen not to believe scientific evidence" (9). This early declaration of intellectual denial establishes a main strand of the book, that Kim will reject the successful life she has created to forge a new, more

\footnotetext{
25 There is a long and important scope of scholarship in the romance genre and popular fiction. Radway offers a thorough examination of the romance in Reading the Romance, and also of popular fiction in $A$ Feeling for Books. Radway, Modelski, and Ebert - who I cite in this chapter - certainly offer an incomplete catalog of this kind of genre criticism, but they nonetheless offer a primer of sorts. For further investigation of romance novels, also see Regis's A Natural History of the Romance Novel and Modleski's Loving with a Vengeance.
} 
satisfactory life elsewhere. As a scientist, Kim is "eminently qualified to analyze data and draw her own conclusions" (10). She is powerful in an intellectual sense but is not really qualified at life. Because she begins from a position of feminine role violation as a smart girl the text implies irony: she can analyze data but can't figure out what matters in her own life.

This failure to understand life becomes clear in an early conversation with her father, Hugo, who chastises her for not being able to date men as smart as she is. Her intellect has prevented her from finding love. Kim admits this is true: "Of course, she wouldn't have the job she loved if she wasn't smart ... but momentarily, her mind drifted to the advantages of cute and funny over brainy" (12). These inner thoughts become a kind of thesis for the book, that being cute and funny is better than being brainy, if you have to choose. In contrast, masculine hero Wade is later portrayed as cute and funny and brawny, but he also understands Kim when she talks as an intellectual (33). The two characters therefore offer perfect contrast to the proper and improper manners of the Redneck. Kim begins the novel as a failed woman because she lacks the ability to mitigate her intellectualism. Wade is a pure and unflawed hero because he is both externally a redneck and because he doesn't flaunt his intelligence. A scientist, the book suggests, will always flaunt her intelligence. Therefore, Wade's redneck persona and biological masculinity create a safe space for his intelligence, and Kim must gain that sort of facade if she is to be successful as a full woman. 
It would be disingenuous to suggest that the kind of gendered world portrayed in Teaming Up is a surprise. After all, even while scholars like Radway and Modleski have identified potential female agency in romance novels, the genre itself cannot be separated from its traditional love tropes: strong man, subordinate woman. Precisely, as Teresa Ebert argues,

[t]he primary ideological function of all contemporary romance narratives ... is the use of desire to reassert the "natural" "inevitability" of female subjectivity and continually to recuperate those subjects — both heroine and reader — who slip out of femaleness into bigendered positions. In doing so, romances conceal and naturalize the difficulties and the precariousness inherent in the position of being constructed as what is not - not male, not having the phallus, not privileged — and effect a narrative resolution of contradictory gender identities, thereby suppressing the ideological incongruities that threaten patriarchal hegemony. (39)

Kim Murphy's list of "Ten Things to Do Before I Die" exists in Teaming Up as the clarified route to the satisfaction of the gender-bending early pages of the novel. Kim begins as a successful woman in the male-dominated world of science. Her intellectual role immediately creates dissonance in the expected patriarchy of both the romance 
genre and, more importantly, the stereotyped masculinity of the NASCAR sub-culture. The list offers a guide for Kim and all potential feminists, showing them the way to pledge support to the Redneck. In turn, the list encourages working class readers to resist liberation that might threaten the status quo. Masculinity is reasserted not just for simple reasons of gender. Instead, masculinity becomes part of a core American identity and a safeguard for a properly subordinate working class.

This latter aspect of masculinity, in fact, lies at the heart of all the subplots of the novel. Problem one is Kim as scientist. Problem two is her cousin Rachel, recently promoted to engine chief of the race car at the center of the story and Wade's prime competitor for a promotion to crew chief. Problem three is Isabel Rogers, a single woman of advanced age who co-owns the Fulcrum Racing team. Each of these women threatens the balance of working class gender roles, and each requires narrative resolution to normalize their positions. For Kim, the list offers a route away from patterns of lonely masculinity into proper subordinate femininity: dating a jock and wearing a push-up bra.

In totality, the list demands that Kim:

1) Play hooky

2) Buy a push-up bra

3) Get a tattoo

4) Get drunk 
5) Be the life and soul of a wild party

6) Drive a stock car

7) Date a jock

8) Make out at the movies

9) Dump the jock

10) Find Mom

In narrative, the list appears among high school mementos: "A sheaf of straightA school reports reflected her accelerated progress through high school. She'd graduated at fifteen, moved on to Duke University. No prom photos, no pressed corsages, no love letters" (14). The list appears among signs of Kim's lack of "normal" high school experience which are, no doubt, meant to be shocking. She is the poor nerdy girl. Smarts denied her love even in high school. Thus the problem of intellectualism and, particularly, female intellectualism is a lack of options. You're either lonely, or not an intellectual. The novel, in turn, offers an exploration of the difficulty of salvation for the girl intellectual. For example, \#3 on the list creates a problem of imagination, as Kim "envisaged a cell division diagram permanently engraved there. Or maybe a daisy" (20). This is the dichotomy of the book. Kim must go one way or the other if she is to follow the proper limits of Redneck America: narrowly girly or stereotypically nerdy. 
Kim's salvation comes quickly, though, when she decides to skip work and hang out at the track. Walking by the pits on this first day of the new her, she finds that her plan works well: "She glanced back over her shoulder after she passed by, saw the mechanic eyeing her bottom in her slim-flitting pants. Yep, this was where she needed to be to complete her list" (28). Kim finds in her own objectification the necessary key to womanhood. From a different perspective, the response to her pants and, later, to her push-up bra also maintains a rigid sexualization of masculinity. The attention of men is drawn without fail by slim-fitting pants. Even their attention to manly engine work can be disrupted by a push-up bra. Their responses rely on and reinforce stereotypical expectations of the jock and redneck - a lack of decorum, a willingness to ogle, an inability to ignore visual sexuality in all things.

In a sense, we're again on Tobacco Road watching the spectacle of Ellie May Lester scooting across the yard. Kim must reflect Ellie May, must create space for herself as a full woman by allowing herself to be viewed sexually if she is really to live. Further, it is the power of her push-up bra that allows Kim to eventually exert influence over Wade: "Dammit, could a new bra give her a whole new level of insight, of confidence? His gaze dropped to her T-shirt and he had trouble dragging it away again" (91). Kim gains power by becoming a sexual object. The new bra has given her new insight and confidence, has saved her from her intellectual self. Moreover, tight pants and push-up bras reveal how Kim must submit to sexualization in order to live at all. Completion of 
her list is narratively tied to her recovery from kidney disease. She must become a new woman who fits into the parameters of the NASCAR romance world and into the Redneck scripts if she is to survive. Kim must demonstrate for her readers that she has learned her lesson. Intellectualism leads to unhappiness and, in fact, death. Worse, intellectualism from the working class threatens the national paradigm, and NASCAR, and America. "Traditional" behavior leads to the embrace of the Redneck narrative and, in turn, the protection of the nation.

While Kim's redemption from loveless scientist to NASCAR bombshell scribes the main arc of the story, Teaming $U p$ works in total to set-up resistance to and finally resolve the "problem" of potential working-class revolution within the redneck world. As I referenced before, the two subplots of the novel engage issues of women seeking or maintaining power in this masculine world of stock car racing. As part owner of the Fulcrum Racing team Isabel carries the greatest power of any primary character in the book. But the novel also clearly establishes that ownership of the team is not enough for Isabel: "Standing next to Hugo made Isabel feel as if one day her world would be right again. Men like him — solid, capable dependable — were the backbone of NASCAR" (56). In her affection for Hugo, Isabel at once reinforces her subordinate position as woman and the mythic status of masculine NASCAR, masculine South, and general patriarchy. She needs him to feel secure, despite her wealth and power. 
By the end of the book, however, Isabel is spurned by Hugo only to find love in the hands of the hyperbolically masculine Clay Mortimer, owner of Turn-Rite Tools and chief sponsor of Fulcrum Racing. Clay is virile, sensually bald, physically powerful. He is properly uneducated but hardworking and, therefore, rich. He is a model Redneck, in fact. He displays a narrative of success within working class trope. He is a bootstrap myth come to life, but he is also a successful individual who poses no threat to national stasis. He pursues Isabel despite her attachment to Hugo, seeks marriage and the control of the novel's symbol of feminine financial success. In brokering a deal that equates his sponsorship of the team with Isabel's companionship, he turns her into a concubine to the racing team. Isabel becomes subordinate to stock car racing and to Clay, therefore defusing her dangerous feminine dominance. The potential of her power and economic force submits to Clay's masculinity, which itself is carefully constrained by working class cliché. As a result, Isabel as working class revolutionary becomes just another pretty face.

For a brief moment, Isabel appears to assert her power and resist the masculine force of NASCAR and hetero-normative marriage. She turns down Clay's first proposal (207). Even this initial refusal, however, implies that Isabel needs masculine NASCAR to be fulfilled. Racing allows her to be "normal" even as she rejects the white knight story. By making herself subordinate to stock car racing as the "hostess" of Fulcrum Racing, she makes space for herself as a working woman in a limited way. But her job demands 
the flirting and cajoling of would-be sponsors, which limits the revolution of her work. This limited resistance follows one of the narratives Ebert criticizes in romance, that "the heroine is presented as a working woman who denies both her femaleness and the imperatives of desire in the interests of traditionally masculine concerns for independence, assertiveness, commitment to a career, and so on" (41). Moreover, in initially rejecting Clay's proposal, Isabel works to dispel “the reader's own anxiety or protest over the narrative's concerted effort to locate the subject in the patriarchal order" (Ebert 43).

Nonetheless, the demands of the genre echo the demands of the NASCARRedneck, so there is little surprise when Isabel knocks on Clay's door to announce she's cutting back on her hostessing duty because she'll be "traveling ... with my husband" (231). In this manner, Isabel allows herself to be taken by a man, gives up her career so she can be a properly fulfilled woman who at least partly depends on a man. Clay thereby satisfies the Lacanian lack that Ebert suggests is "ideologically disguised in the heroine's longing for the hero" (40). Isabel's final desire for Clay draws from the same motive that necessitates Kim's inclusion of \#7 on her list: Kim must date a jock, must submit to a jock in order to make herself whole. Clay functions as the mechanism of revolutionary fizzle. He wins Isabel's heart, which makes the nation safe from her resistance. 
An important ancillary meta-commentary coincides with the cultural coding of Teaming Up. Even as the novel is primarily imbued with normalizing Redneck roles, it also engages the important gendered economics of the specific NASCAR milieu. Initially, Isabel seeks to win Clay's sponsorship by explaining the significant percentage of fans who happen to be female. She aligns that demographic with his business needs since, according to her, women buy a lot of tools as gifts for their men (100). Or, as her brother Dixon puts it, "“Marketers are increasingly finding [NASCAR] a great way to target women'" (99). Externally, this marketing angle is precisely the function of the NASCAR-Harlequin partnership. The books exist to more fully exploit the market potential of the female fan base of stock-car racing, coding romance first of all as a feminine product and, secondarily, implying that just stock car racing doesn't offer fulfillment for female fans. I find the exchange between Dixon, Clay, and Isabel curious, because the novel itself seems to tip its cards to reveal its economic function: NASCAR romances are written as a vehicle to offer deeper market penetration. The books are "a great way to target women," with the bonus result of cultural normalization. ${ }^{26}$

In combining the narrative and meta-narrative interpretations of Teaming $U p$, the encompassing function of the Redneck becomes apparent. The final economic and social impact of the identity category is predicated on the solidification of white, hetero,

\footnotetext{
${ }^{26}$ NASCAR itself bears attention as an ideological entity, a focus taken up by Howell in From Moonshine to Madison Avenue. For regional aspects, see Pierce's "Bib Overalls \& Bad Teeth" and Alderman, Mitchell, Webb, and Hanak's "Carolina Thunder Revisited"; for contemporary political impact, see Vavrus's "Politics of NASCAR Dads"; for identity and racial aspects, see Newman's "NASCAR and Southernization."
} 
masculine power. In the novel, the potentially liberating social mobility of Kim, Rachel and Isabel functions as a threat to the implied norms of the NASCAR/Redneck culture and, by extension, to the hegemonic stasis of the nation. Such threats are summarily resolved by the romance narrative and, moreover, placed back into the normal scripts of the expected cultural milieu. The women of the novel function in direct opposition to the threat of the 1970s opening of the redneck category. In Teaming Up, Gaines writes a way back into Redneck for overachieving women, which is to say it shows how apparent resistance to The Man can be brought back under control. All it takes is the steady hand of a dominant male. In that sense, Gaines reveals the same market savviness as Larry the Cable Guy. Each deploys the stereotypes of the identity category in a way that is both financially viable and ideologically defensive: books and DVDs are sold by keeping the redneck in his usual space and, more, by selling that rigid identity back to the very people who are pejoratively considered as part of the substandard redneck set. Similarly, the apparent but limited social success of the women in Teaming Up echoes the achieving minority status of Jimmy Wang Yang. For all, a veneer of inclusion and progress is brought safely under control by the limitations of the Redneck identity.

This surface inclusion helps conceal the function of the contemporary Redneck identity, offering a quick whiff of inclusion even as it merely reifies the cultural conditions that existed before. In that reification, the contemporary Redneck offers 
complete and total fealty to The Man, is in fact merely another iteration of The Man. In contrast to the 1970s redneck of my earlier chapter, the more clever, more pervasive, more mainstream commodification of Redneck status encourages America to buy into the identity. Thus while the Redneck unsurprisingly sells pickup trucks, he also sells romance novels, also sells comedy trope, also sells a version of American ethnicity that operates as resistance to a globalizing world and nation where no clear American ethnicity defines an individual as purely American.

The Redneck bolsters the guard against threats to a solidified American cultural dominance, even as the historically degraded underclass of the hillbilly or economic redneck is left behind with the bill. Threats come from within, as America chips away at barriers that previously wrote women, ethnic minorities, immigrants, and the poor out of the conversation. The ideological Redneck leaps to the defense of this solidified American dominance. The Redneck functions narratively through Jimmy Wang Yang, Kim Murphy, the Dixie Chicks and Larry the Cable Guy to forestall and envelop the different faces of national participation. The ideological Redneck absorbs that difference itself, renders "American" those individuals who don't obviously fit the traditional white, hetero, masculine image. But he does so by fitting such characters into American discourse in a manner that does not threaten previously unchallenged sources of power. In response to a vacuum of "true" American identity, the Redneck appears as the new American ethnicity. It functions as the one and true way to separate the citizenry and, 
more sinisterly, guarantee that America is preserved for the normative white, hetero, masculine baseline that has become synonymous with Redneck. And in this movement, the Redneck becomes a tool for a broader conservative America, a shifting of the identity from outcast, to renegade, to mainstream totem. 


\section{Chapter Six: Redneck Resistance}

To most effectively open this chapter, I should offer some wise words from my grandpappy, a weathered veteran of the underground mines of northern Appalachia. I should use his life story to frame a discussion of personal identity, to establish my authenticity as an Appalachian, to discuss how my father's own position as the child of a coal miner creates linkage to my own heritage. But problems emerge quickly with that strategy. 1) There is no "grandpappy" in my lineage; 2) the coal mines my father's father toiled in were not the dirty soft coal digging of Appalachia, but the mechanized pit shovel operations of hard coal Eastern Pennsylvania; 3) the linkage of heritages leads to origins as Pennsylvania Dutch, not Appalachian. And if I look toward my mother, things get worse. She's from the midwest, and her father was a Chicago postman.

But I am an Appalachian.

I grew up in the low mountains of Western Pennsylvania, in a coal mining town that mines little coal these days. The creek near my childhood home still bears the rustred stains of underground mine seepage; as a kid, I used to watch rainbow swirls of mine acid seep out from the earth into the tiny stream below our house. Just a few years ago, massive earth moving machines tore the trees and topsoil off a hill where I used to ride my bike, stripping the surface coal, then shipping it to the power plant visible from the top of my parents' farm.

But I do not fit the Appalachian type. 
My father was a college professor. Worse, he taught Environmental

Conservation. My mother was a reading specialist. Worse, she considers impeccable grammar the keenest mark of a learned child. More than once, I've been complimented on my surprising lack of hillbilly accent, my apparent comprehension of the rules of grammar, the flat midwestern pronunciations of my speech. Plus, I'm an academic.

But, again, I am an Appalachian. And the seeming contradictions of that identity are tied up in the very same issues of construction, stereotype, and reception that I've been exploring so far in this project. The idea of the redneck is predicated on a narrowed idea of what constitutes the identity. Because of the limitations of that redneck classification, it's easy enough to apply the label to oneself in a more or less believable manner. Wear the right clothes, listen to the right music, talk the right (wrong) way, and you've got it. Yet it is these very limitations to redneck or Appalachian or Southern identity that create the social and political problems that have been the focus of my study. The applications of faux Redneck identity are deeply invested in the voicelessness of actual "rednecks," as difficult an authenticity as that position may be.

This is the thing: Rednecks are supposed to act a certain way, as I've outlined in some detail. But the voices of the redneck — real voices from the South, from Appalachia, from rural, working-class, impoverished America — offer little rigidity of philosophy. The multiplicity of those voices creates a nuanced and complicated sense of 
just what a modern redneck might be, thus the voices of the regions lying at the center of my project must be ignored in order to fashion the ideological Redneck that I argue reasserts American hegemonies. To this point in this project, I have spent little time discussing the actualities of Appalachia. In part, that's because the "actual" resists typification. Mostly, I've been dealing with this absence because the very lack of definable identity within the Redneck spectacle allows the identity to do its work. The historical baggage of Redneck depends on the constant reapplication of stereotype to the real residents of the regions being portrayed. So just as "actual" rednecks have little voice in the construction and use of the identity, they also suffer from the expectations of the label. Appalachia, in particular, cannot find its way out of hillbilly punchlines, just as I cannot easy separate myself from an Appalachian homeland. To complicate matters, neither the residents of Appalachia nor I would actually want to separate ourselves from our regional link. We are of the place, but we're also externally assigned to stereotyped limitations of the place.

In the case of Appalachia and myself, mere geography defines my identity: the region is my home, and once superficially external markers of the exaggerated requirements of the hillbilly moniker are discarded, space opens for the kind of image resistance that allows me to be authentically Appalachian despite an apparent lack of Redneck attributes. I claim my own identity position as Appalachian, and I similarly offer the complicated claims of others as a means to illuminate the resistance to 
stereotype occurring within the ignored members of the identity class so widely parroted and garroted in popular culture. Such resistance offers hope for the rupture of the Redneck spectacle that I have been examining.

Constructions are difficult to escape. For me, my position as a scholar of things "redneck" creates a troubling response, even in liberal-minded academia. On many occasions, when hearing of the subject of my work in tandem with my membership of the West Virginia University community, academics from other institutions say something like, "that's perfect." They tell me WVU is an ideal place for that kind of work, implying something about the Appalachian Studies strength of my department. Yet it is a department that isn't particularly invested in Appalachian Studies, nor is it disinvested; most scholars within the department simply happen to have other interests.

But as with all things Redneck, truth is and is not. There is some foundation to a suggestion of WVU's perfection as a site of Appalachian work, as our library holds a fabulous collection of Appalachian texts, and until his recent retirement the History department was the home of noted Appalachian scholar Ronald Lewis. In my own department, linguistics professor Kirk Hazen carries on important work on West Virginia dialects.

Even within these bona fide claims for Appalachian expertise, the geographical position of my department collides academic expectation with Appalachian identity. 
Typically, those who comment on the "perfection" of my situation have no knowledge of Appalachian Studies in particular: they wouldn't know about the library, about Lewis, about Hazen, about anything other than the spot on the map where WVU exists. Their conclusions are thus based on simple locale. Since the department happens to reside within a flagship university of an Appalachian state, it must feature an Appalachian Studies cohort. Such is the limitation of the expected identity of Appalachia, required by its regionality to study its own regional situation while at the same time considered unlikely for "mainstream" academic study.

In truth, the response of these other academics who find perfection in WVU's Redneck Studies status is as closely associated with stereotypes of the state of West Virginia as it is with any professional expectations. Perfection is assigned to the combination of my institution and scholarly project not because of any actual academic expertise but, instead, because West Virginia is full of rednecks. It's a perfect place to do my work, in many minds, because I only have to step outside of the English building to see the redneck world around me. Better yet, WVU is a hillbilly institution, so my object of study is present all around me. Obviously, this is kind of insulting.

Yet this is the position of the Appalachian, always pre-defined as something he or she may or may not be. As I have argued throughout this project, the contemporary iteration of the Redneck exerts a powerful representational force in the fashioning of American identity. Perceived within narrow stereotypes aligned with long-standing 
images of the regions of Appalachia and the South, the Redneck identity appears as a static, degraded, sublimated classification. The force of that representational shaping is so strong, and the influence of the Redneck spectacle so pervasive, that real people living within the real regions consumed by the identity are forced into the category. Regardless of individual choice, the day-to-day lives of residents of the South and Appalachia are assumed to coincide with the constructed limits of Redneck action. As a result, individuals living within these Redneck regions are offered little agency; their lives are assumed to be lived in accordance with the expected stereotypes of the regions. Further, any action by such residents that does not automatically fit into the broad expectations of the constructed identity seems false. More so, the force of the spectacle presupposes adherence to the construction and simultaneously presupposes no ability for residents of Redneck regions to act outside of expectation. Once a redneck, always a Redneck. For me, my association with West Virginia University falls into that same trap of construction: it's a perfect place to study rednecks.

As is no doubt immediately evident, this chapter serves as an intervention in more than one way. Appearing within the margins of an overtly scholarly project, the narrative tone I've taken rings a dissonant chord. And this is part of the function. In as much as theory can offer useful ways to examine literature and culture, and even while explicitly scholarly examinations of the function of narrative can help to reveal the 
codes and resonances of text, I also find discomfort in such an exclusive focus. In part, this discomfort lies in the totalizing forces of ideology. Regardless of perspective, theory cannot help but be part of some form of ideology and, through that, theory is at best a limited vision of reality. Useful, but limited.

In one sense, I am also arguing for a concept of new New Southern Studies. One of the chief revisions of new directions in Southern scholarship has been to apply overt theory and usefully expose the representational function of myth and culture. The criticism of older Southern scholarship was a criticism of a perceived unrevealed ideology hiding behind the reiteration of long-told tales. I am suggesting not a return to that old style - which itself may have never been as absent of theory as newer studies imply — but instead a contemporary echo of older versions of Southern scholarship. I am suggesting that story should function alongside theory, roughing up the edges to restore validity to the witnesses of time.

Theory alone creates a canonization of ideas as limiting as the canonization of dominant voices in a literary tradition. By turning in a narrative direction, I am chiefly suggesting that stories have the power to break the rigidity of ideology that has been my focus thus far. Story adds messiness, while theory seeks to generalize. This is a chapter that calls for messiness. This is a chapter that takes an alternate approach in order to help shake loose the rigid binds of identity that allow the Redneck to function in American discourse. Thus I am arguing right now both for the validity of specific 
alternate narratives that rupture the hegemony of Redneck image and for the validity of a narrative voice as a scholarly tool. Story is text and method; story is identity and philosophy.

Turning from personal narrative back to literature, I find similar academic identity issues in the writing of Fred Chappell, who engages with the ambivalent position of a "regional" academic within the pages of Look Back All the Green Valley. The narrator of the book, Jess Kirkman, grew up in the mountains of North Carolina, but now spends his days as a poet, professor, and translator of Dante at UNC-Greensboro. And Kirkman is not beyond generalization: "But since I am Appalachian by heritage, I don't consider myself a southern gentleman and don't particularly desire to be set apart from animals wild or domestic, which are never so low as to clothe themselves in bedsheets and burn crosses. Appalachia is a different world from the Deep South, though few will allow that it is a better one" (21). He sees himself partly through the lens of America, as somehow less than fully human because of his heritage, even if he makes these comments in jest. More, he aligns his animal self as a higher class of organism than the stereotypical KKK members of the representational South: better a hillbilly than a klansman. 
Still, when Kirkman returns home in this novel, he is surprised and displeased to find a faux-hillbilly restaurant gracing his hometown, a "green-and-pink-and-blue miscreation" called "Hillbilly Heaven" (93):

I was ushered from the foyer to the booth upholstered in vile blue plastic by a girl in an outlandish "hillbilly" outfit. Before long, another young lady approached, bearing a glass of water on a tray. Her costume was odder than that of the hostess: a stiff white apron over a longer gray skirt, from under whose hem peeped the tips of Nikes. She also wore a largish calico sun-bonnet, which must have made peripheral vision a chancy proposition. “We're mighty proud to have you amongst us today," she intoned. She handed me an awkward oblong plastic menu and asked if I'd like something from the bar. (93)

Kirkman has entered a simulated space here, and one that evokes all of the stereotypes that have been used against his own Appalachian people. ${ }^{27}$ He strikes up a conversation with the waitress, allowing her to break out of the hillbilly code language that fills the menu and her scripted speech, and finds that she's an anthropology and folklore student from Canton, Ohio (95). She works at this restaurant because it pays better than the others, even though she recognizes the insult of the portrayal she offers.

\footnotetext{
27 I have written elsewhere about the similar simulation that takes place in the real world restaurant, Texas Roadhouse. See Nebula 4.1 (2007).
} 
But representational position is not cut and dry, for Kirkman or the waitress. Kirkman himself claims to feel "vaguely guilty" about reading a menu that seems to have been created by "thumbing through precious antique issues of L'il Abner comics," but he also notes that "the other diners looked contented, local customers and tourists alike" (94). Even put on obvious display, identity politics matter little in this scenario. Locals who should find offense at the representations are happy to eat here, either unaware or unfazed by the stereotypes in action. But Kirkman is troubled, discusses the issue with the waitress:

“How about the homegrown natives? Don't people born in these parts resent it?"

“They don't complain to me. In fact, they seem to like it. Of course, I don't always know who's local and who's a tourist."

"To tell the truth," I said, "I don't quite know which I am myself." (95)

Kirkman finds himself in the uncomfortable space of reality. As a professor, he is incensed by the insensitivity of the stereotypical portrayals of Hillbilly Heaven, which in turn makes him wonder why his "supersensitive politically correct grad students were not roused to indignation by Jed Clampett and Elly Mae and Jethro and the seemint pond" (96). But he is also confronted with the acceptance of the people around him, the locals who have no particular problem dining in a hyper-real hillbilly 
restaurant. Worse, because of his life away from Appalachia, he finds himself conflicted, distanced from his geographical home and similarly distanced from his regional identity. He is resident and tourist at the same moment.

In the same fashion, the restrictions of the Redneck identity create a crisis for residents of the South and Appalachia. They, too, are local and tourist trap. They live real lives in their home regions, but they are perceived by the rest of the nation within the narrative of Redneck trope. Whether they wish to or not, they play the role of the servers in Hillbilly Heaven, real people forced to stand in for fabricated identity. And whether they wish to or not, they are not allowed to choose for themselves whether they want to participate in the recirculation of stereotype. Conservatives demand that Appalachians stay within rigid figurative limits; progressives don't want Appalachians eating at a stereotypical restaurant.

Kirkman faces this complicated lack of option when he finds the grave of an old friend of his father's. Kirkman waxes eloquent about potential engravings for the headstone, all of which celebrate some kind of mountain pride: "But now the thought came to me that in trying to fashion an epitaph for this man, I was seeing through the smoky focus of a literary lens, fashioning him into a symbol of mountaineer independence and rebellion against convention. I, too, was judging him" (106). Coupled with his encounter in Hillbilly Heaven, Kirkman's realization reveals the complexity of his position and the ease with which Appalachian identity slips into caricature. It is too 
easy to liberally sneer at exaggerations that offer no actual offense to local residents, too easy to create a faux-hillbilly restaurant that activates every cliché in the redneck playbook, and too easy for a person of Appalachian heritage to view his own people through the very same essentialized stereotypes that circulate in popular culture.

By slipping into easy regional judgments, Kirkman reflects a deeply-nested lack of agency. He is offended by the caricature of the hillbilly, but feels that he has himself abdicated hillbilly rights to offense because of his residence outside of the region. Meanwhile, he at first refuses to allow local residents to decide for themselves whether or not they are offended. Thus, in the cheap vinyl booth of Hillbilly Heaven, Kirkman silences the voices of both his regional self and of Appalachians. He assigns the power of commentary only to Madison avenue ad-makers and intellectuals. In that silencing, Kirkman has symbolically exerted upon the internal and external Appalachian the same hegemonic force that his intellectual persona criticizes in the restaurant, the marketing, and even his own graduate students' lack of outrage. As well, the fact that locals do not care about the images suggests that they themselves have become tourists in their own land. They don't care about the stereotypes because repetition has naturalized the image of the iconic hillbilly. Those stereotypes have driven the regionality out of the regional residents even while visitors view the locals as the very same hillbilly on the neon sign outside the restaurant. The totality of the stereotype's silencing effects is clear: the hillbilly image consumes reality to invalidate the potential for criticism. "Real" 
hillbillies can neither be offended nor offer offense, because their own situation has adopted the veneer of simulation. Kirkman becomes the conflicted hillbilly-intellectual who can neither fairly criticize the locals for eating in the restaurant nor ignore the offense inherent in the images in play.

Chappell's examination of Hillbilly Heaven leads me into the complicated arena of meta-identity. Just as I began this chapter with credibility-establishing self-narrative, so too does much analysis of regional literature begin with a declaration of authenticity. George Hovis writes, “In much of Chappell's diverse oeuvre ... one finds a preoccupation with the farming life Chappell chose to leave," that the author often engages "themes of exile from his Appalachian past and the struggle to reforge, through poetry, a unity with the past" (389). Moreover, Hovis argues that:

Chappell's geographical exile from Appalachia to the Piedmont cities of Durham and Greensboro has been further exacerbated by the fact that he is an extremely cultivated scholar who has pursued more than a casual interest in a variety of national literatures, translating writings from a variety of languages, writing a substantial body of criticism on poetry from outside his native region, and inevitably coming to see his native land through such ecumenical vision....Chappell's style conflates examples of high 
and low culture and derives a high lyricism from a rural Appalachian vernacular, a strategy that both ennobles the rural subject matter and concretely locates the lyrical expression.

Scholarship implies autobiography, that Chappell first of all must be writing autobiographical fiction and, secondly, that a core incompatibility exists between learnedness and regional nature. Crucially, Chappell writes back against the sort of autobiographical reading that Hovis offers: "I want to ask those who so persistently address that question to me, Why do you wish my pages to be autobiographical? What is it about me that you so ardently desire to know?" ("Too Many Freds" 258). Further, throughout the essay "Too Many Freds," Chappell argues that his writing is categorically not meta-fiction, as scholars often suggest. Indirectly through fiction and directly through this essay, Chappell seeks to dispel the notion of autobiographical authenticity and of regional limitation.

A nice try, Fred. But you're an Appalachian, so that claim doesn't hold water. "I don't know why he is denying the metafictional nature of his fiction so much these days," writes R.H.W. Dillard, "but I have to admit that, while doing so, he sounds to me an awful lot like an adolescent farm boy caught smoking behind the barn, who protests his innocence loudly while one of his horny heels is busily grinding the still smoldering butt out in the red clay" (25). Similarly, J. Spencer Edmunds spends the entirety of an 
essay explaining the metanarrative elements of Chappell's novels ("Metanarrative and the Story of Life in the Kirkman Tetralogy"). Scholarly impulse casts Chappell into the very lot he seeks to avoid: just as WVU is the "perfect" place to study redneck literature since the place is redneck, Chappell must always be seen as a meta, autobiographical and regional writer because the content of his fiction is all of these things.

Yet for Chappell, resisting the appellation of "meta" is as important as recasting the limitations of the term "Appalachian." Chappell denies the label for his writing because he doesn't want other people saying what he is. He seeks to be in control of his own definition, just as Jess Kirkman comes to discover that Appalachians can be in control of their own definitions. ${ }^{28}$ For Chappell, the problem of "meta" is the same as the problem of "regional." Either title traps a writer in rigid boundaries. To be a writer of metafiction is to be just a writer of metafiction, just as being an Appalachian is to be just an Appalachian.

For Jess Kirkman, the process of self-discovery in Look Back All the Green Valley follows a loosening of the same kinds of rigid identity that scholars have sought to place on Chappell. Kirkman has returned home to find a new burial space for his elderly mother, necessary because of a graveyard confusion that would not allow his parents to lie next to each other in perpetuity. In so doing, Kirkman exhumes the

\footnotetext{
28 Importantly, I do not intend to make a metanarrative claim here. I mean only to point out the similarity between Kirkman's growing sense of regional identity and Chappell's reluctance to be a certain kind of writer. Look Back All the Green Valley is not about seeking identity; it merely shows a character forging space for his own sense of self. Of course, in pointing this out I end up supporting the very metanarrative reading I hope to deny - the messiness and inescapability of the meta.
} 
memory of his long-dead father, a complicated man of comic mysteries. But alongside that action, Chappell writes a self-discovery for his main character. He allows Kirkman to experience a multiplicity of identity in a place the narrator had himself pigeonholed as "Appalachia."

Near the end of the novel, Kirkman arranges a picnic for local old-timers, all of whom own family burial plots that are potential resting places for Kirkman's parents. In arranging the catering at a local coffee shop, he expresses misgivings about the California cuisine on the menu. Kirkman doesn't think this West Coast café owner could possibly make the kind of food elderly Appalachians might eat. Instead, he finds that the owner of the cafe is a local: "I evinced surprise at this intelligence. Her beaded headband, the sleeveless denim tunic that displayed her sun and moon tattoos, and her array of turquoise rings had led me to expect that she hailed from some New Age colony that had set up housekeeping on one of the bushier fringes of Pisgah Forest" (176). Moreover, he comes to recognize in her voice, a languorous drawl. There are some who would describe it as a country drawl, but I must forbear, since it is the same one I possess — flavored with the rural, slightly refined by contact with urban talkers, always tinged with a faint ironic undertone. My university crowd had shed a slight academic tint on my sentences; Debbye's California sojourn had brightened hers a little. (177) 
In the end, this is the opening of identity that Chappell argues for in the novel: the oldtimers come to the picnic and enjoy the food. Similarly, throughout the novel Kirkman travels the countryside, never dropping his scholarly self but also never denying his ability to tell folk tales with those he meets. The old-timers are not fixed in history and incapable of appreciating contemporary cuisines, just as Kirkman's intellectualism is not incompatible with Appalachian heritage. The message Chappell writes in the novel equates to a fuller understanding of the potential of being both Appalachian and modern. Being Appalachian does not mean never leaving. Acquiring intelligence, changing accent, or adopting mannerisms not of stereotypical Appalachian sort does not equate to abdication of identity. These things are, in fact, compatible with regional identity, because restrictions on those identities are merely constructs of the outside. Put another way, as Debbye explains about her food, "'Once people from around here try it, they generally like it'" (177). There's nothing integral to being an Appalachian that prevents someone from being like everyone else, or anyone else. Or not.

Trudier Harris recounts the trouble of her name as the first story of her memoir, Summer Snow. "I love my first name," she writes. "Black folks generally love my first name. Although many have difficulties pronouncing it, they usually applaud the creativity that spawned it" (1). The name offers more than mere syllabic confusion for white people, though. Harris explains that after pronouncing her three syllable name to 
other people - Tru-dee-uh — many white people who have heard the proper form of the name frequently introduce her to others as the diminutive "Trudy:" "It's the story of my life, brought home vividly to me recently when a white man just refused to accept the fact that there are three syllables in my first name. And he and his brothers proceeded in their hearing impairment to insist that the world be shaped as they perceive it" (2). So begins the memoir, with an affront to the very identity of the author. Names are, of course, crucial to us, defining our personal identity and carrying the weight of the identity we are given by those who came before. Selecting a name for a child is no easy task, and as Harris explains, the tradition in the black community is significant and resistant, choosing names not to replicate the naming patterns of the larger white culture around them. So the willful, or accidental but pervasive, refusal to hear three syllables establishes a grounding point of identity struggle. Harris is Trudier, not Trudy, but the external culture prefers to place her back in the box labeled Trudy. Her name does not exist in white culture, must be discounted, cannot even be heard. That's where she begins her story, with an assertion of self: I have a name, different from yours, and I will carry it with me and resist your diminutive attempts.

But even this creates trouble for Harris, as in the response to the curiosity, I fall into the role of potential entertainer, that position in which white people are most comfortable with black folks. If they can't control your name, they at least expect you 
to tell them the story of how it came to be. And I do that, but each time I do it, I call this act "fighting for my mother" because I relish any opportunity to celebrate her creativity — no matter the setting. I enjoy passing on the determination with which my mother made sure that my name was spelled as she intended it to be. (3)

For Harris, identity lies at the foreground of both her memoir and her life. As a black woman born in the South in the 1940s, she writes that she "was born into a sharply segregated environment in which the lines between black and white were visible and invisible, physical and mental. It means that I grew up among people who understood precisely the boundaries in their world and observed them almost unconsciously" (ix). It begins with the simplicity of the name, whose complexity pastes itself onto the rigid constructions of her place as a black woman. Harris opens her memoir with the bind, with the rigidity of external definition that prohibits not only her inclusion in her geographical culture, but even the agency to pronounce her own name "correctly." More than that, Harris writes space for herself in this memoir. She makes an argument for her inclusion among those who carry the label of Southerner: "It has taken me a long time to arrive at a basic fact of my existence: I am a Southerner. For a black person to claim the South, to assert kinship with the territory and the mores that most black folks try to escape, is about as rare as snow falling in Tuscaloosa during dog days. It's a reconciliation that many African Americans have not yet made" (177). Just as she 
faces difficulty in defending the full and proper pronunciation of her name, Harris faces the onerous task of fitting into the South. This is the spot of resistance that I am arguing for in this chapter, that individuals speak for their specific positions and thereby transform the fuller definition of their region. As Harris explains, by claiming herself to be a Southerner, she is not claiming the racism and Confederate flags of the stereotypical South (177); she has not become Jimmy Wang Yang, claiming space for Southern identity by succumbing to the label of narrowed "redneck." Instead, Harris recognizes that, "[f]or me to deny the South is to deny all the people who made me who and what I am" (183). She argues even that the racism of her once governor George Wallace "did not erase the presence of my ancestors, and the air was not poisoned because he breathed in the same spaces as the people from whom I sprang" (184). In arguing for her name and for her place in the South, Harris is also arguing against the common understanding of a region that seeks to erase her presence. Erasure, in fact, is the power of the Redneck identity. In claiming the South as a land only of the narrowly defined hillbilly, one also claims the South as a land only for the white. If the racism of the region can be unproblematically allied with the only allowable regional identity, then the region insures itself against racial inclusion. By accepting a narrow version of the Redneck, one rejects the Southernness of Trudier Harris. And by rejecting the Southernness of Trudier Harris, one rejects the inclusion of black Americans in any history of or active participation in the South. Harris thus fights for her space, speaks 
back against the totalizing equation of Redneck and Southern. "Authenticity. That's the issue," she writes. "How did black Southerners manage to claim it in a society that devalued their worth as human beings, a society that certainly did not hear their voices on practically anything? How did they claim voice, authority, and authenticity?" (22). Authenticity is just what Harris claims in her memoir: authenticity of self through naming, authenticity of region through the defense of her own Southern heritage.

The problem "real" redneck writers face is demonstrating authenticity that runs contrary to expectation. Simply enough, as a broad American culture we think we know what rednecks and hillbillies and Southerners are supposed to be. After all, we've seen it on TV, in the movies, in literature that stretches through America's history. Trudier Harris violates expectation simply by seeking to be Southern at all. There is supposed to be such a thing as a black southern experience, but not really such a thing as the experience of a black Southerner. Similarly, there are expected limitations to the philosophies of Appalachian coal miners, tied up in all sorts of backwards or degenerate social codes. As applied in contemporary political areas, these legitimate hillbillies are also fashioned as pro-work, anti-environmental laborers.

But just as Harris can write herself back into the South, coal mining can be written back into a complexity of political perspective. In writing about the coal country of southern West Virginia and eastern Kentucky, Silas House offers a complicated 
revision of identity. Clay's Quilt presents this perspective: “All his life, every boy he knew wanted to escape having to go down in the mines, but Clay thought it the most noble profession any man could have" (14). Thus main character Clay is different, from the other boys and from the usual trope of Appalachian stuckness. He wants to be a part of the coal mining heritage of his ancestors, but he certainly is not willing to remain stuck in the cycles of poverty and poverty-driven violence that surround his life.

Crucially, the novel opens in prologue with a recollection of just that sort of entrapment. Clay rides with his mother in the backseat of a car: "On one side of the road there rose a wall of cliffs, and on the other side was a wooden guardrail. It looked like the world dropped off after that" (1). There are no options here for escape. The driver informs his passengers of the direness of the situation. Stopping would mean freezing to death, while driving on through a blizzard would mean death as well, since the car would undoubtedly slide off the road. In fact, by the end of the prologue the driver and Clay's mother are dead, felled by an inevitable third option; the mother has fled an abusive husband, who has hunted her down.

If Shakespeare teaches us in The Tempest that "what's past is prologue," then the blizzard death of House's prologue opens up the necessity of breaking the cycle of history. Expectation would suggest this as impossible, since the notion of Appalachian reality is to presume an unchangeable repetition of the past. And the novel shows just how following that cycle comes about: "When Clay was little, newscasters boasted that 
the War on Poverty was being waged in those very mountains, but if the government had fought any battles close to Free Creek, no one in the holler heard the guns" (20). Waiting for external assistance means waiting for history to continue: there can be no escape for the residents of Free Creek without personal action.

This autonomy functions within Clay's Quilt as the hopeful anti-cyclical future of the coal mining regions. For one thing, the childhood Clay recalls in Free Creek is identical to a broader American childhood, full of Bob Seger, Star Wars, and Tom Jones (26). The absence of certain musical forms is crucial in positioning these characters: they didn't grow up on a diet of mountain dulcimer. With seemingly superficial cultural background, Clay and his Appalachian friends are drawn as fully American. By writing his characters as listening to the same music as everyone else, as coming from the same pop cultural moment as kids across the nation, House reduces the exotic backwoods nature of Appalachian identity. He's making a claim for inclusion, and he does so without making the sort of chest-thumping declaration that would, in fact, raise questions of validity.

More importantly, as a young adult Clay receives a letter written to him by his mother before she died. In it, she tells Clay of his father, a man she fell deeply and quickly in love with, who ended up disappearing in Vietnam:

Way over to our left we could see a strip mine. The mountain's top had been completely cut off and the sides looked like a big scar on 
the face of the earth. Your daddy studied this strip mine for a long time and finally said he couldn't understand doing that. As God is my witness, I believe that is when I fell in love with him. (122)

It is this declaration against strip mining that marks the potential salvation for Clay. His father's disgust at the destruction of mountain land offers a declaration of love for the land itself even while it does not deny the heritage of coal mining. Clay is connected to the land of his Appalachian heritage, but he is not rigidly fixed to expectations of mindless support of the coal industry. Just as he listened to popular music growing up, Clay also participates in an environmental awareness that fits into a national context. The ability to recognize the destruction of land shows a fullness of character in Clay, and a fullness in and control of identity for Appalachians.

Crucially, the ability to recognize the degradation of strip mining and the love for popular American music do not equate to abandonment of heritage. Appalachian identity is not an either or proposition, backwards as Appalachian or contemporary as one who denies all things Appalachian. In the character of Clay, House offers a version of Appalachia that works with its past to imagine a successful future. For example, by falling in love with and marrying a fiddle player, Clay displays ties to traditional culture. But while on a trip to Myrtle Beach, his wife Alma balks at a man who listens to her music: 
"You sure can play that fiddle," he said. "Lot of musical talent comes out of those mountains. Why is that?"

"Us mountain people can do damn near everthing (sic) good," Alma said, and didn't move.

The man raised his eyebrows and looked at everyone nervously. “I didn't mean anything..." (273)

Yet of course the man did imply something, that the playing of mountain music is an indigenous skill of the hillbilly. Casting musicality as a regional trait suggests that ability has little to do with personal talent or dedication. More, denying individual musical agency delineates an individual as only Appalachian: it's something they all do well. This is the very sort of narrowing that House writes against. His characters participate as Appalachians, mining coal and playing the fiddle, but they do so with a reality of choice. In fact, Alma and Clay visit Myrtle Beach as an escape, allowing Clay to recover from a justified shooting of Alma's ex-husband. And though Alma feels the call of her homeland strongly, she remains willing to stay away as long as necessary to allow her husband to free his mind.

For his part, Clay regains connection to his homeland once he learns of Alma's pregnancy. He demands that they return immediately. Before learning of this pregnancy, Clay appeared content to remain away from Free Creek, perhaps equating escape from Appalachia with escape from the cycle of violent history. He killed a man, just as his 
mother was killed by a man. But clarity comes to him by grace of new life, and he realizes that it is his own choice to leave or stay in Appalachia. Thus he and Alma return to have their child, Maggie, and at the end of the book the three climb the mountains:

At the summit, the sun washed out over the earth, so bright and yellow that he could see through the leaves fluttering on the trees. He walked across the top of the old mountain and looked out at the land below. There were no strip mines to be seen from here, no scars on the face of the earth, only mountains, pushing against the horizon in each direction, rising and falling as easily as a baby's chest. (293)

This mountaintop scene offers great contrast to the final view of Crum that I examined in chapter two. In Crum the final beauty of a marred town becomes visible only when the main character abandons his hometown. In Clay's Quilt the land offers immediate and true beauty. For Silas House, beauty does not have to be searched for in Appalachia, nor must it be created through a long-distance squint. It is there, and one need not abandon one's homeland to see that beauty. Clay witnesses beauty by returning, not leaving. Crucially, an individual has the choice to leave, is not trapped in Appalachia. That same individual also has the autonomy to decide to stay and celebrate the beauty and viability of her or his geographical origins. 
Mountaintop beauty functions outside of the text of Clay's Quilt as well, spilling into the day-to-day life of Silas House. The author has become an outspoken critic of mountaintop removal mining, writing and speaking about the environmentally destructive, economically lucrative practice of modern coal mining. ${ }^{29}$ But House also makes this issue about more than the obvious, about more than mere loss of habitat, waterways, or biological diversity:

The big misconception about mountaintop removal is that it's an environmental issue. Well, of course it is, but more importantly, it's a cultural issue. So let's take into account what we already know about the environmental devastation caused by mountaintop removal and not talk about that. Instead, let's talk about the way it threatens this place we all know and love. I want to look at the way mountaintop removal threatens our storytelling tradition, and our pride. We talk a lot these days about "a sustainable economy." But what about being a sustainable people, a sustainable culture? Those things are just as important. ("A Conscious Heart" 7)

The rhetorical shift House exacts here is one that moves away from the practical into the cultural. This is an important repositioning of argument, since the typical environmental approach leaves the specificity of locale out of the equation.

29 For background on Mountaintop Mining, see: Burns, Bringing Down the Mountains; House and Howard, Something's Rising; Schnayerson, Coal River; and Johannsen et al, Missing Mountains. 
For House, the real issue is the people of the region affected, and these are the same people who have previously had little voice in American history. Or, at least, they have been perceived to speak with a voice of deference to the larger needs of the nation. As House puts it, "For decades now...we've been told that we should be good patriots and accept that we're the sacrificial ground for the rest of the nation's energy resources" (9). He suggests that complaining about the devastation of surface mining has been considered tantamount to treason, that "if we were good Appalachians we'd be quiet and not say anything when our land is destroyed" (9). Furthermore, House argues that such voicelessness is, in fact, related to negative stereotypes about the people of the region, "[b]ecause it all comes down to the fact that everyone thinks that everyone in Appalachia is poor. And poor people never, ever matter" (12). More, he outlines how he's been viewed as a suspicious kind of professor, since many think of him as "the thing (they) had always feared: a redneck. A hillbilly. There are people all over the world who truly believe that we are all rapists with banjoes....not 
understanding that every single person in Appalachia is an individual, and that most of the stereotypes ... were incorrect or at least grossly exaggerated" (13). ${ }^{30}$

Resistance to mountaintop removal mining becomes at least partly resistance to degenerative stereotypes and reclamation of the validity of personal identity. In claiming the Appalachian self as viable, complicated, and modern, House in person and through literature makes an argument for the power of the voices of the region. As vital and legitimate voices, they must be accounted for in the discussion of the region's fate when, before, the perceived invalidity of Appalachian experience worked at the service of the external exploiters of the region. House's literary characters present a freshened complication of Appalachian identity, neither trapped nor pro-mining at all costs, nor anti-mining in an unrealistic fantasia. The author's own activism seeks to further disrupt the stereotypical hillbilly image. House is an active and viable member of his community, just as Clay Sizemore is an active and viable individual in Clay's Quilt. The literature functions alongside the author's activism, offering both literal resistance to the degradation of the mountains and figurative argument for the validity of human

\footnotetext{
${ }^{30}$ As I revised this chapter, the tragedy of constructed hillbilly position reasserted itself in the coal mines of West Virginia. In April of 2010, twenty-nine miners died in an explosion in the Upper Big Branch Mine of Raleigh County. Particular details of the disaster can be found in the archives of regional and national news agencies. Conceptually, the disaster reveals the symbolic effect I engage in this chapter. Recurring safety violations in coal mines exist as a "cost of business" that allows the nation to enjoy cheap energy. But that cost is predicated on a national conception of Appalachian individuals as types and not people. Because the Redneck consumes individual identity, and because the Redneck identity functions at the service of broader hegemonic control, attention strays from the day-to-day realities of energy extraction. The miners who died only matter nationally when they die, because the deaths fit a narrative of disaster. But the disaster itself is created because the miners did not matter as individuals before the disaster. They were stereotypes, mere hillbilly miners whose personal value mattered little in the national conversation about clean coal and energy independence. This is a dire and important effect of the Redneck spectacle.
} 
experience in the region. By writing full characters who move beyond the expected norms of the redneck parameters present in other popular texts I've explored in previous chapters, House makes real the individuals of the region. He authorizes the multiple selves of Appalachia to make possible real, true, authorized discussion about mountain issues. As a result, it becomes more difficult for coal companies to exert their dominance without complaint by the residents negatively affected. Further, the agency that House writes for his characters reflects a reality of experience in the region: hillbillies don't exist in a totalized form; the real people of the region have real things to say and must be accounted for in more than an abstract way.

If there is surprise in the particulars of House's complaint against mountaintop removal mining, it is that a so-called hillbilly offers pro-environment resistance. And the voices and images of grass-roots environmental activism in Appalachia seem jarring at first, since the resistance of the people of the region runs so far against type. Images from protest videos, photos and testimonials on the websites of an anti-mining nonprofit and of a local group opposed to mountain top removal, for example, show the people of the region talking back against the stereotypes of the anti-environment hillbilly (ilovemountains.org; crmw.net). Further, they do so with the accent of the region. As Jay Watson explains, "American ecocriticism suffers from its own peculiar version of the old 'West versus the rest' problem, a regional bias that assigns iconic 
status to the American West as seedbed and Ground Zero of American nature writing, landscape photography, and ecopolitics, relegating other regional landscape and ecosystems to supporting roles" (497). House's pro-environment stance follows that same pattern. Environmental issues aren't supposed to come from the coal fields. That it comes as a surprise that Appalachians and Southerners would have ecological opinions is incongruent both with the environmental reality of the regions - which Watson rightly aligns with socio economic concerns (497) — and with the longstanding claims of Southern relationship to the land. As Jack Temple Kirby argues in his important ecocritical book Mockingbird Song, notable literary frontiersman Natty Bumppo decried the mass slaughter of passenger pigeons in The Pioneers (13), a source point for continued ecological focus in Appalachia and the South.

Nonetheless, hearing the voice of the redneck in defense of the land does not fit the degraded stereotype. So it is easy enough to fit author Janisse Ray's claim, “The story of who I am cannot be severed from the story of the flatwoods" (4), into a long tradition of Southern agrarian relationship: I think here of Jimmy Carter's professions of relationship to land, of plowing barefoot. But Ray's deep connection to the nature of the South is more surprising because it does not argue for land as an aspect of icon. Instead, in Ecology of a Cracker Childhood Ray considers the land as central to real identity. She argues for the importance of the Georgia longleaf pine to her sense of Southern self. For Ray, this is a connection of loss. "My homeland is as ugly as a place gets," she writes. 
"It's flat, monotonous, used-up, hotter than hell in the summer and cold enough in winter that orange trees won't grow" (13). Crucially, she argues that the region used to be different, that a once ubiquitous ecosystem of longleaf pine has been reduced to only 10,000 virgin acres (14-15). In a memoir that shifts between a personal story of growing up in a Southern junkyard and a paean to the forests that used to cover her region, Ray writes a connection between perceptions of the degraded Southerner and the actual degradation of the trees. She writes the conclusion to Silas House's warnings. Ray argues that the loss of landscape at the service of economy leads to the erosion of viability for residents:

Passing through my homeland it was easy to see that Crackers, although fiercely rooted in the land and willing to defend it to death, hadn't had the means, the education, or the ease to care particularly about its natural communities. Our relationship with the land wasn't one of give and return. The land itself has been the victim of social dilemmas - racial injustice, lack of education, and dire poverty. It was overtilled; eroded; cut; littered; polluted; treated as commodity, sometimes the only one, and not as a living thing. Most people worried about getting by, and when getting by meant using the land, we used it. When getting by meant ignoring the land, we ignored it. (164-165) 
Ray has turned the conversation here to one of explicit environmental concerns, and she does so by citing familiar Southern relationships to the land. Crucially, she draws this connection in a way different than Carter. The former president put the relationship of land to use as symbolic capital; his connections to the soil made him Southern, and the soil naturalized his American identity. Ray, in contrast, recognizes the degradation of the land and seeks to create a parallelism between environmental loss and human suffering. The land is not ideologically removed from humanity. It is a physical manifestation of the same social pressures that led to, reinforced, and reified the difficulty of Southern rural life.

Ray writes ecology back into her cracker heritage, arguing that finding pitcher plants "among piles of scrap iron and glittering landmines of broken glass" (127) in her father's junkyard “taught me to love rain....In that plant I was looking for a manera de ser, a way of being - not for a way of being but of being able to. I was looking for a patch of ground that supported the survival of rare, precious, and endangered biota within my own heart" (128). Moreover, witnessing and identifying a common bird, the red cockade, in the junkyard taught her the grace of common people:

No flashiness. Nothing about it could be said to be high-profile or charismatic. No spectacular. It was a working-class kind of bird, trying to make ends meet in a failing avian economy, depending on its clan, and in these ways and also in the way history binds it to 
place, it reminded me of my Cracker kin. The bird was special in the manner a molecule of oxygen is special to air. (155)

This is Ray's call to action, a metaphor for the brilliance of the common person - the actual core of the redneck nobility that is ignored by the ideological function of the Redneck. The latter seeks the flashy, the Larry the Cable Guy, and misses the point: humility and actual want lead to glory and purity. Putting on the tattered shirt when you make millions means very little, means about the same thing as putting on a tie and sitting in a boardroom. Really, the faux-redneck and the corporate raider are individuals of the same sort. They are usurpers of the common person, oppressors who seek to make profit at the expense of those who toil in anonymity. Just as the longleaf forest is trimmed and replaced with commercial pine in Ray's memoir, the "real" redneck of American culture is recast into a commercial version and in so doing loses the diversity of its actual habitat. The redneck loses authenticity and, through that, loses value and meaning. Defending the longleaf and the red cockade offers a way to defend the honor of the actual Southerner, to reclaim self from idea.

More directly, Ray echoes House's claims for the validity of the people. She foregrounds the necessity of resistance. She demands that the common person must stand up against the accepted degradation of Southern and Appalachian environment for economic concerns: 
When we consider what is happening to our forests - and to the birds, reptiles, and insects that live there - we must think also of ourselves. Culture springs from the actions of people in a landscape, and what we, especially Southerners, are watching is a daily erosion of unique folkways as our native ecosystems and all their inhabitants disappear. Our culture is tied to the longleaf pine forest that produced us, that has sheltered us, that we occupy. The forest keeps disappearing, sold off, stolen....All of our names are written on the deed of rapacity. When we log and destroy and cut and pave and replace and kill, we steal from each other and from ourselves. We swipe from our past and degrade our future.

This is a call to action from the place of the degraded. Ray sounds a reveille from the unexpected and ignored individual who is redneck, who does not portray one. Ray and House speak back to the stereotype, offering environmental-social equation as a counter-speech to the more dominant use of the redneck image.

If a political Redneck in the White House can call for bombs, and drilling, and mining as a pseudo-populist necessity, the residents of a region can, perhaps must, step forward to describe the actuality of life as a regional figure. Specific discussion of environmental concerns is somewhat beside the point, whether the issue at hand is 
mountaintop mining or pine forest destruction. Instead, I offer House and Ray as examples of speaking back, the real issue of this chapter. Rednecks aren't supposed to care about these environmental issues, and that is really the significance of these unexpected voices: they can and do make a claim for themselves as a culture, as potent, as mattering at all.

The issue of this chapter and of the entirety of this project is one of multiplicity. I argue here that the voices of Appalachia, of the South, of those whose social and economic positions have been adopted by American pseudo-culture, have things to say that do not fit their popular image. And since I am arguing multiplicity, I find myself in the messiness of blurred distinctions. Simply put, outlining redneck resistance against stereotypical image is an effort without containment, though such an outline would be an important and useful enterprise. However, merely identifying the particular moments when rural Americans act against trope provides little more than a catalog. Instead, I seek in this chapter to raise the issue of resistance and agency, to place into the conversation some of the voices that have been ignored in the social construction of Redneck.

It is important to recognize here the extent to which this opening of multiplicity creates ideological mess. The texts I have referenced in this chapter all work to in some way to break the stereotype of the Redneck, and in that sense these texts operate as tools 
of a growing sense of multiplicity. But the rendition of multiplicity I present is one inescapably colored by my own ideological or theoretical point of view. I am offering texts that counter the national stereotype, which on one hand lends credibility to the stereotype itself. Worse, I am myself implying that my own version of multiplicity gives rise to Appalachian voices more authentically than other versions might provide.

Specifically, notions of natural space bubble through this chapter, and it is clear that I am suggesting that opinions like House's and Ray's are authentic and vital. But it is equally important to recognize the valid space of those who might defend mining, or who might not consider attention to the environment as a crucial Appalachian act. These perspectives, too, must be accepted as authentic Appalachian points of view. The existence of stereotype does not imply that all residents act in opposition to stereotype, nor that "stereotypical" opinions are in some way backward or ill-informed. Further, ignoring the capacity for an individual to support strip mining, for example, would be to write away Appalachian agency as fully as would ignoring the capacity for protest. One isn't necessarily being forced into the Redneck category if one follows expected parameters.

Here, my project echoes the claims of Alden Waitt, who in proposing the inclusion of Appalachian literature in high school classrooms admits that he is demanding that teachers "take on an explicitly political project." He suggests that "[i]f education is truly about presenting students with choices, then Appalachian students 
merit accurate accounts of their history, need tools to critique the erasure of their culture, and deserve to see themselves in the stories that they read" (84). The problem of Redneck identity is that many real people see themselves as stereotypes that do not fit. For the complicated hegemonic reasons I have proposed in this project, many in America adopt and reinforce the stereotypes of the downtrodden, and others find those stereotypes as the only identities left for them to adhere to. The result is both an erasure of actual cultural viability and a tightening of the parameters of American normality, since the Redneck becomes only a totem without agency or reality.

In shifting my focus to one of narrative method, and in arguing for the vocal presence of multiple points of view, I am making a call for voices. The ideological function of the Redneck is to suggest that places like Appalachia speak in one voice. The function of narrative I seek is to reveal that such a notion is patently false. Some of the stories to be told will reinforce stereotype, and no one who drives down a back road in Appalachia can help but recognize the uncomfortable presence of stereotypical images in a real landscape. But some voices will tell stories that compete in small ways and grand strokes; they will identify the surprises that appear within even a stereotypical Appalachian tableau. It is through this layering of voice that the notion of any one kind of Redneck can start to fall away. In telling these stories, residents of Appalachia and the South need not argue away their right to regional identity. Rather, they can tell their way back into national presence just as Trudier Harris tells her way back into the South. 
She claims identity as a Southerner from a position that isn't always given the right to claim Southernness. Such narrative interventions can begin to frame new images that cannot be easily assumed as either monolithic or theoretical.

That's story. That's what my grandpappy would be doing in this chapter, even if I could trace my lineage back to a West Virginia coal mine. And, in a sense, I can. My wife's grandfather ran a motor in such a mine, and her grandmother's family came from the hollers of the state where I earned my Ph.D. I am and I ain't, in just the way the real people of the region are and are not. That's messy, perhaps not quite scholarly but, most importantly, impossible to render in clear ideological form: a Pennsylvania Dutch redneck from Appalachia with a doctorate. And to be totally up front about it all, I've even gone skiing. 


\section{Conclusion}

It all comes down to the imposition of expectation. The long history of redneck characters in American literature affixes to a long tradition of down-homey criticism, which seeps out in popular perceptions of the rural poor. For politicians, comedians, and anyone else who desires a quick link to American authenticity, simplistic perceptions become easy shorthand. Thus the Redneck becomes a totem, stands in for a wide variety of hard-to-pin-down political positions: the Redneck is easy to recognize but hard to finally define.

The supposed villains in this appropriation of identity are difficult to indict. Consider even Deliverance, a text I have already criticized and one responsible for a hefty portion of America's current Redneck image file. Alone, neither the book nor the film deserves blame for the images that lie within. Indeed, there are plenty of stereotypes in action, and there's a strong assertion of narrowed masculinity, but each artifact is also simply a piece of literature. Deliverance's cultural resonance occurs only through the interplay of the literary and cultural with the long-standing expectation of rural depravity.

Early in this project I offered an examination of Tobacco Road, and I did that for more than simple academic genealogy. By the time Tobacco Road came around, readers already expected rural characters to be questionable human beings; this had long been established by the rural rubes of New England and the lazy farmers of the 
Southwestern humorists. Tobacco Road fit into the line of perception well. It reaffirmed the reader expectation of depravity and, more importantly, applied that depravity to a specific agri-economic milieu. So the novel allowed readers to apply perceived authenticity to the characters of the novel. It allowed readers to see the characters as stand-ins for real people — remember the photographs that were included in the 1974 edition. Reality therefore superimposes itself onto literature, which creates a stabilized phantom image for the Redneck.

This veneer of reality, driven by expectation and parallel to literary history, is the ultimate function and source of the Redneck phenomenon I have been exploring. People expect rednecks to be Rednecks, find reinforcement in the literary and cultural characters I have cited in this study, and are therefore predisposed to accept the artificial authenticity of individuals who claim the Redneck identity for their own purposes. The imposition of expectation onto reality has become so complete, in fact, that the Redneck cannot be ignored, has in fact become an almost incontrovertible truth of American popular life.

As a final example of this phenomenon, I turn to Daniel Woodrell's novel Winter's Bone, which also appeared as a film in the summer of 2010. Here, I am less concerned with the novel itself than with the film adaptation. And I am less concerned with the actual on-screen action of the movie than I am with the publicity interviews that went along with it. The film's release coincided with breathless commentary from 
critics, most of who cited the Sundance Film Festival Grand Jury Prize honor for the movie and the indie nature of the director.

In reviewing the film, critic David Edelstein said, “Far be it from me to lecture you on how much better some little indie movies can be for you than mega-budget studio junk....But when you start to get that ' $\mathrm{BP}^{\prime}$ ' feeling, like blobs of gunk are floating in your head, you might actually crave something sharp and true to eat through all the muck" (CBS Sunday Morning). Or, in his print review:

There are moments in the harshly beautiful Winter's Bone in which the characters are so deeply, unfathomably mean in response to a 17-year-old girl's pleas to find her father (or at least his body) that we search their faces for a glimmer of sympathy, kinship anything human. Some filmmakers ... would settle for their masks of indifference or malevolence, because that would clinch the case, Q.E.D., that these clannish Ozark hill folk were born to, or just worn down to, pure evil....But Ree won't stop trying to appeal to something decent in her people....This director, Debra Granik, doesn't let the actors go dead: There is movement, barely perceptible, under the surface. Some vein of compassion, however thin, must be down there. Somewhere. 
While Edelstein's reviews aren't particularly ire-raising, they do include the undercurrent of pop culture interpretation that factors heavily in the Redneck identity. Film and reality begin to conflate; the film's stark images and lack of compassion collide with the preconceived notions of "clannish Ozark hill folk" we've all seen before in Deliverance and elsewhere.

More to that point, if less professionally credentialed, a reviewer from the online Monsters and Critics offers more overt melding of film and reality. "It's unfamiliar terrain in this closed society, the moonshine wars, blood feuds, poverty, and impossibility of escape," Anne Brodie writes. "It's criminal that people live in this forsaken place in this day and age, in the heart of the richest country in the world. The place we see onscreen could be northern Siberia, but it's not - it (sic) a few miles from entertainment and gambling hub Branson, Missouri in one direction and St. Louis the other." Pushing the cinéma vérité further than Edelstein, Brodie editorializes on the horrid conditions of Ozark life. She applies an imagined reality upon the region through the combination of film and previous pop culture experience. Winter's Bone is not a call to action to save Ozark people from their plight, but to Brodie the images within the film ring true enough that the movie becomes a revelation of social injustice.

This is the Redneck at work. This is the unseen function of the image that I've outlined in this project. As Americans, we know what rednecks are because of the images we've seen throughout literary history. As Americans, we know how to respond 
to rural images because of that prior representational experience. Our reaction requires little actual experience, requires even little literary background. The residue of Tobacco Road and Deliverance and Smoky and all the rest create a faux authenticity of region, and the concomitant perceptions let us see, once again, the depraved space of the Redneck.

Typically, the best we' re left with is condescension. As Debra Granik, the director of Winter's Bone, explained on the radio program Fresh Air,

We did choose to shoot in actual homes. It would've been a very difficult feat and probably with very little fruit to, like, try to imitate those homes or build a set that replicates it. Instead, we did come to believe that the only way that we would get the film just jammed with visual detail that was very precise and very much from those coordinates where we were filming was to actually go the full tilt and ... gain access to collaborate with certain families, and then work on their properties, film. (Fresh Air)

She explained it more succinctly in another interview: "There was no chance that this film could come to life in any way that would be close to the book or close to any anthropological sense of precision unless we did it there" (All Things Considered). Granik explains in great detail the wonderful texture of "hand-built" homes in the Ozarks, how filming in houses lent authenticity to the movie's images, since the acquired knickknacks of actual residents set the scene properly. She marvels at how wardrobe 
designers traded new Carhart clothing for old, lived-in stuff the actors could wear on set. She explains her epiphany of respect in filming a scene portraying the lead actor teaching siblings to shoot a gun. Throughout, Granik offers two likely subtexts, one intentional and one likely accidental. 1) The film is authentic, therefore a snapshot of real life; 2) Her filmwork catches and, more importantly, validates the curious lives of this curious region. Granik refers to her work as "anthropology," revealing the truth of the view: she is the regular, viewing the irregular as an object of study. She implies, for example, that normal people would see guns as dangerous. A heritage involving guns appears as abnormal. The lack of violence associated with them surprises Granik, which causes her to assign overwrought cultural significance to the act of firearm education. Thus a tender scene of children portraying that education becomes, for her, a moment to be proud of. In this moment, Granik trumpets her own liberal-mindedness and shares it with the world. The fact of existence for those Appalachians who hunt, shoot, and otherwise deploy firearms becomes a typed action that becomes a mechanism for selfcongratulation. Moreover, it is not the actual passing on of hunting traditions that moves Granik but her own filmed scene of the act. The facsimile becomes the motivating source.

And that, of course, is the problem of rural portrayals. Granik's interpretations and whole-hearted belief in her accuracy are, in turn, the function of the Redneck identity. Film and fiction consume reality, make for us a real world out of the stuff of 
books. The Redneck identity, in the end, is animated by a failure of narrative comprehension. The culprit is not the literature of place itself. The novel Winter's Bone is a lovely, cruel thing, but the author knows his position. He has called himself "country noir," and his writing fits into the same sort of gritty space as Elmore Leonard or Dashiell Hammett — but no one thinks everyone in L.A. is a character in a murder thriller. Indeed, Woodrell offers this comment in the same interview where Granik marvels at her own creation of authentic Ozark life:

I mean, most of the Ozarks life is so tranquil and peaceful and easygoing that you have to kind of sometimes look for this part to find it. It's here, but it's not the overwhelming daily experience or anything. But I have, just by luck or maybe - my father said I had a real instinct for finding these things. And so I just have, one way or another been standing there when enough happened to fill my imagination with what else could happen. (Fresh Air)

Woodrell writes a violent Ozarks because he imagines it as a portion of the world he inhabits. He writes the same sort of grit lit as Harry Crews, Lewis Nordan, Larry Brown — caustic Southern tales that meld the gothic and the violent with a keen sense of place. But each knows, as well, that such tales are not the place. Woodrell, for his part, knows that Appalachia is and it isn't: it is a poverty-stricken region ignored by the rest of the nation, but Appalachia is not only that. For authors, complexity means writing within 
the boundaries of life. Complexity includes an expanse of stereotype, truth, exaggeration, and imagination. Woodrell does no violence to Appalachia in writing violent stories from it because Woodrell, like other regional authors, understands that fictional images and real people are not one in the same.

That kind of conflation is left for the Redneck. Such conflation allows Redneck to lose its roots in region and economy, to become a friable identity that can be put to use to win at Sundance, to sell novels, promote race cars, popularize film, and to create vacant political ideology. The force of words bonds to the persistence of pop culture and creates ideology out of thin air. The Redneck icon divorces image from reality, turns region to trope. It vacates the identity of substance and leaves "redneck" ripe for appropriation.

A fuller understanding of the heritage of the literary redneck and the function of the pop cultural Redneck refills the empty space of the identity. Certainly, the violent images of the backwoods will not disappear, and it would be naïve to expect them to be revised away. In fact, I admire writers like Woodrell and even Dickey: they turn phrases well, write a place well, spin a tale worth reading. But reading such stories requires a complex understanding of their images. To reassert control over the image, readers must recognize the Redneck as production. To become immune to the sort of political image shaping that prevents laid-off Rubbermaid workers from recognizing the horror of shopping at Wal-Mart, or creates support for a war by recirculating tired cowboy 
rhetoric, or reasserts old patriarchal dominance by limiting the agency of strong female redneck characters, Americans must recognize that Redneck is used carefully, consciously, and craftily as a way to win support.

I am arguing in this project for the reassertion of narrative validity, since it is through the stories of the actual regions of Appalachia and the South that a more complicated truth can emerge. Moreover, it is through the multiplicity of these stories and their apparent violation of Redneck expectation that the powerful tropes of that identity can be defused. Real stories of the regions must be told and heard to prevent the recirculation of stereotype that has long churned through American literature. The potential of these unheard stories is the devaluation of Redneck identity: understanding the regions of Appalachia and the South as different than their legends allows regional residents to be seen as different than their caricatures.

Likewise, understanding that these regions harbor, encourage, and allow differing opinion opens up new space where Barack Obama can't be automatically tripped up by a comment on guns. It opens up space where George W. Bush cannot claim Redneck identity and the authority to speak for working class America when he comes from a social background neither redneck nor working class. Narrative, not stereotypical story, offers a way to see, understand, and transform the understanding of regional American rurality and its frequent poverty. Narrative gives America a way to hear and accept the Dixie Chicks as viable critics from within their own subculture, and 
it gives America a way to understand that such criticism is antithetical to neither "country values" nor patriotism. Narrative offers a way to break free from the stale stories that refuse to recognize or respond to the real conditions of the rural poor.

One thing disrupts the rigidity of redneck stereotype: the ability to choose one's identity for oneself. Certainly, rednecks and hillbillies and Southerners and Appalachians are not the only groups of people presented with limited identification choices. And certainly they are not the only groups of people who seek to fashion their own senses of self. But it is these groups I engage in this project, those who are too easily placed into the reductive space of Redneck. I began by considering the term "redneck" itself, a simple word that despite a lack of precision nonetheless has worked to prohibit the exertion of self-formed identity. Conceptually, "redneck" functions as a predetermined defense against diversity. Effectively, the continual reassertions of that identity stabilize mainstream America against incursions of multiplicity. The authors I've cited chip away at the support structures of both the term "redneck" and the ideological functionality of its concurrent identity. In failing to adhere to the presupposed limits of Redneck identity, these redneck authors loosen the hold of the spectacle and offer hope for a future rupture in the exploitation of the rural image.

As an ideology, Redneck means homophobia, xenophobia, eco-phobia, misogyny, racism, economic oppression. Figuratively, Redneck means Larry the Cable Guy, 
Deliverance, NASCAR romance, and the continual reassertion of the lampooned redneck and butt-scooting Southern white trash.

I instead offer a litany of a different sort:

1) Silas House — writing back against King Coal, offering for Appalachians both validity of existence and defense of landscape.

2) Fred Chappell — writing back against the hegemony of identity, arguing that being Appalachian means one can also be intellectual, can leave and still be part of the region, can fashion an identity that couples intellectualism with folk ways.

3) Trudier Harris — writing back against racial limitation, forging space for the authentic Black Southerner who claims identity as Southerner and not as imposition upon the imagined purity of a white South.

4) Janisse Ray — writing back against the disavowal of landscape, claiming the importance of defense of both environment and person.

Yet I do all of this in a manner that cannot be anything other than incomplete. I write my own project of criticism and renewal with the recognition that more work remains. Fuller examinations must argue for the broadest inclusion of counter-intuitive "redneck experience." What of Dorothy Allison writing back against white trash stereotypes in Bastard Out of Carolina, claiming space for the lesbian Appalachian to forge a community of women? What of Lan Cao and Roberto Gonzalez and Susan Choi, writing back against the white-black racial duality of the South in Monkey Bridge and 
Holy Radishes and The Foreign Student? What about Harry Crews and Lewis Nordan and Larry Brown writing new versions of the Southern white trash, who bring validity to the impoverished even as they refuse to succumb to romantic and elitist visions of the equal parts dire equal parts beautiful lives therein? What about the authors unknown, undiscovered, or still so uncelebrated that I've failed to make note? What about those who write new versions of masculinity, new versions of race, new versions of impoverished life, who seek to assert the validity of their own experiences within the symphony of redneck identity?

I can offer nothing more concrete than a question to close this examination: what else, who else, can offer beautiful complication to an identity too easily simplified? 


\section{Bibliography}

Adorno, Theodor W. The Culture Industry: Selected Essays on Mass Culture. J.M. Bernstein, ed. London: Routledge, 1991. Print.

“Airport '07." Family Guy. Fox. 4 Mar. 2007. Television.

Alderman, Derek H., Preston W. Mitchell, Jeffrey T. Webb, and Derek Hanak. “Carolina Thunder Revisited: Toward a Transcultural View of Winston Cup Racing." Professional Geographer 55.2 (2003): 238-249. Print.

Allen-Mills, Tony and Nina Berman. "God, Guns and Glory.” The Sunday Times (London). 3 Aug. 2008. Web. 15 Jan. 2010.

Althusser, Louis. "Ideology and Ideological State Apparatuses." Lenin and Philosophy and Other Essays. New York and London: Monthly Review Books, 1971. 127-186. Print. Antonowicz, Anton. "Proud to be a Redneck: Palin Dad-to-be in Web Boast." The Mirror 3 Sept. 2008. Web. 15 Jan. 2010.

Applebome, Peter. Dixie Rising: How the South is Shaping American Values, Politics, and Culture. New York: Times Books, 1996. Print.

Arnold, Edwin T. “Unruly Ghost: Erskine Caldwell at 100.” Southern Review 39.4 (2003): 851-868. Print.

Azzerad, Michael. “Grandpa was a Honky-Tonker.” Rolling Stone 1 Dec. 1998: 38. Print. Bageant, Joe. Deer Hunting With Jesus: Dispatches from America's Class War. New York: Random House, 2007. 
Ballard, Sandra. "Where Did Hillbillies Come From? Tracing Sources of the Comic Hillbilly Foil in Literature." Back Talk From Appalachia: Confronting Stereotypes. Eds.

Dwight B. Billings, Gurney Norman, and Katherine Ledford. Lexington, KY: U Press of Kentucky, 2001. 138-149. Print.

Barnett, Pamela E. “James Dickey's Deliverance: Southern, White, Suburban Male Nightmare or Dream Come True?" Forum for Modern Language Studies 40.2 (2004): 145-59. Print.

Bartley, Numan V. The New South, 1945-1980. Baton Rouge: LSU Press, 1995. Print. Bass, Jack and Walter De Vries. The Transformation of Southern Politics: Social Change and Political Consequences Since 1945. Athens, GA: U Georgia Press, 1995. Print. Baudrillard, Jean. "Simulacra and Simulations." Jean Baudrillard: Selected Writings. Ed. Mark Poster. Stanford: Stanford U Press, 2001. 169-187. Print.

-----. “The System of Objects." Jean Baudrillard: Selected Writings. Ed. Mark Poster. Stanford: Stanford U Press, 2001. 12-31. Print.

Biggers, Jeff. The United States of Appalachia: How Southern Mountaineers Brought Independence, Culture, and Enlightenment to America. Emeryville, CA: Shoemaker\&Hoard, 2007. Print. Billings, Dwight B., Gurney Norman, and Katherine Ledford, eds. Back Talk From Appalachia: Confronting Stereotypes. Lexington: U Press of Kentucky, 2001. Print. Black, Clint. “Iraq and Roll” Clint Black, 2003. Digital Music. 
Black, Earl and Merle Black. Politics and Society in the South. Cambridge, MA: Harvard U Press, 1987. Print.

-----. The Vital South: How Presidents are Elected. Cambridge, MA: Harvard U Press, 1993. Print.

------. The Rise of Southern Republicans. Cambridge, MA: Belknap Press of Harvard U Press, 2002. Print.

Blue Collar Comedy Tour, the Movie. Dir. C.B. Harding. Perf. Jeff Foxworthy, Bill Engvall, Ron White, Larry the Cable Guy. Gaylord Films, 2003. DVD.

Blue Collar Comedy Tour Rides Again. Dir. C.B. Harding. Perf. Jeff Foxworthy, Bill Engvall, Ron White, Larry the Cable Guy. BC Productions, 2004. DVD.

Bly, Robert. Iron John. Reading, MA: Addison-Wesley, 1990. Print.

Bone, Martyn. The Postsouthern Sense of Place in Contemporary Fiction. Baton Rouge: LSU Press, 2005. Print.

Boulton, Andrew. "The Popular Geopolitical Wor(1)ds of Post-9/11 Country Music." Popular Music and Society 31.3 (July 2008): 373-387. Print.

Brodie, Anne. “Winter's Bone Movie Review.” Monsters and Critics 20 June 2010. 22 June 2010. Web.

Bronner, Simon J., ed. Manly Traditions: The Folk Roots of American Masculinities. Bloomington IN: Indiana U Press, 2005. Print. 
-----. "Menfolk." Manly Traditions: The Folk Roots of American Masculinities. Ed. Simon J. Bronner. Bloomington IN: Indiana U Press, 2005. 1-58.

Brundage, W. Fitzhugh. The Southern Past: A Clash of Race and Memory. Cambridge, MA: Belknap Press, 2005. Print.

Bullock III, Charles S. and Mark J. Rozell, eds. The New Politics of the Old South, 3rd Edition. Lanham, MD: Rowman \& Littlefield, 2007. Print.

Burns, Shirley Stewart. Bringing Down the Mountains: The Impact of Mountaintop Removal on Southern West Virginia Communities. Morgantown, WV: West Virginia U Press, 2007. Print.

“'Cable Guy' Makes it Big.” 60 Minutes. Narr. Bob Simon. CBS. 12 Aug 2007. Television. Caldwell, Erskine, Tobacco Road. 1932. Savannah, GA: Beehive Press, 1974. Print.

Cao, Lan. Monkey Bridge. New York: Penguin, 1998. Print.

Carr, Duane. A Question of Class: the Redneck Stereotype in Southern Fiction. Bowling Green, OH: Bowling Green U Popular Press, 1996. Print.

Carter, Jimmy. Keeping Faith: Memoirs of a President. New York: Bantam Books, 1982.

-----. An Hour Before Daylight: Memories of a Rural Boyhood. New York: Simon \& Schuster, 2001. Print.

Carter, Julian B. The Heart of Whiteness: Normal Sexuality and Race in America 1880-1940. Durham, NC: Duke U Press, 2007. Print.

Chappell, Fred. Look Back All the Green Valley. New York: Picador, 1999. Print. 
-----. "Too Many Freds." More Lights Than One: On the Fiction of Fred Chappell. Ed.

Patrick Bizzaro. Baton Rouge: LSU Press, 2004. 256-271. Print.

Choi, Susan. The Foreign Student. New York: Harper Perennial, 1999. Print.

Clinton, Bill. My Life. New York: Alfred A. Knopf, 2004. Print.

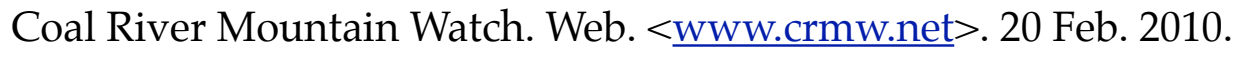

Cobb, James C. Redefining Southern Culture: Mind and Identity in the Modern South.

Athens, GA: U of Georgia Press, 1999. Print.

-----. Away Down South: A History of Southern Identity. New York: Oxford U Press, 2005.

Print.

Cook, Sylvia Jenkins. Erskine Caldwell and the Fiction of Poverty: The Flesh and the Spirit.

Baton Rouge: Louisiana State U Press, 1991. Print.

Cooper, James Fenimore. The Pioneers. 1823. Leatherstocking Tales I. New York: Library of America, 1985. Print.

-----. The Last of the Mohicans. 1826. Leatherstocking Tales I. New York: Library of America, 1985. Print.

-----. The Prairie. 1827. Leatherstocking Tales I. New York: Library of America, 1985. Print. Cowboy Take Me Away. Perfs. Dixie Chicks. Dir. Nancy Bardawil. 1999. Music video. CMT. Web. 4 March 2010.

Cowie, Jefferson. "From Hard Hats to the NASCAR Dads." New Labor Forum 13.3 (Fall 2004): 9-17. Print. 
Darling, Eliza Jane. "O Sister! Sarah Palin and the Parlous Politics of Poor White Trash.” Dialectical Anthropology 33.1 (March 2009): 15-27. Web.

Davis, Dee. “Why Don't Those Hillbillies Like Obama?" Salon 20 May 2008. Web. 15 Jan. 2010.

Debord, Guy. The Society of the Spectacle. 1967. New York: Zone Books, 1994. Print.

Deliverance. Dir. John Boorman. Perf. John Voight, Burt Reynolds, Ned Beatty. Warner Brothers Films, 1972. DVD.

Deloria, Philip J. Playing Indian. New Haven: Yale U Press, 1998. Print.

Dickey, James. Deliverance. New York: Houghton Mifflin, 1970. Print.

Dickinson, Georgia. “'Redneck' Boyfriend Joins Palins on Stage.” Canberra Times 4 Sept. 2008. Web. 15 Jan. 2010.

Dixie Chicks. “Cowboy Take Me Away.” Fly. Nashville: Monument Records, 1999. CD.

Dixie Chicks. “Goodbye Earl.” Fly. Nashville: Monument Records, 1999. CD.

Duck, Leigh Anne. The Nation's Region: Southern Modernism, Segregation, and U.S. Nationalism. Athens, GA: U Georgia Press, 2006. Print.

Duggan, Lisa. The Twilight of Equality? Neoliberalism, Cultural Politics, and the Attack on Democracy. Boston: Beacon Press, 2003.

Dukes of Hazzard. CBS, 1979-1985. Television.

Dyer, Richard. White. London: Routledge, 1997. Print. 
Ebert, Teresa L. “The Romance of Patriarchy: Ideology, Subjectivity, and Postmodern Feminist Cultural Theory." Cultural Critique 10 (Autumn 1988): 19-57. Print.

Edelstein, David. “Ozark Gothic.” New York Magazine 6 June 2010. 22 June 2010. Web.

Edelstein, David. CBS Sunday Morning. CBS. 20 June 2010. Television.

Edmunds, J. Spencer. "Metanarrative and the Story of Life in the Kirkman Tetralogy." More Lights Than One: On the Fiction of Fred Chappell. Patrick Bizzaro, ed. Baton Rouge: LSU Press, 2004. 92-118. Print.

Elder, Ronald. "Foreword." Back Talk from Appalachia: Confronting Stereotypes. Eds. Dwight B. Billings, Gurney Norman, and Katherine Ledford. Lexington, KY: U Press of Kentucky, 2001. Print.

Elias, Amy J. “Postmodern Southern Vacation: Vacation Advertising, Globalization, and Southern Regionalism." South to a New Place: Region, Literature, Culture. Eds. Suzanne W. Jones and Sharon Monteith. Baton Rouge, LA: LSU Press, 2002. 251-282. Print. Emerson, Ralph Waldo. "Self-Reliance." Self-Reliance and Other Essays. New York: Dover, 1993. 19-39. Print.

Encyclopedia of Appalachia. Eds. Rudy Abramson and Jean Haskell. Knoxville: U of Tennessee Press, 2006. Print.

Encyclopedia of Southern Culture. Eds. Charles Reagan Wilson and William R. Ferris. Chapel Hill: U of North Carolina Press, 1989. Print. 
Entzminger, Betina. "Come Back to the Raft Ag'in, Ed Gentry." Southern Literary Journal 40.1 (Fall 2007): 98-113. Print.

Farmer, Angela. “The Worst Fate: Male Rape as Masculinity Epideixis in James Dickey's Deliverance and the American Prison Narrative." Atenea 28.1 (June 2008): 103-115. Print.

Fernandez, Roberto. Holy Radishes. Houston: Arte Publico Press, 1995. Print.

Ferrence, Matthew. “Make it Up, Make it Right: Presidential Truth Through

Biographical Falsity in Edmund Morris's Dutch." EAPSU On-line 3.1 (Fall 2006):

131-143. Web.

-----. “Home Sweet Roadhouse.” Nebula 4.1 (March 2007): 84-89. Web.

Fischer, David Hackett. Albion's Seed: Four British Folkways in America. New York: Oxford U Press, 1989. Print.

Fones-Wolf, Ken and Ronald L. Lewis, eds. Transnational West Virginia: Ethnic Communities and Economic Change, 1840-1940. Morgantown, WV: West Virginia U Press, 2002. Print.

Gaines, Abby. Teaming Up. Toronto: Harlequin Books, 2008. Web.

Gator. Dir. Burt Reynolds. Perf. Burt Reynolds, Jerry Reed, Lauren Hutton. LevyGardner-Laven, 1976. DVD.

“George W. Bush.” WhiteHouse.gov. The White House. 2 Feb. 2010. Web. 
Goldberg, David Theo. Racist Culture: Philosophy and the Politics of Meaning. New York: Wiley, 1993. Print.

-----. “The Social Formation of Racist Discourse." Anatomy of Racism. David Theo Goldberg, ed. Minneapolis: U of Minnesota Press, 1990. 295-318. Print.

Goodbye Earl. Perfs. Dixie Chicks. Dir. Evan Bernard. 2000. Music video. CMT. Web. 4 March 2010.

Grammer, John. Pastoral and Politics in the Old South. Baton Rouge: LSU Press, 1996. Print.

Greenhaw, Wayne. Elephants in the Cottonfields: Ronald Reagan and the New Republican South. New York: Macmillan, 1982. Print.

Hale, Grace Elizabeth. Making Whiteness: the Culture of Segregation in the South, 1890-1940. New York: Pantheon Books, 1998. Print.

Harnden, Toby. “Daughter's ‘Redneck' Boyfriend Adds to Palin's Campaign Woes.” The Daily Telegraph 3 Sept. 2008. Web. 15 Jan. 2010.

Harkins, Anthony. Hillbilly: A Cultural History of an American Icon. New York: Oxford U Press, 2005. Print.

Harris, George Washington. Sut Lovingood Yarns Spun By a "Nat'ral Born Durn'd Fool," Warped and Wove for Public Wear." New York: Sick and Fitzgerald, 1867. Print. Harris, Trudier. Summer Snow: Reflections from a Black Daughter of the South. Boston: Beacon Press, 2003. Print. 
Harvey, Paul. Freedom's Coming: Religious Culture and the Shaping of the South from the Civil War through the Civil Rights Era. Chapel Hill, NC: U of North Carolina Press, 2005. Print.

Hauhart, Robert C. "The Blue Collar Comedy Tour: Southern Fried Humor in the Context of Class Society." Journal for Cultural Research 12.3 (July 2008): 269-279. Print. Hoggart, Richard. The Uses of Literacy: Aspects of Working Class Life. London: Chatto \& Windus, 1957.

House, Silas. Clay's Quilt. Chapel Hill, NC: Algonquin Books, 2001. Print.

-----. “A Conscious Heart.” Journal of Appalachian Studies 14.1/ 2 (Spring 2008): 7-19.

Print.

-----, and Jason Howard. Something's Rising: Appalachians Fighting Mountaintop Removal. Lexington KY: U of Kentucky Press, 2009. Print.

Hovis, George. “'When You got True Dirt You Got Everything You Need': Forging an Appalachian Arcadia in Fred Chappell's Midquest." Mississippi Quarterly 53.3 (Summer 2000): 389-414. Print.

Howell, Mark D. From Moonshine to Madison Avenue: A Cultural History of the NASCAR Winston Cup Series. Bowling Green, OH: Bowling Green U Popular Press, 1997. Print. Huber, Patrick. "'A Short History of 'Redneck': the Fashioning of a Southern White Masculine Identity." Southern Cultures 1.2 (1995): 145-166. Print. 
------. “Rednecks and Red Bandanas: Appalachian Coal Miners and the Coloring of Union Identity, 1912-1936." Western Folklore 65.1 (Winter 2006): 195-210. Print. ILoveMountains.org. Web. 20 Feb, 2010.

Jackson, Alan. "Where Were You (When the World Stopped Turning)." Drive. Arista, 2002. DVD.

Jarosz, Lucy and Victoria Lawson. “Sophisticated People Versus Rednecks: Economic Restructuring and Class Difference in America's West." Antipode 34.1 (Jan 2002): 8-27. Print.

JefJimmy Wang Yang. 2007. World Wrestling Entertainment. Web. 17 June 2007. Johannsen, Kristin, Bobbie Ann Mason, and Mary Ann Taylor-Hall. Missing Mountains: We Went to the Mountaintop but it Wasn't There. Nicholasville, KY: Wind Publications, 2005. Print.

Jones, Anne Goodwyn. "The Tools of the Master: Southernists in Theoryland." Bridging Southern Cultures. Ed. John Lowe. Baton Rouge, LA: LSU Press, 2005. 172-196. Print. Jones, Suzanne W. and Sharon Monteith, eds. South to A New Place: Region, Literature, Culture. Baton Rouge: LSU Press, 2002. Print.

Keith, Toby. "Courtesy of the Red, White, \& Blue (The Angry American)." Unleashed. Dreamworks, 2002. DVD.

Kellner, Douglas. "Media Spectacle and the 2008 Presidential Election." Cultural Studies<->Critical Methodologies 9.6 (Dec 2009): 707-716. Print. 
Key, V.O. Southern Politics in State and Nation. 1949. Knoxville. TN, U of Tennessee Press, 1984. Print.

Kimmel, Michael S., editor. The Politics of Manhood. Philadelphia: Temple U Press, 1995. Print.

-----. “'Born to Run': Nineteenth-Century Fantasies of Masculine Retreat and ReCreation (or The Historical Rust on Iron John". The Politics of Manhood. Michael S. Kimmel, ed. Philadelphia: Temple U Press, 1995. 115-150. Print.

------ and Michael Kaufman. “Weekend Warriors: the New Men's Movement." The Politics of Manhood. Michael S. Kimmel, ed. Philadelphia: Temple U Press, 1995. 15-43. Print.

King, Florence. “Words Mean...Things.” National Review 47.2 (1995): 84. Print.

King, Vincent. “Hopeful Grief: The Prospect of a Postmodernist Feminism in Allison's Bastard Out of Carolina." Southern Literary Journal 33.1 (Fall 200): 122-140. Print. Kirby, Jack Temple. Mockingbird Song: Ecological Landscapes of the South. Chapel Hill, NC: U of North Carolina Press, 2006. Print.

Kneeland, Douglas E. “Reagan Campaigns at Mississippi Fair.” The New York Times 4 Aug. 1980: A11. Print.

Knepper, Steven. “Do You Know What the Hail You're Talkin' About?: Deliverance, Stereotypes, and the Lost Voice of the Rural Poor." James Dickey Newsletter 25.1 (2008): 17-29. Web. 
Kreyling, Michael. Inventing Southern Literature. Jackson, MS: U Mississippi Press, 1998.

Print.

“Larry the Cable Guy Before Redneck.” Video. You Tube. Web. 10 Jan. 2010.

Larry the Cable Guy: Git-R-Done. Dir. Michael Drumm. Perf. Larry the Cable Guy. Parallel Entertainment, 2004. DVD.

Lawrence, D.H. Studies in Classic American Literature. New York: Thomas Seltzer, Inc., 1923. Print.

Ledford, Katherine. “'A Landscape and a People Set Apart:' Narratives and Travel in Early Appalachia." Back Talk From Appalachia: Confronting Stereotypes. Eds. Dwight B. Billings, Gurney Norman, and Katherine Ledford. Lexington, KY: U Press of Kentucky, 2001. 47-66. Print.

Leibovich, Mark. "Rednecks for Obama?" The Caucus: the Politics and Government Blog of The Times New York Times Co. 25 Aug. 2008. Web. 15 Jan. 2010.

Longstreet, Augustus Baldwin. Georgia Scenes. New York: Harper \& Row, 1840. Print. Lowe, John. Bridging Southern Cultures. Baton Rouge, LA: LSU Press, 2005. Print.

McDonald, Robert. The Critical Response to Erskine Caldwell. Westport, CT: Greenwood, 1997. Print.

Macintyre, Ben. “Who'd Have Thought it? There's a Redneck Revolution Taking Shape in Them Thar' Hills." The Times (London) 4 Oct. 2008. Web. 15 Jan. 2010. 
Madden, Ed. “The Buggering Hillbilly and the Buddy Movie: Male Sexuality in Deliverance." The Way We Read James Dickey Eds. William B. Thesing and Theda Wrede. Columbia SC: U of South Carolina Press, 2009. 195-209. Print.

Malphurs, Ryan. “The Media's Frontier Construction of President George W. Bush.” Journal of American Culture 31.2 (2008): 185-201. Print.

Malone, Bill C. Don't Get Above Your Raisin': Country Music and the Southwestern Working Class. Urbana: U of Illinois Press, 2002. Print.

Marlacher, Jay. “'A Wallow in Slime': the Attempt to Censor Tobacco Road in New Orleans." Journal of American Drama and Theatre 15.3 (Sept. 2003): 87-100. Print. Maynard, Lee. Crum. 2nd Edition. Morgagntown, WV: Vandalia Press, 2001. Originally published New York: Washington Square Press, 1988. Print.

McCarthy, Anna. “Blue-Collar Joke.” New Labor Forum 15.2 (Summer 2006): 135-140. Web.

McPherson, Tara. Reconstructing Dixie. Durham, NC: Duke U Press, 2003. Print.

Miller, Dan B. Erskine Caldwell: The Journey from Tobacco Road. New York: Knopf, 1995. Print.

Miller, Danny. American Vein: Critical Readings in Appalachian Literature. Athens, OH: Ohio U Press, 2005. Print.

Mills, Charles W. The Racial Contract. Ithaca: Cornell U Press, 1997. Print. “Modern Library: 100 Best Novels.” Random House 1998. Web. 9 Nov. 2009. 
Modleski, Tania. “The Disappearing Act: A Study of Harlequin Romances.” Signs 5.3 (Spring 1980): 435-448. Print.

-----. Loving with a Vengeance: Women's Narrative Pleasures. Hamden CT: Archon Books 1982. Print.

Murphy, Reg and Hal Gulliver. The Southern Strategy. New York: Charles Scribner's Sons, 1971. Print.

Nelson, Dana. National Manhood: Capitalist Citizenship and the Imagined Fraternity of White Men. Durham, NC: Duke U Press, 1998. Print.

Newman, Joshua I. “Old Times There are not Forgotten: Sport, Identity, and the Confederate Flag in the Dixie South." Sociology of Sport Journal 24.3 (Sept. 2007): 261-282. Print. and Michael D. Giardina. “NASCAR and the 'Southernization' of America: Spectatorship, Subjectivity, and the Confederation of Identity." Cultural Studies, Critical Methodologies 8.4 (Nov. 2008): 479-506. Print.

O'Brien, Michael. Placing the South. Jackson, MS: U Press of Mississippi, 2007. Print. Oxford Encyclopedia of American Literature. New York: Oxford U Press, 2004. Print. Palin, Sarah. Going Rogue: An American Life. New York: Harper, 2009. Print. Palmer, Louis. “Bourgeois Blues: Class, Whiteness, and Southern Gothic in Early Faulkner and Caldwell." Faulkner Journal 22.1-2 (2006): 120-139. Web. 
Parry-Giles, Shawn J. and Trevor Parry-Giles. Constructing Clinton:

HyperrealityEPresidential Image-Making in Postmodern Politics. New York: Peter Lang, 2002. Print.

Peterson, Richard A. Creating Country Music: Fabricating Authenticity. Chicago: U of Chicago Press, 1997. Print.

Pierce, Dan. “Bib Overalls \& Bad Teeth: the Southern Piedmont Working-Class Roots of Nascar." Atlanta History 46.2 (Jan 2004): 26-41. Print.

Radway, Janice A. Reading the Romance: Women, Patriarchy, and Popular Literature. Chapel Hill: U of North Carolina Press, 1984. Print.

-----. A Feeling for Books: the Book-of-the-Month Club, Literary Taste, and Middle-Class Desire. Chapel Hill: U of North Carolina Books, 1999. Print.

Ransom, John Crowe et al. I'll Take My Stand: the South and the Agrarian Tradition. New York: Harper, 1962. Print.

Ray, Janisse. Ecology of a Cracker Childhood. Minneapolis: Milkweed Editions, 1999. Print.

“Redneck.” The Oxford English Dictionary. $2^{\text {nd }}$ ed. 1989. Web.

Reed, John Shelton. “The South's Midlife Crisis.” Bridging Southern Cultures. Ed. John Lowe. Baton Rouge: LSU Press, 2005: 254-264. Print.

-----. "Southern Culture: On the Skids?" American South in the Twentieth Century. Eds.

Craig S. Pascoe, Karen Trahan Leathem, and Andy Ambrose. Athens GA: U of Georgia Press, 2005: 143-153. Print. 
Reid, Jan. The Improbable Rise of Redneck Rock. 1977. Austin, TX: U Texas Press, 2004. Print.

Reingold, Beth and Richard S. Wilke. "Confederate Symbols, Southern Identity, and Racial Attitudes: the Case of the Georgia State Flag." Social Science Quarterly 79.3 (Sept. 1998): 568-580. Print.

Regis, Pamela. A Natural History of the Romance Novel. U of Pennsylvania Press, 2003. Print.

Roberts, Diane. "Afterword: The South of the Mind." South to a New Place: Region, Literature, Culture. Eds. Suzanne W. Jones and Sharon Monteith. Baton Rouge: LSU Press, 2002. 363-373. Print.

Rodgers, Raymond S. "Images of Rednecks in Country Music: the Lyrical Persona of a Southern Superman." Journal of Regional Cultures 1.2 (1981): 71-81. Print.

Rogin, Michael Paul. Ronald Reagan, the Movie: and Other Episodes in Political Demonology. Berkeley: U of California Press, 1987. Print.

Romine, Scott. "Where is Southern Literature? The Practice of Place in a Postsouthern Age." South to a New Place: Region, Literature, Culture. Eds. Suzanne W. Jones and Sharon Monteith. Baton Rouge, LA: LSU Press, 2002. 23-43. Print.

-----. The Real South: Southern Narrative in the Age of Cultural Reproduction. Baton Rouge: LSU Press, 2008. Print. 
Rubin, Louis. The Mockingbird in the Gum Tree: A Literary Gallimaufry. Baton Rouge: LSU Press, 1991. Print.

"A Saga in the Ozarks, Suited for the Screen." Fresh Air. Narr. Terry Gross. National Public Radio. WHYY. 16 June 2010. Print. Transcript.

Shakespeare, William. The Tempest. Print.

Shapiro, Henry. Appalachia on My Mind: the Southern Mountains and Mountaineers in the American Consciousness, 1870-1920. Chapel Hill, NC: U of North Carolina Press, 1986.

Print.

Shelby, Anne. “The 'R' Word: What's so Funny (and Not so Funny) About Redneck Jokes." Back Talk From Appalachia: Confronting Stereotypes. Eds. Dwight B. Billings, Gurney Norman, and Katherine Ledford. Lexington, KY: U Press of Kentucky, 2001. 153-160. Print.

Shiflett, Dave. "Bush vs. Brush: the Zen of the President's Pastime." National Review 28 Jan. 2002: 28-30. Print.

Shnayerson, Michael. Coal River. New York: Farrar, Straus and Giroux, 2008. Print. Shut Up and Sing. Dirs. Barbara Kopple and Cecilia Peck. Cabin Creek Films, 2006. DVD. Silver, Andrew. “Laughing Over Lost Causes: Erskine Caldwells's Quarrel with Southern Humor." Mississippi Quarterly 50.1 (1996). Web. Simpson, Lewis. The Fable of the Southern Writer. Baton Rouge: LSU Press, 2003. Print. 
Slotkin, Richard. Regeneration Through Violence: the Mythology of the American Frontier,

1600-1860. Middletown, CT: Wesleyan U Press, 1973. Print.

-----. Fatal Environment: the Myth of the Frontier in the Age of Industrialization, 1800-1890.

New York: Antheneum, 1985. Print.

-----. Gunfighter Nation: the Myth of the Frontier in Twentieth-Century America. New York:

Atheneum, 1992. Print.

Smith, Heather A. and Owen J. Furuseth, eds. Latinos in the New South: Transformations of Place. Burlington, VT: Ashgate Publishing, 2006. Print.

Smith, Henry Nash. Virgin Land: The American West as Symbol and Myth. Cambridge, MA: Harvard U Press, 1950. Print.

Smith, Jon. "Southern Culture on the Skids: Punk Retro, Narcissism, and the Burden of Southern History." South to a New Place: Region, Literature, Culture. Eds. Suzanne W. Jones and Sharon Monteith. Baton Rouge: LSU Press, 2002. 76-95. Print.

Smokey and the Bandit. Dir. Hal Needham. Perf. Burt Reynolds, Sally Field, Jerry Reed, Jackie Gleason. Rastar Pictures, 1977. DVD.

“Stone Mountain.” 30 Rock. NBC. 29 Oct. 2009. Television.

Taylor, Helen. Circling Dixie: Contemporary Southern Culture through a TransAtlantic Lens. Piscataway, NJ: Rutgers U Press, 2000. Print.

Tilove, Jonathan. “Obama's Appalachian Problem. The Seattle Times 15 May 2008. Web. 15 Jan. 2010. 
True Blood. HBO. New York, 2008-1010. Television.

Turner, Frederick Jackson. The Frontier in American History. New York: Henry Holt, 1920. Print.

Vavrus, Mary Douglas. “The Politics of NASCAR Dads: Branded Media Paternity.” Critical Studies in Media Communication 24.3 (Aug. 2007): 245-261. Print.

Vials, Chris. "Whose Dixie? Erskine Caldwell's Challenge to Gone with the Wind and Dialectical Realism." Criticism 48.1 (2006): 69-94. Print.

Von Doviak, Scott. Hick Flicks: the Rise and Fall of Redneck Cinema. Jefferson, NC: McFarland \& Co, 2005. Print.

Waitt, Alden. “'A Good Story Takes Awhile': Appalachian Literature in the High School Classroom." Journal of Appalachian Studies 12.1 (Spring 2006): 79-101. Web.

“Wallace's Army: the Coalition of Frustration." Time 18 Oct. 1968. 15 Sept. 2010. Web.

Watson, Jay. “Economics of a Cracker Landscape: Poverty as an Environmental Issue in Two Southern Writers." Mississippi Quarterly 55.4 (Fall 2002): 497-513. Print.

Webster, Gerald R. and Jonathan I Leib. “Whose South is it Anyway? Debating the Confederate Battle Flag in South Carolina." Political Geography 20.3 (March 2001): 271-99. Print.

White, Betty. “More Than Macho.” Saturday Evening Post 250.6 (Sept. 1978): 60-128. Print. 
White Lightning. Dir. Joseph Sargent. Perf. Burt Reynolds, Jennifer Billingsley, Ned Beatty. Levy-Gardner-Laven, 1973.

Williamson, Jerry Wayne. Hillbillyland: What the Movies Did to the Mountains and What the Mountains Did to the Movies. Chapel Hill: U of North Carolina Press, 1995. Print. Willman, Chris. Rednecks and Bluenecks: the Politics of Country Music. New York: New Press, 2005. Print.

Wilson, Gretchen. “Redneck Woman." Here For the Party. Nashville: Sony Records, 2004. CD.

Wilson, Gretchen. Redneck Woman: Stories From My Life. New York: Warner Books, 2006. Print.

“Winter's Bone Director Re-creates Life in the Ozarks." Narr. Michelle Norris. All Things Considered. National Public Radio. 11 June 2010. Radio.

Woodrell, Daniel. Winter's Bone. New York: Little, Brown, and Co. , 2006. Print. Worley, Darryl. “Have You Forgetten?” Have You Forgotten? DreamWorks, 2003. CD. Wray, Matt. Not Quite White: White Trash and the Boundaries of Whiteness. Durham, NC: Duke U Press, 2006. Print.

Wrede, Theda. “Nature and Gender in James Dickey's Deliverance: an Ecofeminist Reading." The Way We Read James Dickey Eds. William B. Thesing and Theda Wrede. Columbia SC, U of South Carolina Press, 2009. 177-192. Print.

Wright, Chely. "The Bumper of My S.U.V." The Metropolitan Hotel. Dualtone, 2004. CD. 
Zernike, Kate. "Palin Assails Obama at Tea Party Meeting." New York Times 6 Feb. 2010. Web. 18 March 2010.

Zombieland. Dir. Ruben Fleischer. Perf. Woody Harrelson. Columbia Pictures, 2009. DVD. 


\section{Curriculum Vitae \\ Matthew Joseph Ferrence \\ mferrenc@mix.wvu.edu}

\section{EDUCATION}

Ph.D. West Virginia University, Morgantown, WV, December 2010.

Swiger Doctoral Fellow

Emphasis: American Literature

M.F.A. University of Pittsburgh, Pittsburgh, PA, 1999.

Creative Writing

B.A. Indiana University of Pennsylvania, Indiana, PA, 1997.

summa cum laude

Major: English

Minor: Biology

\section{DISSERTATION}

You Are and You Ain't: Redneck Literature and the Imposition of Identity.

Committee: John Ernest, director (WVU); Gwen Bergner (WVU); Timothy Sweet (WVU); John Grammer (University of the South); Dennis Allen (WVU).

M.F.A. THESIS

Primitive Conditions: a novel.

Lewis Nordan, director; Catherine Gammon; James Knapp.

TEACHING ACTIVITIES

Indiana University of Pennsylvania-Indiana, PA

-Assistant Professor (full-time, non-tenure), Fall 2010-Spring 2011.

-Instructor (full-time, non-tenure), Fall 2008-Spring 2010.

ENG 101: College Writing

ENG 121: Humanities Literature

ENG 202: Research Writing

ENG 212: American Literature to 1900 
Winter Wheat Festival at Bowling Green State University - Bowling Green, $\mathrm{OH}$ -Session Instructor, November 12-14, 2009.

"The Lyrical Jock." Creative Nonfiction Writing Seminar.

West Virginia University-Morgantown, WV

-Swiger Doctoral Fellow, Fall 2005-Summer 2008.

ENG 102: Composition II

ENG 253: Southern Writers

-Guest Instructor, Spring 2008.

ENG 618: Graduate Writing Workshop, Nonfiction

ENG 242: American Literature II

-Writing Tutor, Fall 2005-Spring 2006.

University Writing Center

Cochise College-Sierra Vista, AZ

-Adjunct Instructor, Spring 2002.

ENG 101: Freshman Writing

University of Arizona-Tucson, AZ

-Graduate Associate Teacher, Fall 2001.

ENG 101: Writing I

Clarion University-Clarion, PA

-Instructor (full time, non-tenure), Fall 2000-Spring 2001.

ENG 110: Writing I

ENG 111: Writing II

ENG 130: Literary Experience

Cambria County Area Community College-Johnstown, PA

-Adjunct Instructor, Summer 1999.

ENG 101: Writing I

University of Pittsburgh—Pittsburgh, PA

-Part-time Instructor, Fall 1997-Spring 1999.

University Writing Center

General Writing Intensive

\section{SCHOLARLY PUBLICATIONS}

"Breaking the Filibuster of Race: the Literary Resonance of the Emmett Till Murder." Arkansas Review 41.1 (Spring 2010): 45-62. 
"The Naturalized Redneck: Performing Citizenship through Patriotic Submission." Popular Culture Review 19.2 (Summer 2008): 61-67.

"Make it Up, Make it Right: Presidential Truth Through Biographical Falsity in Ed- mund Morris's Dutch." EAPSU On-line 3.1 (Fall 2006): 131-143.

Book abstract. Bedford Bibliography for Teachers of Basic Writing Ed. Greg Glau and Linda Adler-Kassner. Bedford-St Martins, 2001.

\section{CREATIVE PUBLICATIONS}

"Museum Piece." Literary essay. Puckerbrush Review 27.1 (Summer/Fall 2010): 31-34.

“Spaces Between." Literary essay. Blue Mesa Review 23 (Spring 2010): 66-78.

"Rules of the Game." Literary essay. Stymie 2.1 (Summer 2009): 21-29. Nominated for 2009 Pushcart Prize and 2010 Dzanc Books Best of the Web Prize.

"Highways and Fairways." Literary essay. Crab Orchard Review 14.1 (Winter/ Spring 2009): 174-182.

"Viewed From Above." Literary essay. Concho River Review 22.2 (Fall 2008): 69-80.

"On the Turquoise Tee." Literary essay. Blue Mesa Review 20/21 (Fall 2007/Spring 2008): 68-77.

"Home Sweet Roadhouse." Literary essay. Nebula 4.1 (March 2007): 84-89.

"Envy in the Sky." Literary Essay. Verbsap April 2006; selected for special highlight issue in July 2006.

“Marianna Trench.” Poem. New Growth Arts Review, Spring 1997.

\section{CONFERENCE PRESENTATIONS}

"Redneck Spectacle." Conference Paper. Pop Culture Association of the South/ American Culture Association of the South Annual Conference. Savannah, GA. October 7-9, 1010.

"The Lyrical Jock." Session instructor. Creative Nonfiction Writing Seminar. Winter Wheat Festival at Bowling Green State University. Bowling Green, OH. November 12-14, 2009.

"Blue Collar Supremacy Tour: Larry the Cable Guy and the Battle for America's Cultural Color." Conference paper. Pop Culture Association of the South/ American Culture Association of the South Annual Conference. Wilmington, NC. October 1-3, 2009.

"The Written Redneck: Regional Image, National Identity." Invited keynote presentation. IUP Undergraduate English Conference. Indiana University of Pennsylvania, Indiana, PA. February 16, 2009.

"Truckers and Redneck Jokes: How The Man Became a Redneck." Conference paper. Louisville Conference on Literature and Culture Since 1900. University of Louisville, Louisville, Kentucky. February 21-23, 2008. 
"The Naturalized Redneck: Performing Citizenship through Patriotic Submission." Conference Paper. Far West Popular Culture Association/Far West American Culture Association Annual Conference. Las Vegas, Nevada. January 25-27, 2008.

"Redneck, White, and Blue: Rural Identity as Patriotic Act." Conference paper. Futures of American Studies Institute. Dartmouth College, Hanover, NH. June 18-24, 2007.

"Cartoons and Corrupted Images: the Representation of Life Story in Maus and Persepolis." Conference paper. West Virginia University Graduate Colloquium. Morgantown, WV. April 13-14, 2007.

“Definite Ambiguity: Memento's Destabilizing Package." Conference paper. Louisville Conference on Literature and Culture Since 1900. University of Louisville, Louisville, Kentucky. February 24-27, 2007.

"Make it Up, Make it Right: Finding Truth Through Biographical Falsity in Edmund Morris's Dutch." Conference paper. Politics of Memory Conference. University of Toronto, Toronto, Ontario, Canada. March 31-April 2, 2006.

"Whose Autobiography is this Anyway?: Alex Haley's Interpretive Presence in The Autobiography of Malcolm X." Conference paper. Changing Trends in Authorship Conference. University of Rochester, Rochester, NY. March 3-4, 2006.

"Writing on Writing on Writing: The Presence and Pertinence of Popular Writing Guide Books." Conference paper. West Virginia University Graduate Student Colloquium, Morgantown, WV. April 7-8, 2006.

"Home Sweet Roadhouse: Simulation and Power at the Local Texas Roadhouse Restaurant." Conference paper. West Virginia University Graduate Student Colloquium, Morgantown, WV. April 7-8, 2006.

\section{SCHOLARSHIP ACTIVITY UNDER REVIEW}

You Are and You Ain't: Redneck Literature and the Imposition of Identity. Scholarly book. Under review by request at McFarland \& Company.

Turquoise Tee. Book-length essay collection.

"Getting There." Literary essay.

"Tools." Literary essay.

"Rain." Literary essay.

"Last Shots." Literary essay.

SERVICE ACTIVITIES

Indiana University of Pennsylvania

English Club Advisor: Spring 2009-present.

English Emphasis Residence Cluster Faculty Liaison: Spring 2009-present. 
Alternate Faculty Delegate, APSCUF: Fall 2010-present.

Judge, IUP Undergraduate Creative Nonfiction Writing Contest: Spring 2010. Judge, Poetry Out Loud Regional Contest (Indiana County, PA): February 23, 2010.

Judge, IUP Undergraduate Fiction Writing Contest: Spring 2009.

West Virginia University

Doctoral Professional Seminar Text Selection Committee: Spring 2008.

Graduate Program Committee, Ph.D. Representative: Fall 2006-Spring 2008.

West Virginia University Graduate Colloquium Organizing Committee: Fall 2006-Spring 2008.

University Writing Center, Tutor: Fall 2005-Spring 2006.

English 101 Essay Contest, Judge: Spring 2006.

Clarion University of Pennsylvania

Writing Committee: Fall 2000-Spring 2001.

Visiting Writer's Committee: Fall 2000-Spring 2001.

English Department Budget Committee: Fall 2000-Spring 2001.

English Department Recruitment Committee: Fall 2000-Spring 2001.

University of Pittsburgh

General Writing Placement Committee: Summer 1998.

\section{PROFESSIONAL DEVELOPMENT}

Winter Wheat Festival of Writing. Bowling Green State University. Bowling Green, OH. November 12-14, 2009.

West Virginia University Summer Seminar in Literary and Cultural Studies. Led by Phil Deloria, University of Michigan. West Virginia University, Morgantown, WV. June 5-8, 2008.

Winter Wheat Festival of Writing. Bowling Green State University. Bowling Green, OH. November 8-11, 2007.

Futures of American Studies Institute. Dartmouth College, Hanover, NH. June 18-24, 2007.

\section{PROFESSIONAL WRITING AND EDITING EXPERIENCE}

Web Editor, Stymie Magazine. November 2010-present.

Professional Editor, Teaching Science with Geospatial Technology: Designing Effective Professional Development for Secondary Teachers. For James Makinster, Hobart 
and William Smith Colleges; Nancy Trautmann, Cornell Lab of Ornithology; Michael Barnett, Boston College. November-December 2010.

Professional Editor, National Science Foundation Grant Application. For

Professor James Makinster, Hobart and William Smith Colleges, Geneva, NY, May 2008.

Professional Editor, Science Education Research Article. For Professor James

Makinster, Hobart and William Smith Colleges, Geneva, NY, March 2008.

Freelance writer: May 2001-September 2005.

Columnist, The Indiana Gazette, Indiana, PA: May 1999-May 2001.

Staff Writer, The Indiana Gazette, Indiana, PA: May 1999-July 2000.

Correspondent, The Indiana Gazette, Indiana, PA: July 1998-May 1999.

\section{OTHER PUBLICATIONS}

"Golfing the Turquoise Valley." Article. Highroads Magazine July / August 2004.

"Arizona Cactus Botanical Gardens." Article. Arizona Highways Magazine

November 2003.

Twice weekly columns in The Indiana Gazette May 1999-May 2001.

250+ articles in The Indiana Gazette July 1998-May 2001.

\section{PROFESSIONAL AWARDS AND GRANTS}

Certificate of Merit, in Recognition of Faculty Productivity in Published Scholarship, April 2010.

Nominated, 2009 Pushcart Prize. For essay "Rules of the Game."

Nominated, 2010 Dzanc Books Best of the Web Prize. For essay "Rules of the Game."

Certificate of Merit, IUP Trustees Banquet in Recognition of Faculty Productivity in Published Scholarship, March 2009.

Swiger Doctoral Fellowship, West Virginia University, August 2005-July 2008.

Vehse Award for Doctoral Travel. \$500, Spring 2008.

Eberly College or Arts and Sciences Doctoral Travel Grant. \$300, Spring 2008.

Eberly College or Arts and Sciences Doctoral Travel Grant. \$500, Spring 2007.

Eberly College or Arts and Sciences Doctoral Travel Grant. \$300, Spring 2006.

Second Place, 2001 Keystone Press Awards; Sports Writing.

Finalist, 2000 Golden Quill Press Awards; Column Writing.

Second Place, 2000 Keystone Press Awards; Feature Writing.

\section{MEMBERSHIPS}

English Graduate Organization of West Virginia University.

President, Fall 2006-Spring 2008.

Associated Writing Programs. 
Modern Language Association.

Phi Kappa Phi National Honor Fraternity.

Mortar Board National Honor Society.

Sigma Tau Delta English Honor Fraternity.

\section{FOREIGN LANGUAGES}

French: Advanced conversational skills; intermediate reading and writing skills.

German: Intermediate conversational skills; low-intermediate reading and writing skills.

\section{REFERENCES}

John Ernest, Eberly Family Distinguished Professor of American Literature; West Virginia University, Morgantown, WV: (304) 293-3107 $<$ John.Ernest@mail.wvu.edu>

Kevin Oderman, Professor of English and Creative Writing; West Virginia University, Morgantown, WV: (304) 293-3107 <kevin.oderman@gmail.com> Gwen Bergner, Associate Professor; West Virginia University, Morgantown, WV: (304) 293-3107<Gwen.Bergner@mail.wvu.edu>

Christopher McCarrick, Associate Professor of English, Writing Director; Clarion University of PA, Clarion, PA: (814) 393-2154<cmccarrick@clarion.edu> 